\title{
Exploring Proactive Market Strategies Managing the Market to Create Valve
}

\section{Harald Brege}

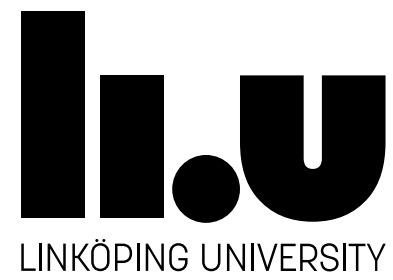

\author{
2018 \\ Department of Management and Engineering \\ Linköping University \\ SE-581 83 Linköping, Sweden
}


(C) Harald Brege, 2018

Exploring Proactive Market Strategies: Managing the Market to Create Value

Linköping Studies in Science and Technology, Licentiate Thesis No. 1809

ISBN: 978-91-7685-267-5

ISNN: 0280-7971

\section{Printed by:}

LiU-Tryck, Linköping, 2018

Distributed by:

Linköping University

Department of Management and Engineering

SE-581 83 Linköping, Sweden

Tel: $+46(0) 13-281000$ 
FOR MOM AND DAD, LOVE YOU 


\section{Abstract}

How can firms become more successful and achieve higher business performance? How can they manage more complex and dynamic markets and maintain a high competitiveness? The answer is: through a more proactive approach to managing the market and creating customer value. This thesis explores proactive market strategies, which are firm's proactive strategies for creating, communicating, and delivering superior value to their customers, thereby achieving superior business performance. Prior literature in market orientation has touched the area of proactiveness in firms' approach to the market, but never properly defines proactiveness and lacks a clear connection to actual firm activities. Thus, in order to better understand how firms can gain the performance benefits from proactiveness, this thesis sets out to explore what proactiveness in a market-strategic context entails and what proactive activities firms perform in implementing their proactive market strategies.

The research is based on two papers, each detailing one of the two complementary branches of the research. The first paper presents the conceptual work, focusing on a typology of marketoriented strategic behaviors, which are important for understanding how firms can gain the potential performance benefits of market orientation and how they can achieve behavioral fit among their activities. The second paper presents the empirical work, focusing on the qualitative case study performed and the themes of proactiveness that emerged from it. These papers are then synthesized into a holistic view of proactive market strategies in the thesis.

The thesis finds that proactiveness at the firm level in a marketing context means a firm is future-oriented, initiative-taking, change-inducing, and creative. With a basis in this definition and the extensive literature on market orientation, the thesis presents conceptual developments that are important for understanding proactiveness in market strategy, such as a framework for understanding market strategies through firm activities and one for identifying and categorizing different types of proactive activities. Furthermore, the thesis gives more detailed descriptions of the case firms and how their proactive activities help them achieve success.

This results in a thorough exploration of proactive market strategies, which contributes to the marketing and strategic management literatures by clearly defining proactiveness, conceptualizing and describing proactive market strategies, and delineating proactive firm activities to better understand how firms are being proactive. In doing so, the thesis provides interesting directions for future research and presents interesting implications for managerial practice. 


\section{Sammanfattning}

Hur kan företag bli mer framgångsrika och uppnå högre lönsamhet och tillväxt? Hur kan de hantera mer komplexa och dynamiska marknader medan de uppehåller en hög konkurrenskraft? Svaret är: genom en mer proaktiv hållning till att hantera marknaden och skapa kundvärde. Den här avhandlingen utforskar proaktiva marknadsstrategier, vilka är företags proaktiva strategier för att skapa, kommunicera och leverera överlägset kundvärde och därigenom uppnå överlägsna resultat. Tidigare litteratur inom marknadsorientering har berört området, men har aldrig definierat proaktivitet ordentligt och saknar en tydlig koppling till faktiska företagsaktiviteter. För att bättre förstå hur företag kan få de potentiella fördelarna från proaktivitet så ska den här avhandlingen därför utforska vad proaktivitet i en marknadsstrategisk kontext innebär samt vilka proaktiva aktiviteter som företag utför när de ska implementera sina proaktiva marknadsstrategier.

Forskningen är baserad på två papper, som vart och ett beskriver en av de två kompletterande delstudierna som arbetet utgår från. Det första pappret beskriver det konceptuella arbetet, med fokus på en typologi för marknadsorienterade strategiska beteenden, vilka är viktiga för att förstå hur företag kan uppnå de potentiella fördelarna av proaktivitet samt hur de kan uppnå god beteendemässig passform mellan sina olika aktiviteter. Det andra pappret presenterar det empiriska arbetet, med fokus på den kvalitativa fallstudien som genomförts och de proaktivitetsteman som uppkommit i denna. Dessa två papper syntetiseras sedan till en helhetsbild av proaktiva marknadsstrategier i kappan till avhandlingen.

Studien konstaterar att proaktivitet på företagsnivån i en marknadsföringskontext innebär att ett företag är framtidsorienterat, initiativtagande, förändringsbenäget och kreativt. Med bas i denna definition samt den omfattande litteraturen om marknadsorientering så presenterar avhandlingen de konceptuella utvecklingar som är viktiga för att förstå proaktivitet i en marknadsstrategisk kontext, såsom ett ramverk för att förstå marknadsstrategier genom företagsaktiviteter och ett för att identifiera och kategorisera olika typer av proaktiva aktiviteter. Vidare så ger avhandlingen mer detaljerade beskrivningar av fallföretagen från fallstudien och hur deras proaktiva aktiviteter hjälpt dem uppnå framgång.

Detta resulterar i en grundlig utforskning av proaktiva marknadsstrategier, vilket bidrar till marknadsförings- och företagsstrategilitteraturen genom att tydligt definiera proaktivitet, konceptualisera och beskriva proaktiva marknadsstrategier, och förtydliga proaktiva företagsaktiviteter för att bättre förstå hur företag är proaktiva. Genom att göra det så belyser avhandlingen intressanta riktningar för framtida forskning samt presenterar intressanta implikationer för företagsledare. 


\section{Acknowledgements}

When I was asked back in the spring of 2015 if I wanted to do a PhD, I hadn't really thought all that much about it. Being from the background that I am, I somehow had expected that I would do a $\mathrm{PhD}$ at some point, but it was definitely not going to be so soon after finishing my Master studies. But, after half a year of working as a research assistant at Industrial Engineering and Management and being presented with a super interesting research project, I readily accepted anyways. I have for a long time had an interest in the intersection between business strategy, marketing, and technology, and I felt doing research in proactive market strategies would allow me to study all of those things. Writing this thesis has been quite the journey for me, and there are many who have helped and supported me along the way.

Firstly, I want to thank my supervisors, Daniel Kindström and Johan Holtström, who have been ever so supportive and patient with me. Special thanks to Daniel for the many interesting discussions while writing the two papers together and for helping me develop my thoughts and improve my frameworks. Through all delays and (sometimes) overly ambitious theoretical developments, you have helped and supported me, and I hope we can continue working together for many more years.

Secondly, I want to thank my parents, Staffan and Maria, and the rest of my family, who have been supporting me the entire time. Dad, you have always been an inspiration for me to focus on what I find interesting and to strive for greater knowledge and personal fulfillment, rather than just earning money. Mom, you have always inspired me to think critically, to view things from many perspectives, and to strive to do things as well as I can. Both sides of my family have academical backgrounds and I have always been taught that knowledge is the only burden that does not increase the more you carry of it. Without you, I would not have been able to do this.

Thirdly, I want to thank all of my wonderful colleagues at INDEK and IEI. Through fikas, lunches, after works, interesting discussions and equally interesting arguments, you have helped me stay sharp, develop my research, and learn new things (especially about American politics, blockchains and AI). Huge thanks to Alexey, Daniel, Ehsan, Emelie, Fredrik, Jonathan, Mario, Markus, Martin, Mohammad, Mojtaba, Per, Sarah, Ya, Özgün, and everyone else who have made my time at IEI thus far such an intellectually stimulating and fun experience.

Finally, I want to thank all of my friends, who have been providing me with so many great memories, interesting discussions, long walkabouts, and have been interested in what I've been doing (or at least have pretended to be $(-)$ ). You know who you are! 


\section{Appended Papers}

\section{Paper I: Conceptual Study}

Harald Brege \& Daniel Kindström

Submitted for review

\section{Paper II: Empirical Study}

Harald Brege \& Daniel Kindström

Submitted for review 


\section{Table of Contents}

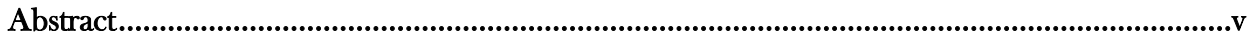

Sammanfattning ....................................................................................................................ii

Acknowledgements ............................................................................................................................. ix

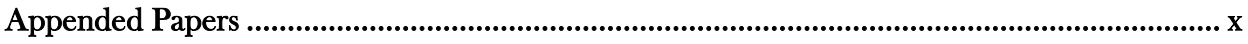

Lists of Tables and Figures ...................................................................................................... xiii

1 Introduction................................................................................................................ 1

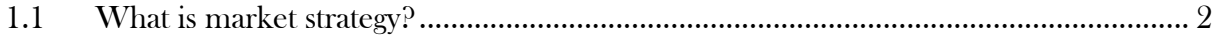

1.2 How to manage market strategy in modern markets? ................................................... 3

1.3 How to create proactive market strategies? ........................................................................ 5

1.4 Research purpose and research questions.................................................................. 5

1.5 Contributions of the papers to answering the research questions ................................ 7

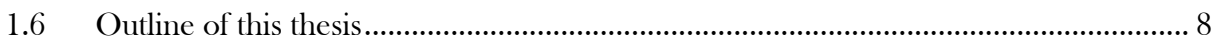

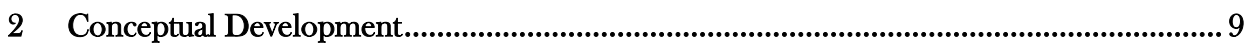

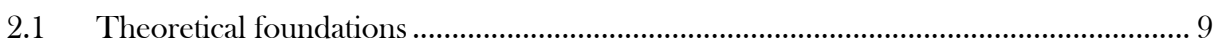

2.2 Defining proactiveness in the marketing context .......................................................... 17

2.3 A framework for conceptualizing market strategy ................................................... 21

2.4 Conceptualizing proactive market strategies and proactive activities............................ 23

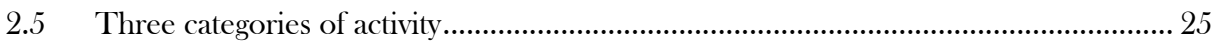

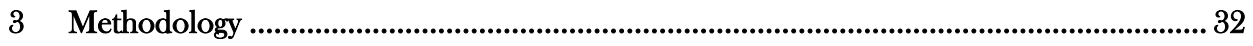

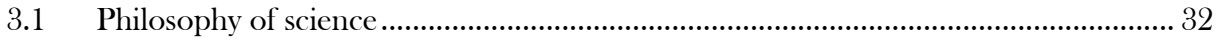

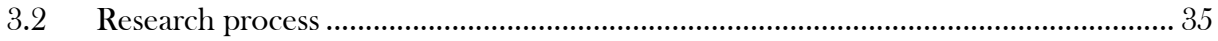

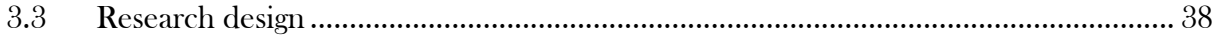

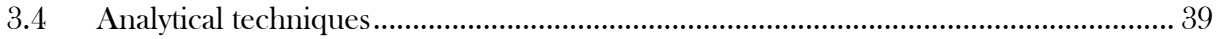

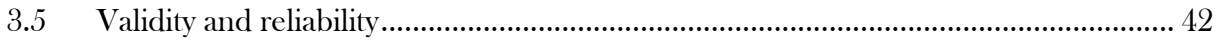

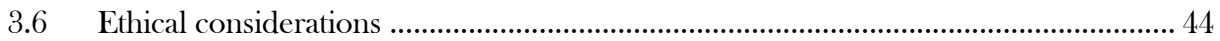




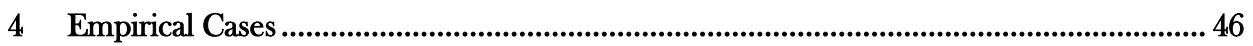

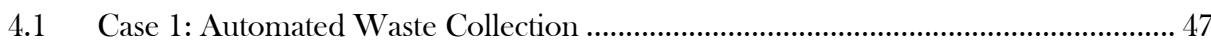

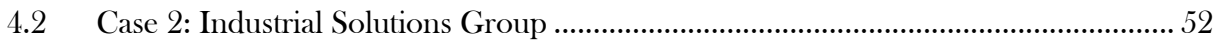

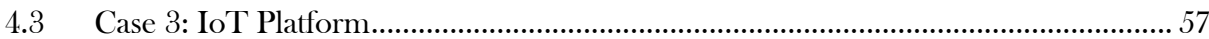

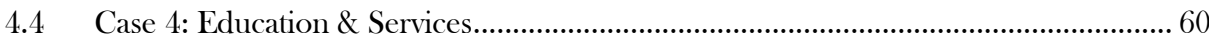

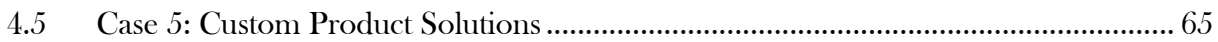

5 Summaries of the Appended Papers ...................................................................................... 70

$5.1 \quad$ Paper I: Conceptual study ................................................................................................. 70

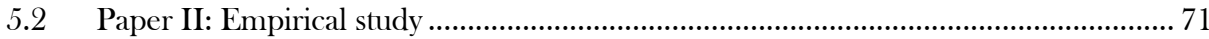

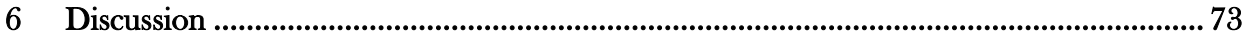

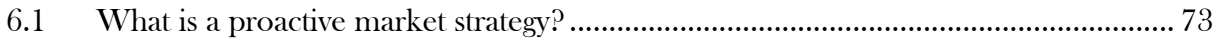

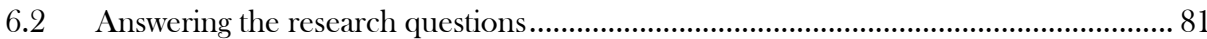

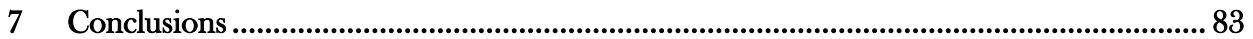

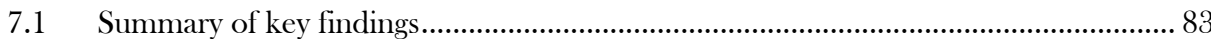

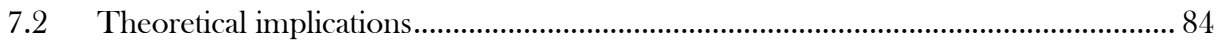

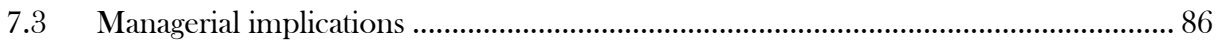

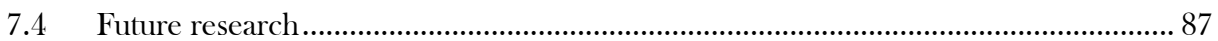

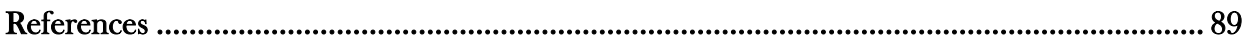

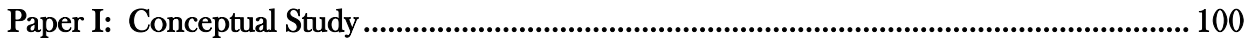

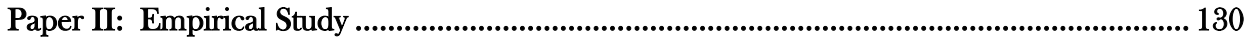




\section{Lists of Tables and}

Figures

\section{List of tables}

Table 1: Individual contributions of papers to purpose ………................................................... 7

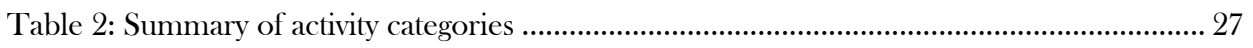

Table 3: Types of conceptualizations (adapted from MacInnis, 2011, p. 138) .......................... 39

Table 4: Analytical techniques for different steps of conceptual development............................ 40

Table 5: Analytical techniques for different steps of case study analysis ....................................... 41

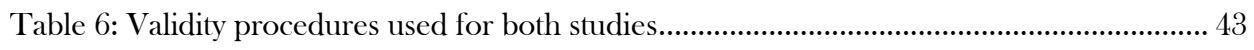

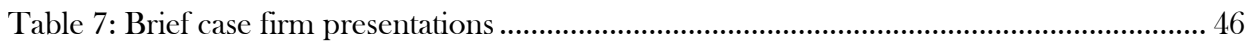

Table 8: Summary of proactive activities of Automated Waste Collection (from Paper II) ...... 51

Table 9: Summary of proactive activities of Industrial Solutions Group (from Paper II) .......... 56

Table 10: Summary of proactive activities of IoT Platform (from Paper II) .............................. 59

Table 11: Summary of proactive activities of Education \& Services (from Paper II) ................. 64

Table 12: Summary of proactive activities of Custom Product Solutions (from Paper II) ......... 69

Table 13: Proactive profiles for the case firms (from Paper II) .................................................. 77

Table 14: Profiles for the themes of proactiveness (from Paper II) ........................................... 78

Table 15: Summary of case firms' use of the themes of proactiveness (from Paper II) ............. 79

\section{List of figures}

Figure 1: The model for extended market orientation (from Matsuno et al., 2005) .....

Figure 2: Four approaches to current and future customer needs (from Ketchen et al., 2007). 16 Figure 3: Performance effects of balanced ambidextrous market orientation (from Herhausen, 2016)

Figure 4: The strategic orientation-market strategy-strategic behavior framework .................... 22

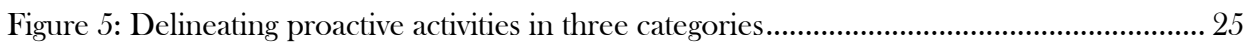

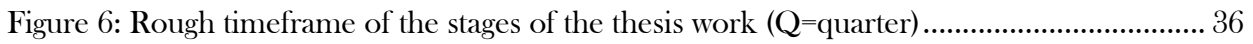

Figure 7: The typology of market-oriented strategic behaviors (from Paper I) .......................... 76 


\section{Introduction}

How can a firm become better at identifying and satisfying customer needs? How can a firm create more innovative market offerings that deliver superior value to its customers? How can a firm shape its competitive environment to its advantage? The answer to all of these questions lies, at least partially, with proactiveness. A firm that can become more proactive in its management of the market in general, and its approach to handling customers in particular, is better prepared to tackle the problems and increased competition of modern, globalized market environments (see e.g. Narver, Slater \& MacLachlan, 2004; Day, 2011). To demonstrate this point, here is a quote from a sales region manager who works for the global leader in automated waste collection systems:

\section{"Being proactive is very important in what we do; you can't just wait for customers to come to you in our business. We talk to people in many [organizations] and try to get them around to understand [the benefits]. Without working long-term on influencing these people and stimulating demand for our systems, our sales wouldn't be near where they are today."}

The word 'proactive' is often criticized for being a rather empty management buzzword used instead of words like 'assertive' or 'decisive'. However, when delving more deeply into what it means in a market-strategy context, 'proactive' becomes a lot more interesting than jargon such as that deride by Scott Adams (1997) as "proactively leveraging synergies" in his highly popular Dilbert comic strips. Instead, proactiveness is primarily about three things: taking the initiative, creating change for the better, and thinking creatively (Bateman \& Crant, 1993; Crant, 2000; Grant \& Ashford, 2008). 
In general, proactive work behavior results in improved work performance (Bateman \& Crant, 1999; Seibert, Crant \& Kraimer, 1999), and, as complexity and turbulence in the environment increases, so do the potential advantages of being proactive (Tsai, Chou \& Kuo, 2008). Crant (2000, p. 435) shows that "/als work becomes more dynamic and decentralized, proactive behavior and initiative become even more critical determinants of organizational success". However, all of this holds true only for as long as you know what you are doing; proactive action coupled with a poor understanding of the situation at hand can result in drastically decreased performance (Chan, 2006).

Proactiveness is thus unfortunately not quite a silver bullet for securing superior performance. Furthermore, studies on proactiveness in a firm's market strategies show that the performance impact of proactive behavior is dependent on the market environment; in an environment where customer needs are easy to understand and predict, there is potentially little for a firm to gain from being very proactive (see e.g. Tsai et al., 2008; cf. Narver \& Slater, 1990).

In a market strategy context, proactiveness has been identified as an important driver of firm innovativeness (Zhang \& Duan, 2010), new product success (Narver et al., 2004), customer value creation (Blocker et al., 2011) and superior business performance (Slater \& Narver, 1998; Herhausen, 2016), yet little research has delved into how proactive firms gain these benefits. It is thus relatively clear that firms which are proactive in their market strategies gain benefits, but it is unclear how firms can become proactive or which of the activities they perform lead to these benefits (cf. Kennedy, Goolsby \& Arnould, 2003; van Raaij \& Stoelhorst, 2008). Moreover, as previously discussed, greater proactiveness does not always lead to beneficial results (Chan, 2006), and there are costs associated with becoming more proactive that can potentially hamper firms' proactive efforts (Herhausen, 2016; March, 1991). This raises the question: What activities should a firm perform to become more proactive in its market strategies and how should they be performed?

\subsection{What is market strategy?}

The marketing concept can succinctly be described as the principle that firms gain superior business performance through a superior ability to create value for their customers (Kotler, 1972; McNamara, 1972). Adopting this concept obviously has far-reaching consequences for the strategies that firms formulate in order to be successful, implying the need to focus on customer needs and value-creating activities (Kohli \& Jaworski, 1990; Day, 1994). Thus, marketing can have a great impact on firm strategy, leading to the creation of competitive advantage (Day, 1992; Varadarajan, 1992). This domain of the strategic aspects of marketing is usually referred to as strategic marketing (Varadarajan, 2010).

There has long been discussion in the strategic marketing field regarding how to translate this broader concept into constructs for aiding managerial decision-making and the management of marketing activities (e.g. Wind \& Robertson, 1983; Day, 1992; Varadarajan, 1992; Reibstein, Day \& Wind, 2009). The term marketing strategy is often used to refer to the broader translation of the strategic considerations of strategic marketing into an organizational strategy construct (Varadarajan, 2010). Marketing strategy roughly refers to firms' decisions and 
processes for target market selection and marketing activities, aimed at delivering value to customers (Varadarajan, 2010). However, Varadarajan (2010) also notes that is are a multitude of other labels used to describe conceptualizations of strategic marketing issues, some of which are unnecessary, but many of which are helpful in describing particular aspects of strategic marketing in a more focused way than the broad conceptualization of marketing strategy can achieve.

The way I conceptualize "market strategy" (Swedish: marknadsstrategl) in this thesis is as a subset of marketing strategy. More precisely, market strategy refers to a firm's strategies, and associated activities, for creating, communicating, and delivering superior value to their customers, aimed at gaining a competitive advantage (cf. Kindström, Kowalkowski \& Parment, 2012). This conceptualization is more focused on the actual strategies and activities that a firm performs, as opposed to the broader term marketing strategy, which includes all types of strategic marketing considerations.

\subsection{How to manage market strategy in modern markets?}

Modern firms face increasingly complex and dynamic market environments; ongoing developments such as increasing globalization, shorter product life-cycles, faster imitation cycles, and more fickle customers all increase the competitive intensity and decrease profitability. Day (2011) makes the case that this situation cannot be managed through the internal development of operational capabilities and reacting to changes in the market environment alone. Instead, to handle this new market environment, firms have to improve their ways of managing the market and engaging with customers by strengthening their marketing capabilities (Day, 1994, 2011). In order for firms to manage this shift, they must become more market-oriented, more proactive, and refocus their strategy formulation on developing value-creating market strategies (Day, 2011).

Market-oriented firms are those that have implemented the marketing concept, meaning they are focused on creating customer value through a variety of key activities (Kohli \& Jaworski, 1990). Developing a market orientation enables a firm to generate insights into customer needs and use them to improve their creation of customer value, leading to increased engagement with the customers, resulting in yet more insights, and so on (Morgan, Vorhies \& Mason, 2009; Kohli \& Jaworski, 1990). Through this process, market orientation helps a firm to continuously develop and refine the capabilities it needs to consistently deliver superior customer value through its market strategies (Day, 1994, 2011)

A multitude of studies over the last few decades has shown that market-oriented firms achieve superior business performance than others and that the relationship is consistent over many types of conditions (see e.g. Narver \& Slater, 1990; Slater \& Narver, 1994; Matsuno \& Mentzer, 2000; Slater \& Narver, 2000; Kirca, Jayachandran \& Bearden, 2008; Morgan et al., 2009). However, more recent research shows that the relative gains from market orientation are decreasing and that the relationship between market orientation and performance is becoming 
more complex (see e.g. Kumar et al., 2011; Frösén et al., 2016; Frambach, Fiss \& Ingenbleek, 2016). It increasingly seems to be the case that market orientation is a necessary, but not sufficient condition for higher-than-average business performance. As an illustrative example, Frösén et al. (2016, p. 76) find that “...a market-oriented organizational culture is needed to tap into the tacit, fuzzy aspects of markets. However, [market orientation] is seldom a sufficient condition for high performance..." It is thus no longer a question of whether to be marketoriented, but rather how to be market-oriented. Kumar et al. (2011, p. 28) summarize this point well: "...to have a unique advantage, companies must continuously identify new dimensions of this construct to distinguish themselves".

This is where proactiveness becomes important to consider. In response to criticism that market orientation makes firms less innovative and liable to be led by their customers (see e.g. Christensen \& Bower, 1996; Berthon, Hulbert \& Pitt, 1999), Narver et al. (2004) developed an extension of the market orientation construct, dividing it into proactive market orientation and responsive market orientation. In this expanded view, responsive market orientation relates to firms eliciting needs from customers and then satisfying those expressed needs, while proactive market orientation relates to striving for a deeper understanding of the customer, which enables the proactive firm to find and satisfy the latent needs of customers (Narver et al., 2004; Atuahene-Gima, Slater \& Olson, 2005). This more innovative stance on market-oriented behavior, enabled by proactiveness, drives firms to search for latent and future customer needs to satisfy, as well as latent solutions to their articulated problems. Furthermore, these two aspects of market orientation are complementary rather than mutually exclusive, acting as different dimensions of market-oriented behavior, meaning that they can be simultaneously adopted by a firm (see e.g. Atuahene-Gima et al., 2005; Tsai et al., 2008; Herhausen, 2016). As Kumar et al. (2011) suggest, to gain the full potential benefit of market orientation, firms must find a way to apply the concept that matches their unique situation. Part of finding the market orientation configuration that best fits a particular firm's circumstances then also involves finding the right level of proactiveness in the firm's market strategies.

Thus, proactiveness is a key driver of more innovative and market-oriented firms which, through their proactive market strategies are better equipped to handle the complexity and competition of modern markets. It is not only market-oriented firms that employ market strategies-indeed I cannot imagine a firm that does not have any form of strategy for delivering value to its customers-but market orientation is still an important foundation for enabling superior value creation, meaning non-market-oriented firms will face greater difficulty in achieving superior performance (Blocker et al., 2011; Day, 2011; Frösén et al., 2016). Proactive market strategies thus represent the ways in which proactive firms leverage their superior insights and market-oriented capabilities to enable superior value creation (cf. Day, 1994; Narver et al., 2004; Blocker et al., 2011), which is especially important in the more complex and dynamic environments of modern markets (cf. Tsai et al., 2008; Day, 2011; Bodlaj, Coenders \& Zabkar, 2012). 


\subsection{How to create proactive market strategies?}

While proactive market strategies help in enabling firms to create superior value for their customers, it is quite unclear how firms can become more proactive in their creation of customer value. Firstly, despite many research efforts in the area, there is still a lack of understanding concerning how firms should successfully implement a market orientation (see e.g. Ruekert, 1992; Kennedy et al., 2003; Beverland \& Lindgreen, 2007; van Raaij \& Stoelhorst, 2008). This venture is made more complex by the notions presented by Kumar et al. (2011) that there is no one "cookie cutter" way of gaining the full potential benefits from market orientation. The "right" type of market orientation for a firm is thus determined by the configuration of firm capabilities and market environment for that firm (see e.g. Noble, Sinha \& Kumar, 2002; Kumar, Subramanian \& Yauger, 1998).

The configurational approach to strategy that this situation demands is not new, however, but enables a more nuanced way of handling the different trade-offs between firm situation, behavior, and strategy (see e.g. Miles \& Snow, 1978; Miller, 1986; Lukas, 1999; Olson, Slater \& Hult, 2005). Thus, a firm must not only find the configuration of proactive and responsive market orientation that is the right fit for its present circumstances, but also anticipate and adapt to how this "sweet spot" might evolve over time as the firm's capabilities develop and the market environment changes. This increasing complexity of successfully using market orientation to achieve superior performance exacerbates the issues other scholars have highlighted around the lack of insight into the actual strategies and activities of market-oriented firms that help enable value creation (e.g. Kennedy et al., 2003; van Raaij \& Stoelhorst, 2008).

The implications of this for proactive market strategies is that a firm must find a way to achieve strategic fit between the firm's capabilities, the characteristics of the market environment, and the proactive market strategies themselves, in order to achieve the full potential benefits (cf. Olson, Slater \& Hult, 2005; Zajac, Kraatz \& Bresser, 2000; Chom, 1991).

\subsection{Research purpose and research questions}

The overall aim of this licentiate thesis is to explore the ways in which firms use proactiveness in their market strategies-i.e. how they are being proactive in their strategies for creating, communicating, and delivering superior value to their customers-in order to better understand proactiveness in a strategic marketing context. As the thesis is in the field of strategic marketing, it lies in between marketing and strategic management, and my aim is to contribute to both disciplines. Marketing scholars have long been concerned that marketing is losing influence in the strategy field, mostly because of the decreasing research into strategic marketing issues and the diminishing impact of the results (e.g. Wind \& Robertson, 1983; Day, 1992; Varadarajan, 1992; Reibstein et al., 2009; Varadarajan, 2010). Reibstein et al. (2009) warn that marketing is being marginalized in this way because of the lack of managerial applicability of much of the 
research that is being conducted. This sentiment is shared by Steenkamp (2018, p. 171), who in an editorial for the Journal of the Academy of Marketing Science argues that:

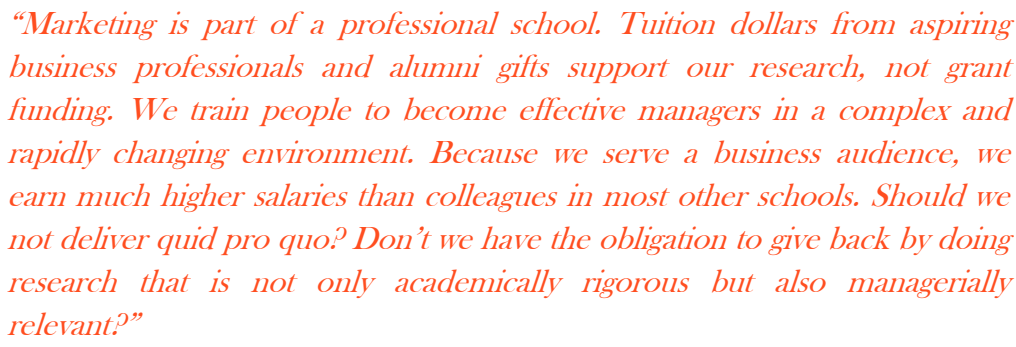

I fully agree with this sentiment and I would argue that part of the reason for the marginalization of strategic marketing research is the lack of research into how firms can actually implement a market orientation-being one of the core strategic marketing constructs-and which of the activities they perform are giving rise to the performance benefits. Since my research uses market orientation as a foundation, this is an important consideration. Therefore, going forward, it is my aim to ensure that I can capture actual firm activities and create constructs that have useful managerial implications.

Since the area of proactive market strategies is mostly unexplored, the research presented in this thesis is focused on qualitatively describing and conceptualizing the proactive market strategies that firms use and the activities involved in them. These conceptualizations can then open up space for deeper investigations into causal relationships-e.g. the antecedents and consequences of proactive market strategies-and efforts to quantitatively measure different aspects-e.g. measuring performance effects or the influences of different contingency factors-in the future.

Based on this, the final purpose of this licentiate thesis is as follows:

\section{This thesis aims to explore how firms use proactive market strategies.}

In order to conduct the study, this purpose is then further broken down into the following two research questions:

\section{RQ1 What does proactiveness in a market-strategic context entail?}

The first research question of the thesis concerns the lack of a detailed definition of proactiveness in market strategy, or even in a broader marketing context. The term 'proactive' is used in several management and marketing research topics, such as proactive environmental management (e.g. Aragón-Correa \& Sharma, 1998), proactive market orientation (e.g. Narver et al., 2004), and proactive customeroriented innovation (e.g. Stock \& Zacharias, 2011), without a proper definition. This lack of clarity makes it difficult to study proactive market strategy, and thusly, the first question of the thesis is aimed at exploring what proactiveness in market strategy entails, in order to define and conceptualize key concepts. 
Just as there is a lack of understanding regarding the implementation of a market orientation and how, more precisely, this enables value creation (e.g. Kennedy et al., 2003; Beverland \& Lindgreen, 2007), there is also a lack of understanding of the activities performed by firms in implementing their proactive market strategies. This research question is thus aimed at providing a deeper understanding of proactive market strategies by investigating the activities performed and how they are linked to these strategies. Furthermore, in order to ensure that the research provides managerially useful implications, it is important to create a conceptualization that helps link proactive market strategies and actual firm activities.

\subsection{Contributions of the papers to answering the research questions}

This thesis contains two appended papers that help to answer the research questions previously posed and achieve the research purpose, presented in Table 1 below:

Table 1: Individual contributions of papers to purpose

\begin{tabular}{|l|l|l|l|l|}
\hline Paper & Subject & Design & Key contribution(s) & Link to RQ(s) \\
\hline Paper I & $\begin{array}{l}\text { Strategic } \\
\text { behavior, } \\
\text { market } \\
\text { orientation, } \\
\text { proactiveness, } \\
\text { firm activities }\end{array}$ & $\begin{array}{l}\text { Conceptual } \\
\text { typology }\end{array}$ & $\begin{array}{l}\text { Puts forward a typology that } \\
\text { describes how different } \\
\text { configurations of proactive and } \\
\text { responsive market orientation result } \\
\text { in different types of market- } \\
\text { oriented strategic behaviors and } \\
\text { how these behaviors arise from } \\
\text { various market activities }\end{array}$ & RQ1 \& RQ2 \\
\hline Paper II & $\begin{array}{l}\text { Market } \\
\text { strategy, } \\
\text { proactiveness, } \\
\text { firm activities }\end{array}$ & $\begin{array}{l}\text { Qualitative } \\
\text { multiple } \\
\text { case study }\end{array}$ & $\begin{array}{l}\text { Three common themes of } \\
\text { proactiveness that permeate the } \\
\text { proactive market activities of the } \\
\text { firms, linking proactiveness to } \\
\text { different aspects of managing the } \\
\text { market }\end{array}$ & RQ1 \& RQ2 \\
\hline
\end{tabular}

As can be seen in Table 1 above, each of the two papers helps to answer both of the research questions. This is intentional, since they reflect different approaches to exploring proactive market strategies and by having both papers study both questions, my thesis can provide more nuanced answers and conclusions.

Paper I is focused on conceptually investigating the activities associated with different configurations of proactive and responsive market orientation, as well as developing a typology of market-oriented strategic behaviors that arise from these activities. The contribution to answering both RQ1 and RQ2 stems from the types of market-oriented strategic behaviors that 
are presented, where the Visionary and Ambidextrous behaviors indicate how the proactive activities that firms perform are combined in a firm's value-creating efforts, i.e. its proactive market strategy. Thus, RQ2 is answered by the description of the proactive activities and RQ1 is answered through the strategic behaviors of the typology.

My role in Paper I was that of main author; I designed the study, gathered the literature to use, performed the different stages of conceptualization, and wrote the main part of the article. My co-author provided advanced discussion and help during the conceptualization work, assisted in collecting literature, and helped improve on my manuscripts.

Paper II is a qualitative multiple case study that investigates the proactive market strategies of different successfully proactive firms. The study aimed to describe the actual proactive activities of the case firms, thereby answering RQ2. Furthermore, three patterns of proactive activities, called themes of proactiveness, were identified. These themes describe how various proactive activities across different categories of activity are coordinated and integrated to create customer value, thereby describing the proactive market strategies of the case firms, and thus answering RQ1.

My role in Paper II was also that of main author, wherein I designed the study, performed most of the interviews, took the lead during the different stages of case analysis, and was the lead writer on paper manuscript. My co-author also performed interviews, provided helpful discussion during the analysis, and helped improve the manuscript.

\subsection{Outline of this thesis}

The rest of this licentiate thesis will be structured as follows:

- In Chapter 2, I will present the theoretical foundations that underpin the studies in the thesis and detail the conceptual developments I have undertaken.

- In Chapter 3, I will present the methodology used in the thesis work, including my view on the philosophy of science, the research design, and analytical techniques. I will discuss the validity and reliability of the study, and describe the relevant ethical considerations.

- In Chapter 4, I will describe the case firms of the empirical study presented in Paper II in greater detail.

- In Chapter 5, I will briefly summarize the two appended papers.

- In Chapter 6, I will discuss the exploration of proactive market strategy in the two studies that together make up the work of this thesis and will synthesize them into a holistic perspective, followed by my answering the two research questions posed in the thesis.

- Finally, in Chapter 7, I will present the conclusions of the study, including a summary of the key findings, a discussion of the thesis' theoretical contributions, the directions for future research, and the managerial implications. 


\section{Conceptual Development}

There are multiple studies in the strategic marketing literature that touch upon various aspects of proactive market strategies, but, to the best of my knowledge, none that take a holistic view of the area. The lack of existing constructs that describe proactive market strategies means that the exploratory work presented in this thesis contained a lot of conceptual development. These developments are aimed at conceptualizing and defining the key constructs and frameworks needed to describe and understand proactive market strategy.

\subsection{Theoretical foundations}

In this first section, I will outline the theoretical foundations of the conceptual work that will be presented later on in the chapter. At its core, this licentiate thesis is based in the field of strategic marketing and uses the extensive literature on market orientation as a starting point for its conceptualization and exploration of proactive market strategies. Starting from the marketing concept, considered by many scholars to be the very core of the marketing discipline (Kohli \& Jaworski, 1990), this outline will describe the important fields of strategic marketing and marketing strategy, followed by a description of the key concept of market orientation. 


\subsubsection{The marketing concept and creating customer value}

One of the foundations of the marketing field is the marketing concept, which refers to the business principle that it is by consistently delivering superior value to their customers that firms become successful (e.g. Kotler, 1972; McNamara, 1972; McCarthy \& Perreault, 1991). The idea is that by because a firm has a superior market offering, customers will preferentially engage in business transactions with that firm, giving it a competitive advantage that enables it to achieve superior business performance. As Kotler (1972, p. 50) puts it: "The marketer is attempting to get value from the market through offering value to it'.

The problem is that, since there are obviously many different ways of providing the market with offerings, how can the firm ensure that it is providing the market with superior value? This is achieved by putting "the [customer], not the company, in the middle" (Keith, 1960, p. 35), i.e. by ensuring that the firm is focused on satisfying the needs and wants of the customer. The marketing concept thus represents one of the earliest views of outside-in strategy (e.g. Day \& Moorman, 2010), i.e. that it is through understanding the market that a firm becomes successful. The view of value and value creation in the marketing concept as can succinctly be described with this quote from Kotler:

\section{"Value is completely subjective and exists in the eyes of the beholding market. Marketers must understand the market in order to be effective in creating value. This is the essential meaning of the marketing concept." (Kotler, 1972, p. 50)}

This view on value and value creation matches rather closely that presented in the service literature, namely that "value ... is uniquely, experientially and contextually perceived and determined by customers" (Gröönros \& Gummerus, 2014, p. 207). Thus, it is through a superior understanding of the customer, what they value and what they need, that a firm can create the superior offerings that enable superior business performance (Narver \& Slater, 1990).

\subsubsection{Strategic marketing and marketing strategy}

The marketing concept obviously has far-reaching implications for firm strategy. Many decisions that the marketers at a firm have to make, such as target market selection, customer segmentation, and so on, have an impact on the strategic management of the firm. The strategic considerations of marketing decisions are usually referred to as strategic marketing (Day, 1992; Varadarajan, 1992). This field straddles the boundary between marketing and strategic management

Strategic marketing is thus the field of study concerned with the marketing issues and marketing decisions that have consequences for the strategic management of the firm (Varadarajan, 2010). The domain of strategic marketing concerns can be formally defined as follows: 


\begin{abstract}
"The domain of strategic marketing encompasses the study of organizational, inter-organizational and environmental phenomena concerned with (1) the behavior of organizations in the marketplace in their interactions with consumers, customers, competitors and other external constituencies, in the context of the creation, communication and delivery of products that offer value to customers in exchanges with organizations, and (2) the general management responsibilities associated with the boundary spanning role of the marketing function in organizations." (Varadarajan, 2010, p. 126)
\end{abstract}

While strategic marketing refers to the entire domain of marketing decisions with implications for the strategic management of firms, it does not, however, explicitly capture the translation of these strategic issues into firm strategy (Varadarajan, 2010). This is instead the focus of marketing strategy, which can be seen as concerned with the decisions involved in creating and pricing market offerings, targeting customer segments, choosing market channels, and developing promotional content for the firm's offerings, i.e. decisions involved with the firm's marketing mix (Varadarajan \& Clark, 1994; Varadarajan \& Jayachandran, 1999).

Varadarajan (2010) continued the development of the marketing strategy concept to grasp a broader perspective than the marketing mix decision allows for; he instead views marketing strategy as the organizational strategy construct that captures the considerations raised by strategic marketing issues. Marketing strategy can thus be defined as:

\begin{abstract}
"Marketing strategy refers to an organization's integrated pattern of decisions that specify its crucial choices concerning markets to serve and market segments to target, marketing activities to perform and the manner of performance of these activities, and the allocation of marketing resources among markets, market segments and marketing activities toward the creation, communication and/or delivery of a product that offers value to customers in exchanges with the organization and thereby enables the organization to achieve specific objectives." (Varadarajan, 2010, p. 128)
\end{abstract}

In summary, strategic marketing refers to the broader set of strategic considerations associated with marketing activities, while marketing strategy refers to the creation and execution of organizational strategy which enables a firm to manage these considerations and create customer value (Day, 1992; Varadarajan \& Clark, 1994; Varadarajan \& Jayachandran, 1999; Varadarajan, 1992, 2010).

\title{
2.1.3 Market orientation
}

One of the chief constructs-if not the most important one-of strategic marketing is market orientation (Kohli \& Jaworski, 1990), which according to Kohli, Jaworski \& Kumar (1993, p. 467) represents "...the foundation of high-quality marketing practice". Market orientation refers to the implementation of the market concept in a firm, meaning that a market-oriented firm is one that has embraced the principle that superior business performance is achieved by creating superior customer value (Kohli \& Jaworski, 1990). 
However, ever since the term was coined in the late 1980s, market orientation has been an elusive concept to capture in terms of conceptualization, measurement, and implementation (Matsuno, Mentzer \& Rentz, 2005). This section will start by expanding upon the two core conceptualizations of market orientation, followed by a detailing of the relationship between market orientation and performance. Thereafter, the development of the construct into proactive and responsive market orientation will be described. Finally, the recent development of an organizational ambidexterity view of market orientation will be discussed.

\subsubsection{Conceptualizing market orientation}

As it is a key concept within marketing, market orientation has been investigated in numerous studies over the years (see Liao et al., 2011 for a review of market orientation literature). It was originally developed to conceptualize the behavior of market-oriented firms, i.e. firms that were very focused on their way of serving their customers and creating value for them (Shapiro, 1988). The two seminal papers on market orientation from 1990 (Narver \& Slater, 1990; Kohli \& Jaworski, 1990) share the same overall view of market orientation as an important driver for firm performance and highlight the need for firms to be more focused on creating customer value. However, they differ in their conceptualizations of what market orientation is.

Narver \& Slater (1990) conceive of market orientation as an organizational culture that is committed to creating superior value for a firm's customers. In their view, the market-oriented behavior seen in many successful firms arises from a set of values that involve customer orientation, i.e. a focus on how to provide superior value for customers, and competitor orientation, i.e. a focus on how to provide greater value for customers than the competitors can (Narver \& Slater, 1990). These two orientations guide a firm in its strategy-making processes (cf. Noble, Sinha \& Kumar, 2002), enabling it to maintain a comprehensive focus on creating customer value. However, being customer-oriented and competitor-oriented is not enough for a firm to be market-oriented, it must also have an inter-functional coordination that enables all parts of the firm to be aware of customer needs and competitor activities and to focus their activities on creating customer value (Narver \& Slater, 1990). This inter-functional coordination can thus be seen as an organizational capability that enables the market-oriented firm to achieve the full benefit of its customer-oriented and competitor-oriented activities (Gatignon \& Xuereb, 1997; Noble et al., 2002). Thus, Narver \& Slater (1990) conceptualize market orientation as an organizational culture that is focused on creating superior customer value.

Kohli \& Jaworski (1990) instead choose to focus on market orientation as a firm-wide implementation of the marketing concept. Thus, they conceive of the marketing concept as a sort of business philosophy that drives firms to strive to create superior value for their customers, while market orientation represents the implementation of that philosophy in the firm, i.e. a market-oriented firm is one "whose actions are consistent with the marketing concept" (Kohli \& Jaworski, 1990, p. 1). In this view, market-oriented behavior thus arises from a set of activities that a firm that has implemented the marketing concept performs, activities which Kohli \& Jaworski (1990) divide into three types: Market-oriented firms perform activities focused on: (1) generating market intelligence, (2) disseminating that intelligence across the whole organization, and then (3) responding to that intelligence. This view is much more focused on what the market-oriented firm is actually doing, as opposed to the cultural values in the organization that might be drivers for such actions and behaviors (Matsuno, Mentzer \& 
Rentz, 2005). Thus, Kohli \& Jaworski (1990) conceptualize market orientation as the implementation of the marketing concept, resulting in market-intelligence-related activities.

In their paper detailing the antecedents of market orientation, Jaworski \& Kohli (1993) themselves highlight cultural aspects such as the emphasis of top management and interdepartmental dynamics as well as the organizational system of the firm as important drivers of market-oriented behavior, although they do not relate them to the Narver \& Slater model. Kohli, Jaworski \& Kumar (1993) do, however, criticize the cultural view of market orientation for being too narrowly focused on just customers and competitors, rather than encompassing the wide range of market factors that are potentially relevant to creating customer value, such as suppliers and other partners, market regulation, broader social/cultural trends, and macroeconomic developments. Furthermore, they argue that the cultural conceptualization of market orientation lacks insight into the specific activities that market-oriented firms perform (Kohli et al., 1993) However, the conduct conceptualization of market orientation has also been criticized for putting too great an emphasis on customer intelligence as opposed to broader market intelligence (Pelham, 1997). Moreover, this view has problems with the fact that firmwide dissemination of intelligence and the response to it does not necessarily result in the creation of customer value if the organization does not understand or value information about its customers (Pelham, 1997; Matsuno et al., 2005).

While quite different in their approaches, the perspectives of Kohli \& Jaworski (1990) and Narver \& Slater (1990) are possible to reconcile. Matsuno et al. (2005) conceive of market orientation as organizational culture and organizational capability, i.e. the Narver \& Slater (1990) view, as being an antecedent to market orientation as conduct, i.e. the Kohli \& Jaworski (1990) view. Matsuno et al. (2005) use this synthesis of the two views of market orientation to create a model of what they refer to as extended market orientation, which can be seen in Figure 1 below.

\begin{tabular}{|c|c|c|}
\hline \multirow{3}{*}{$\begin{array}{l}\text { Internal Environment } \\
\text { Factors }\end{array}$} & \multirow{4}{*}{$\begin{array}{l}\text { Extended Market Orientation } \\
\text { (EMO) as Conduct }\end{array}$} & \multirow[b]{2}{*}{ Consequences } \\
\hline & & \\
\hline & & \multirow{4}{*}{\begin{tabular}{|l|} 
- Economic (ROA, \\
ROI, ROS, Relative \\
Market Share, Sales \\
Growth, New \\
Product Sales as \% \\
of Sales, Overal \\
Performance) \\
- Organizational \\
(Organizational \\
Commitment, Espri de \\
Corps)
\end{tabular}} \\
\hline $\begin{array}{l}\text { - Cullural Antecedents (Market } \\
\text { Orientied Culture) }\end{array}$ & & \\
\hline 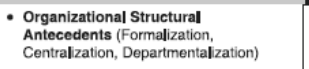 & \multirow{2}{*}{$\begin{array}{l}\text { - Intelligence Generation } \\
\text { - Intelligence Dissemination } \\
\text { - Responsiveness to the } \\
\text { Intelligence }\end{array}$} & \\
\hline $\begin{array}{l}\text { - Other Organizational Antecedents } \\
\text { (Sonior Managament Interdopartmontal } \\
\uparrow^{\text {Dynamics, Organizational Systems) }}\end{array}$ & & \\
\hline$\downarrow$ External Environment $\downarrow$ & \multirow{3}{*}{$\begin{array}{l}\text { Extended scope of Market Factors } \\
\checkmark \text { Customers } \\
\checkmark \text { Competition } \\
\checkmark \text { Suppliers } \\
\checkmark \text { Regulatory Factors } \\
\checkmark \text { Social/Cultural Trends } \\
\checkmark \text { Macroeconomic Environment }\end{array}$} & \\
\hline & & Moderators \\
\hline 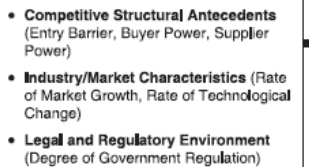 & & $\begin{array}{l}\text { - Strategy types } \\
\text { - Supply-Side } \\
\text { Factors } \\
\text { - Demand-side } \\
\text { Factors }\end{array}$ \\
\hline
\end{tabular}

Figure 1: The model for extended market orientation (from Matsuno et al., 2005) 
This synthesis and extension of the original conceptualizations of market orientation details how different internal factors (such as organizational culture and structure) and external factors (such as the general characteristics and competitive intensity of the market) act as antecedents to market-oriented behavior (Matsuno et al., 2005). The market-oriented behavior takes off from the market-intelligence-related activities conceived by Kohli \& Jaworski (1990), but widens the scope of market factors to be considered, as per the suggestions of other researchers (e.g. Pelham, 1997; Jaworski \& Kohli, 1996; Kohli et al., 1993). Through this reconciliation of the cultural and conduct perspectives, combined with the necessary wider scope of relevant market factors, market orientation is conceptualized in a way that enables easier comparisons between the market-oriented cultural drivers of a firm's activities and the market-oriented behaviors that ensue from those activities. This distinction will become important for investigating the activities that are part of proactive market strategies.

\subsubsection{Market orientation and performance}

Over the past 25 years, there has been a multitude of studies into the relationship between market orientation and performance, and there is a preponderance of evidence suggesting that market orientation does lead to superior firm performance (e.g. Narver \& Slater, 1990; Jaworski \& Kohli, 1993; Slater \& Narver, 1994; Han, Kim \& Srivastava, 1998; Matsuno \& Mentzer, 2000; Kirca, Jayachandran \& Bearden, 2005; Morgan, Vorhies \& Mason, 2009; Kumar et al., 2011; Frambach, 2016; see Liao et al., 2011, for a review of performance-related market orientation literature). While this relationship has held strong for a long time, more recent research by Kumar et al. (2011) nuances the performance implications of market orientation. They find that, while there is still a positive effect on firm growth and profitability from being market-oriented, this effect has been steadily shrinking since the 1990s (Kumar et al., 2011). They attribute this to the fact that, because more and more firms are becoming market-oriented to manage stiffer competition, being market-oriented becomes less of a competitive advantage. Thus, they argue that market orientation is transforming from a source of competitive advantage into a cost of competing (Kumar et al., 2011; Frösén et al., 2016).

This means that the time of easy performance gains from market orientation is over, but it does not mean that market orientation has lost its importance for firms. In order to stand out in a market environment where everyone is market-oriented to some degree, firms must find ways of being market-oriented that are adapted to their circumstances and go beyond the standard implementation (Kumar et al., 2011). While it is true that few firms manage to achieve higherthan-average performance from just leveraging their market orientation, it is also the case that few firms manage to achieve high performance without being market-oriented (Frösén et al., 2016; Frösén \& Tikkanen, 2016). Thus, market orientation has turned from a unique source of competitive advantage into a necessary yet not sufficient condition for superior performance. For example, Frösén et al. (2016) find that market orientation is only a predictor of superior performance when combined with the right type of marketing performance measurement, but they also do not find any consistent configurations that lead firms to superior business performance without being market-oriented.

Thus, not only is it more important than ever for firms to become market-oriented, but they must also develop a market orientation that fits with their particular circumstances. 


\subsubsection{Proactive and responsive market orientation}

One important aspect for firms striving to find the best way of being market-oriented is the division into proactive and responsive market orientation. During the 1990s and early 2000s, market orientation received criticism for causing firms to be led by their customers and hence unable to innovate properly (e.g. Christensen \& Bower, 1996; Berthon, Hulbert \& Pitt, 1999). Slater \& Narver (1998) argue against these accusations and hold that there is a difference between being a customer-led firm that just listens to customer demands and a customerleading, market-oriented firm that not only listens to customer demands but also takes a more proactive approach in helping customers to find and satisfy their latent needs, i.e. needs they were previously unaware of having.

The culmination of this development was the reconceptualization of market orientation into two types: responsive market orientation and proactive market orientation (Narver, Slater \& MacLachlan, 2004). Responsive market orientation refers to the customer-led type of marketoriented firm that is focused on finding and satisfying the expressed needs of the customer using expressed solutions, i.e. solutions of which the customer is aware (Narver et al., 2004). Proactive market orientation, on the other hand, refers to firms that go beyond customer demands and strive for a deeper understanding of the customers' circumstances, which enables them to identify and satisfy their customers' latent needs (Narver et al., 2004; Slater \& Narver, 1998). Moreover, proactive market-oriented firms use latent solutions, i.e. solutions of which the customer is unaware, to satisfy both their expressed and their latent needs, further indicating the greater innovativeness of a proactive firm.

\subsubsection{Ambidextrous market orientation}

While originally conceived as two different types of market orientation, further research revealed that proactive and responsive market orientation are actually complementary rather than mutually exclusive (Atuahene-Gima, Olson \& Slater, 2005). This opened up the opportunity for a broader field of study of market orientation using proactiveness and responsiveness as two dimensions to span a broader range of market-oriented behaviors (e.g. Tsai, Chou \& Kuo, 2008; Zhang \& Duan, 2010; Li, Lin \& Chu, 2011; Blocker et al., 2011; Bodlaj, Coenders \& Zabkar, 2012; Lamore, Berkowitz \& Farrington, 2013; Herhausen, 2016). Atuahene-Gima et al. (2005) actually found that there were negative consequences for a firm's new product performance from combining the two aspects, but subsequent research has mostly shown positive results from simultaneously having a high proactive market orientation and a high responsive market orientation (Herhausen, 2016; see Aspara \& Tikkanen, 2013, for another example of negative results). Ketchen, Hult \& Slater (2007) characterize the different combinations of responsive and proactive market orientation as shown in Figure 2 below, with responsiveness on the vertical axis and proactiveness on the horizontal axis. 


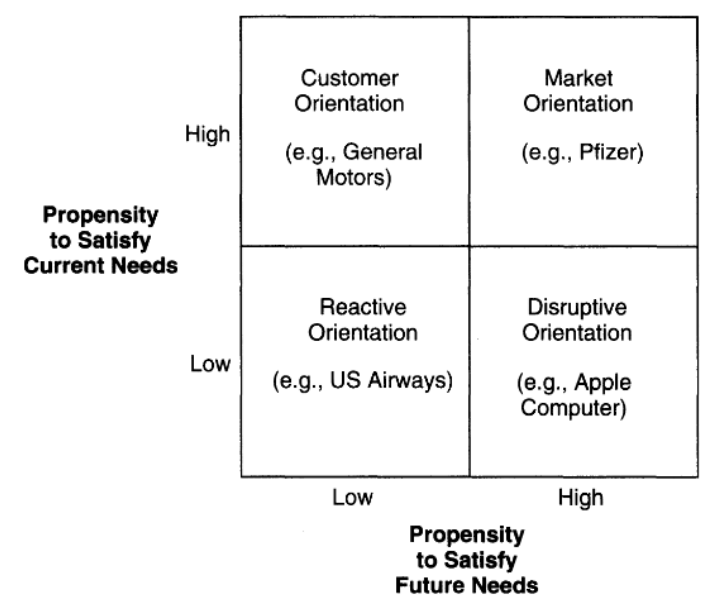

Figure 2: Four approaches to current and future customer needs (from Ketchen et al., 2007)

This highlights the argument that a truly market-oriented firm, as opposed to one that is merely customer-oriented, should strive to satisfy both the latent and expressed needs of their customers (Ketchen et al., 2007). Herhausen (2016) comes to a similar conclusion in finding that, not only are the performance effects from market orientation larger when a firm ambidextrously balances its levels of proactive and responsive market orientation, but they also increase as the level of the balance increases. Thus, firms achieve the greatest performance gains by simultaneously adopting proactive and responsive market orientation and striving to get both balanced on a high level (Herhausen, 2016; Ketchen et al., 2007; Tan \& Liu, 2014), which can be seen in Figure 3 below. 


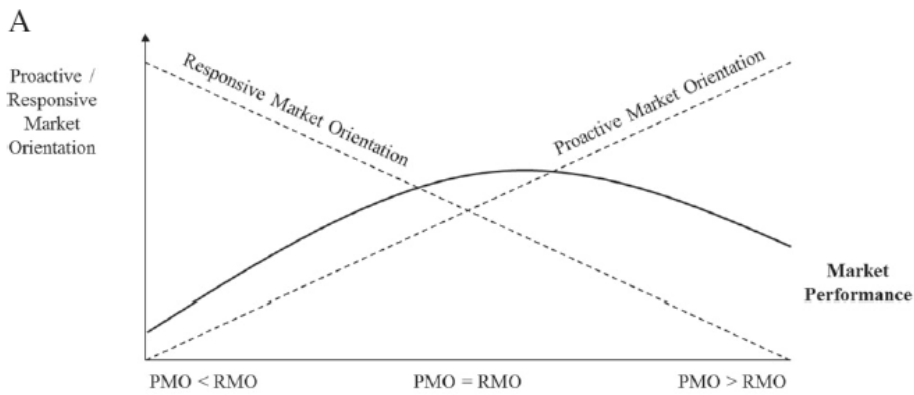

B

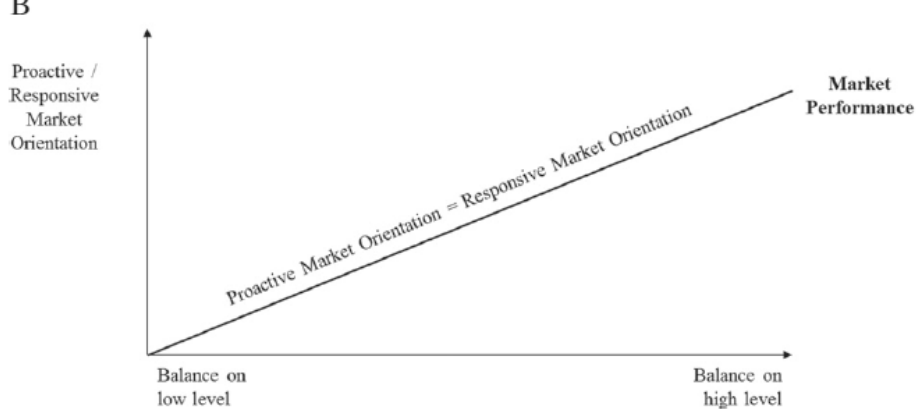

Note $\mathrm{PMO}=$ proactive market orientation, $\mathrm{RMO}=$ responsive market orientation.

Figure 3: Performance effects of balanced ambidextrous market orientation (from Herhausen, 2016)

However, such an ambidextrous combination of the exploitation of present opportunities (satisfying expressed customer needs) with exploring future opportunities (identifying and satisfying latent customer needs) is not without cost (Atuahene-Gima et al., 2005; Ketchen et al., 2007; Herhausen, 2016; cf. March, 1991). Atuahene-Gima et al. (2005) warn that the costs a firm accrues in being ambidextrous with regard to market orientation can outweigh the benefits, thereby undermining the firm's performance (Ketchen et al., 2007). Herhausen (2016) also considers the resource expenditure for a strategy of maximizing both aspects to be very high, but maintains that there are ways to gain increased benefit from ambidextrous market orientation without incurring these costs by instead focusing on balancing proactive and responsive market orientations, as shown in part $\mathrm{A}$ of Figure 3 above.

\subsection{Defining proactiveness in the marketing context}

One important missing factor in further exploring proactive market strategy was a clear and concise definition of what proactiveness at a firm level entails. Therefore, one of the first conceptual developments I made was a synthesis of the two main streams of research into proactiveness as a behavior: organizational behavior (e.g. Bateman \& Crant, 1993; Frese et al., 
1996) and market orientation (e.g. Narver et al., 2004; Atuahene-Gima et al., 2005). This synthesis subsequently served as the foundation for developing a useful definition of firm-level proactive behavior in a market strategy context.

\subsubsection{Proactiveness in organizational behavior}

From an organizational behavior perspective, proactive behavior is a type of highly motivated behavior exhibited by persons at work (Bateman \& Crant, 1993). The highly influential stream of literature studying proactive personality in an organizational context was introduced by Bateman and Crant (1993, p. 103), who in their seminal paper define proactive behavior as "the relatively stable tendency to effect environmental change". The main characteristic of proactive behavior from this early definition is thus for persons to change things in their work environment. However, one of the issues with this definition is that it describes the outcome of proactive behavior rather than characterizing what makes a particular behavior proactive, thus making it less useful for identifying proactiveness in people's behaviors (Crant, 2000).

Crant (2000, p. 436) further develops this definition, defining proactive behavior as "taking initiative in improving current circumstances or creating new ones; it involves challenging the status quo rather than passively adapting to present conditions". He then elaborates that "proactive people actively seek information and opportunities for improving things; they don't passively wait for information and opportunities to come to them" (Crant, 2000, p. 437). This definition of proactive behavior obviously builds upon Bateman's and Crant's (1993) work, but highlights a few interesting aspects that were absent in the previous definition. Firstly, it makes it much clearer that proactive behavior is about initiative-taking; behavior is not proactive just by reactively creating environmental change, it has to actively aim to create such change (Bateman \& Crant, 1999). Secondly, proactive behavior is implied to be opportunity-creating, i.e. aimed at creating a better situation in the future by effecting some form of change in the environment (Crant, 2000).

However, there is still one major aspect of proactive behavior that is absent from Crant's (2000) definition. A European branch of research into proactiveness under the term personal initiative (e.g. Frese et al., 1996; Frese \& Fay, 2001) has shown that proactive behavior contains a significant anticipatory characteristic, i.e. proactive behavior is about acting in advance, in anticipation of a future event (Grant \& Ashford, 2008). In an attempt to reconcile the personal initiative approach to proactiveness with the proactive personality construct of Bateman and Crant (1993), Grant and Ashford (2008, p. 8) define proactive behavior as "anticipatory action that employees take to impact themselves and/or their environments". This highlights the future-oriented and pre-emptive nature of proactive behavior, in which a person acts in anticipation of environmental change rather than in response to it (Frese \& Fay, 2001).

Finally, one important characteristic of proactive behavior is mindfulness (Weick \& Roberts, 1993). Grant and Ashford (2008) argue that proactive behavior has an intended impact, i.e. that action is taken with a specific goal in mind. This is alluded to by Bateman and Crant (1999) as well, who note the importance of setting effective and change-oriented goals to achieve success with proactive behavior. 
These definitions are, however, developed for characterizing the behavior of people as they work in organizations, and, to a lesser degree, the behavior of managers who lead organizations. Thus, work must be done to adapt these definitions to behavior at the firm level.

\subsubsection{Proactiveness in market orientation}

There has been comparatively little research into characterizing proactive firm behavior, especially in a marketing context, and no clear definitions of proactive firm behavior have been coined. One of the main research streams into proactiveness in a firm context is proactive market orientation (Narver et al., 2004; Atuahene-Gima et al., 2005), which is part of the broader market orientation literature. The proactive behavior exhibited by a firm with proactive market orientation is focused on gaining a deeper understanding of the firm's customers and their circumstances in order to identify and satisfy their latent needs-i.e. the needs they were unaware of having-as opposed to just serving their expressed needs (Narver et al., 2004). Proactiveness in the sense of PMO is thus defined as leading the customer by identifying and satisfying their latent needs.

Furthermore, Narver et al. (2004, p. 336) state that "This [proactiveness] is distinguished from another use of proactive in which a business is simply highly energized in attempting to satisfy target customers' expressed needs. No matter how energetically an organization attempts to satisfy customers' expressed needs, such behaviors do not comprise proactive market orientation". This is an important distinction which implies that proactive firm behavior in a market strategy context should be focused on a more proactive approach to creating customer value, rather than just an increased attentiveness to customer wants (Narver et al., 2004). Findings by Blocker et al. (2011) that proactive market orientation is an important driver of customer value across different cultural contexts also lend credibility to this interpretation of proactiveness.

Regarding the proactive aspect of proactive market orientation, Narver et al. (2004, p. 335) also argue for “... 'proactivity' in the anticipatory sense”, referring to firms' requirement to anticipate the needs of their customers and not just deliver offerings to satisfy their expressed needs. This way of viewing proactiveness shows some similarities with the organizational behavior perspective (e.g. Frese et al., 1996), but puts more emphasis on creativity in identifying and satisfying customer needs. The anticipatory aspect of proactive behavior is also found in other firm-level proactive concepts, such as proactive corporate environmental strategy (e.g. AragónCorrea, 1998; Arragón-Correa \& Sharma, 2003; Buysse \& Verbeke, 2003) and proactive CSR (e.g. Du et al., 2007; Groza et al., 2011).

Another important aspect of proactiveness in a proactive market orientation context is that it revitalizes firm innovation efforts (Narver et al., 2004). Since the concepts of customer-leading firms (Slater \& Narver, 1998) and proactive market orientation were introduced chiefly in response to criticism that market-oriented firms became customer-led and failed to innovate (e.g. Christensen \& Bower, 1996; Berthon et al., 1999), it is natural that innovativeness and creativity should be part of a firm-level proactive behavior. This connection between proactiveness and greater firm innovativeness can be seen through results indicating that 
proactive market orientation improves firms' innovation performance (Atuahene-Gima et al., 2005; Bodlaj et al., 2012; Herhausen, 2016).

However, many of the characteristics of proactive behavior from the organizational behavior literature, such as initiative-taking and mindfulness, are not explicitly mentioned in the definitions of proactiveness from proactive market orientation. Thus, for a useful definition of proactive firm behavior in a market strategy context, these streams of research must be synthesized into a definition that has the nuance of the organizational behavior definitions, but also places added emphasis on the aspects of proactive firm behavior that arise from the proactive market orientation literature.

\subsubsection{Developing a new definition of proactiveness at the firm level}

By synthesizing the three main views of proactive behavior: (1) proactive personality (e.g. Bateman \& Crant, 1993; Crant, 2000), (2) personal initiative (e.g. Frese et al., 1996; Frese \& Fay, 2001), and (3) PMO (e.g. Narver et al., 2004; Atuahene-Gima et al., 2005), I arrive at the following definition of proactive behavior at the firm level:

\section{In a market strategy context, proactive firm behavior is defined as future-oriented, initiative-taking, change-inducing, and creative.}

The four main characteristics of proactive firm behavior in my definition will now be delineated.

\section{Future-oriented}

One of the key defining characteristics of proactive behavior is taking action in anticipation of the future (Frese et al., 1996; Frese \& Fay, 2001; also seen in e.g. Narver et al., 2004; Aragón-Correa \& Sharma, 2003; Groza et al., 2011). Furthermore, proactive behavior is aimed at improving present conditions or creating future opportunities (Crant, 2000), also indicating that it is a vision of a better future state that drives proactive behavior. This means that proactive behavior is future-oriented, in the sense that it is driven by the anticipation of potential future events or desired states.

\section{Initiative-taking}

Proactive behavior should also be initiative-taking (Crant, 2000) and self-starting (Frese \& Fay, 2001), meaning that the impetus for taking action should be internal rather than a stimulus from the external environment. This characteristic of proactiveness helps differentiate proactive behavior from responsive or reactive behavior by highlighting that proactive behavior is never forced by or initiated because of factors in the contemporary environment, but rather self-started by the firm in order to achieve some goal. Thus, proactive behavior is based around the concept of seizing the initiative and taking action without the need for external stimuli. 


\section{Change-inducing}

The original central characteristic of proactive behavior is effecting change on the environment (Bateman \& Crant, 1993). This is further elaborated into proactive behavior being centered on improving current conditions or creating new opportunities (Crant, 2000), clearly indicating the intended direction of change. Another important aspect of this characteristic is that firms take action with an intended impact in mind (Grant \& Ashford, 2008; Bateman \& Crant, 1999), meaning that not only should proactive behavior create change, it should be clearly intended to do so.

\section{Creative}

Finally, proactive firm behavior is characterized by creativity (Narver et al., 2004; Bateman \& Crant, 1999). Since one of the central aspects of proactively creating customer value is to identify and satisfy the latent needs of customers using latent solutions, i.e. solutions of which the customer is unaware (Narver et al, 2004), it is important to capture this characteristic in the definition of proactive behavior. Creativity has also been seen as an important part of proactive behavior at the individual level, helping to explain parts of the relationship between proactive behavior and improved job performance (e.g. Bateman \& Crant, 1993; Seibert, Kraimer \& Crant, 2001; Parker, Bindl \& Strauss, 2010).

\subsection{A framework for conceptualizing market strategy}

One of the research questions of this thesis concerns the activities that firms perform in the implementation of their market strategies. In order to delve deeper into this topic, a conceptualization of how the two terms are connected is needed. Furthermore, there are two other important strategy concepts whose relationship with market strategy must be defined: strategic orientation (e.g. Venkatraman, 1989; Narver \& Slater, 1990; Gatignon \& Xuereb, 1997; Noble, Sinha \& Kumar, 2002) and strategic behavior (e.g. Burgelman, 1983; Olson, Slater \& Hult, 2005; Slater, Hult \& Olson, 2007), which represent important strategic antecedents and consequences of firm action. Moreover, market orientation is to a large degree a strategic orientation (Narver \& Slater, 1990; Deshpandé et al., 1993) and proactive action has a large impact on behavior (Bateman \& Crant, 1993; Grant \& Ashford, 2008), meaning that the two terms must both be taken into consideration when conceptualizing market strategy using the theoretical foundations of this thesis.

The four central concepts whose relationships are to be conceptualized are thus: (1) market strategy, (2) activities, (3) strategic orientation, and (4) strategic behavior. To the best of my knowledge, there exist no conceptualizations that detail the relationship between these four concepts. Therefore, I chose to develop a simple conceptual framework for relating them, as seen in Figure 4 below. The framework is intended to represent a simple causal relationship between the four concepts (cf. Matsuno, Mentzer \& Rentz, 2005) and does not consider the dynamics of how strategic orientations can change or how external influences can impact upon the strategic behavior of a firm. Each of the components will now be delineated. 


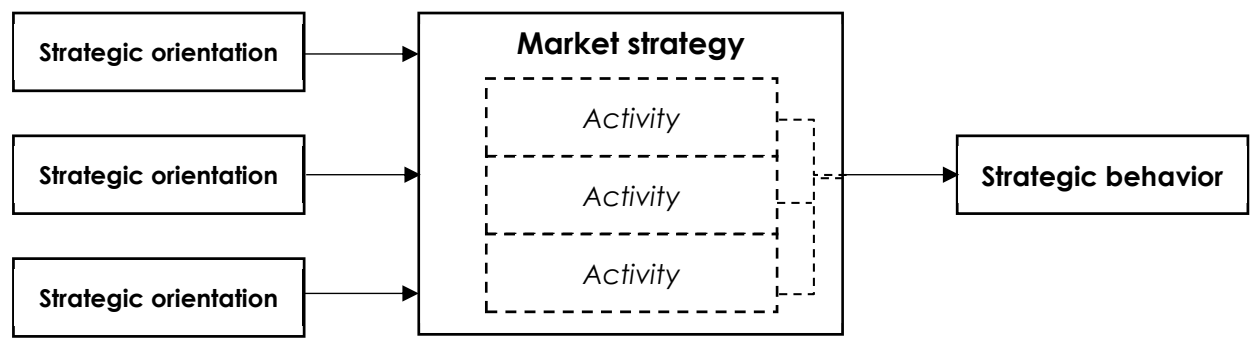

Figure 4: The strategic orientation-market strategy-strategic behavior framework

In this thesis, market strategy, found in the center of Figure 4 above, is conceptualized as overlapping certain areas of marketing strategy and business strategy, which is the strategy concerned with producing a competitive advantage for the firm (Varadarajan \& Clark, 1994; cf. Porter, 1980). Market strategy concerns the firm's strategy for creating, communicating, and delivering superior value to its customers (Kindström et al., 2012), thereby gaining a competitive advantage and achieving superior business performance.

In implementing its market strategy, a firm performs certain activities, intended to execute the strategy and achieve its goals (Noble, 1999; Okumus, 2001a; 2001b). The activities can thus be viewed as both parts of the strategy, in the sense that they are performed under the umbrella of a market strategy, and also as the realization of the strategy, being the concrete actions that are aimed at turning the abstract strategy into reality (Porter, 1996). It is also important to note that a firm does not have to use extensive planning to be strategic; strategy can just as well arise from a consistent pattern in the stream of activities the firm performs (Mintzberg, 1987; Miles \& Snow, 1978). Furthermore, not all activities of a firm fall within one of its pre-planned strategies, giving rise to the phenomenon of emergent strategy, which blends with the firm's planned strategy to become the realized strategy (Mintzberg \& Waters, 1985).

This conceptualization of market strategy and activities thus enables the study of a market strategy through the study of its associated activities.

Strategic orientations, found to the left in Figure 4 above, can be viewed as "...guiding principles that influence a firm's marketing and strategy-making activities” (Noble et al., 2002, p. 25). These strategic orientations act as a sort of organizational philosophy for successfully doing business, as reflected by the values that managers hold as important in strategy development (Venkatraman, 1989; Narver \& Slater, 1990; Ruekert, 1992; Gatignon \& Xuereb, 1997; Zhou, Yim \& Tse, 2005). It is important to make it explicit at this stage that a firm may have several strategic orientations-referred to as the strategic orientation mix by Gatignon \& Xuereb (1997)-reflecting the firm's more nuanced views of what is important for superior value creation (Olson, Slater \& Hult, 2005). Thus, it is based upon the strategic orientations that drive a firm that the firm's managers devise market strategies to achieve superior business performance (Narver \& Slater, 1990).

Finally, the strategic behavior of a firm, found to the right in Figure 4 above, can be viewed as the consequence of the totality of the firm's strategic activities (Burgelman, 1983; Matsuno et al., 2005). This means that the strategic behavior reflects the common behavioral patterns in the 
series of activities the firm performs as it implements its market strategy (cf. Mintzberg, 1987). In this sense, the strategic behavior of a firm can also be seen as a consequence of its strategic orientations, since the orientations influence the activities that give rise to the behavior (Burgelman, 1983; Matsuno et al., 2005). Slater, Hult \& Olson (2007) use this link to describe the strategic behavior of a firm in terms of the strategic orientations which fuel that behavior, finding that the strategic behavior has important consequences for achieving a strategic fit between target markets and business strategy.

The difference between strategic orientation and strategic behavior from this perspective is that, while the orientation only represents a tendency to act in a particular way, the behavior represents the actual activities that have been performed (Noble et al., 2002; Burgelman, 1983). Thus, the strategic orientation of a firm can be considered to be an internal antecedent for action, while the strategic behavior is a consequence of the firm's implementation of its market strategies (Matsuno et al., 2005).

To summarize, the strategic orientations of a firm guide and influence its creation of market strategies to create customer value. The market strategy itself concerns the choice of activities the firm should perform, and the patterns in these activities give rise to the firm's strategic behavior. Thus, the strategic behavior can be seen as the realization of the market strategy.

\subsection{Conceptualizing proactive market strategies and proactive activities}

With a clearer notion of what proactive firm behavior in a marketing context entails and a framework for understanding market strategy in place, the final conceptual development required is to create a framework for proactive market strategies and associated proactive activities. As shown in the market strategy conceptualization earlier, activities are integral parts of the market strategies they are meant to implement, meaning that proactive market strategies will be realized through proactive activities. This means that a framework must enable the identification of proactive activities. By using the definition of proactive firm behavior and the established links between proactiveness and various forms of activities from the existing literature on strategic orientations in general and proactive market orientation in particular, this framework enables the identification and deeper understanding of proactive activities and proactive market strategies.

\subsubsection{Delineating proactive activities in three components}

The proactive activity framework is based on the framework developed by Gatignon \& Xuereb (1997), which delineates the factors influencing firm innovation performance and customer value creation using three strategic orientations: customer orientation, competitor orientation, 
and innovation orientation'. This framework has been further developed in later studies (e.g. Olson et al., 2005; Zhou et al., 2005; Slater et al., 2007) and captures many relevant aspects of firm performance. It is based on the cultural perspective on market orientation (Narver \& Slater, 1990), which has been complemented by technology orientation to capture an alternative approach to improving firm performance that is not covered by the original market orientation literature (Gatignon \& Xuereb, 1997; Workman, 1993).

Studies of market orientation from the 1990s (e.g. Deshpandé et al., 1993; Hurley \& Hult, 1998) have found that innovation is an important factor in understanding the relationship between market orientation and performance. However, Narver et al. (2004) maintain that this is because of a misrepresentation of market orientation as being only responsive, and that investigating proactive market orientation as well will show that innovation is not a missing link between market orientation and performance, but an integral part of it. Nevertheless, the study by Gatignon \& Xuereb (1997), as well as others using this framework (e.g. Olson et al., 2005; Slater et al., 2007; Zhou et al., 2005), have shown that an orientation that captures innovation directly-as opposed to the more indirect link between it and market orientation-enables the framework to better capture the factors driving the performance of firms. Thus, innovation orientation is a valuable addition to the framework, beyond the two orientations derived from market orientation (Gatignon \& Xuereb, 1997).

Furthermore, there is some criticism of Narver \& Slater's (1990) way of conceptualizing market orientation that should be addressed. They conceptualize market orientation into three behavioral components: customer orientation, competitor orientation, and inter-functional coordination (Narver \& Slater, 1990). Of these, customer orientation and competitor orientation are strategic orientations that guide a firm, while inter-functional coordination is more like an organizational capability that enables the firm to leverage these strategic orientations into superior performance (Narver \& Slater, 1990; Gatignon \& Xuereb, 1997). However, this conceptualization has been criticized for being too narrowly focused on just customers and competitors, and thus lacking the broader consideration of stakeholders and market aspects that the term market orientation implies (Kohli et al., 1993; Matsuno et al., 2005).

In order to capture these broader perspectives, the framework is amended by changing the term competitor orientation into competition orientation (e.g. Tajeddini, Trueman \& Larsen, 2006) to explicitly show that it is focused on a wider range of factors related to the competitive environment and management of stakeholders than just competitors. Inter-functional coordination is an important aspect of an organization's structure and capabilities that is crucial for achieving the potential benefits of a market orientation, and other orientations as well (Felton, 1959; Narver \& Slater, 1990; Kohli \& Jaworski, 1990; Gatignon \& Xuereb, 1997). However, in agreement with many other scholars, we consider it to lie outside the strategic orientation framework itself, instead being a powerful mediator (Gatignon \& Xuereb, 1997; Olson et al., 2005; Zhou et al., 2005; Slater et al., 2007).

\footnotetext{
${ }^{1}$ Originally called technology orientation by Gatignon \& Xuereb (1997), but in keeping with Olson et al. (2005) I have chosen to use the term innovation orientation (e.g. Hurley \& Hult, 1998; Siguaw et al., 2006; Stock \& Zacharias, 2011).
} 
With this amendment in place, the framework can be used to delineate the proactive activities associated with proactive market strategies.

\subsection{Three categories of activity}

Since we perceive the market strategy of a firm to be guided by the firm's strategic orientations, and this market strategy results in the concrete activities performed by the firm to implement the strategy, it follows that the firm's activities are also guided by its strategic orientations. The activities associated with a strategy are of key importance to the strategy, partly in terms of successfully implementing it (Okmus, 2001a, 2001b) but also because of the key importance of choosing the right activities to generate a competitive strategy (Porter, 1996). Furthermore, it is through its activities that a firm gains (or loses) performance potential from its strategic orientations. As Kohli \& Jaworski (1990, p. 1) put it: "a market-oriented organization is one whose actions are consistent with the marketing concept", clearly indicating that a firm is not really driven by a strategic orientation if it does not engage in activities that are aligned with that orientation. It is because of this importance of activities that a framework for understanding proactive activities associated with proactive market strategies is so important. By combining the strategic orientation framework with the conceptualization of market strategy and its relationships from section 2.3, I arrive at the framework in Figure 5 below.

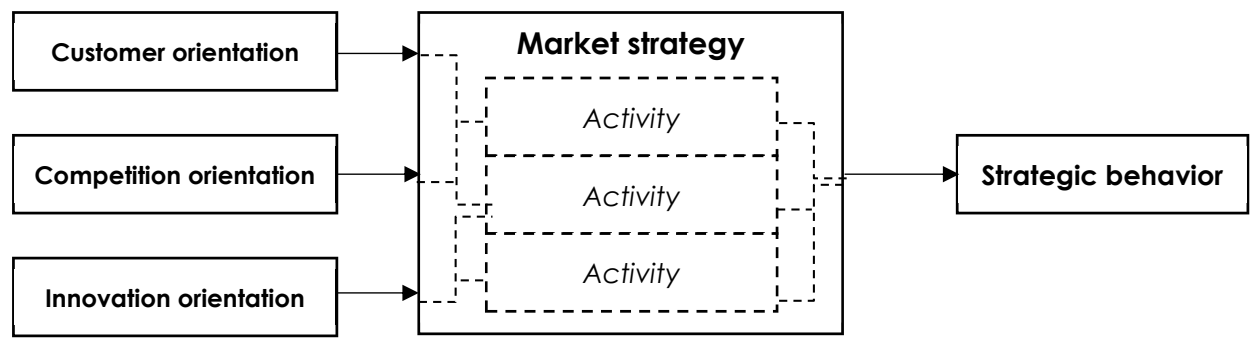

Figure 5: Delineating proactive activities in three categories

This framework can be used to classify activities associated with a market strategy based on the strategic orientations that guide the strategy. Through understanding the component activities and what guides them, it is possible to create a link between individual activities and the market strategy. This link then enables a deeper understanding of the market strategy itself, through an understanding of the activities (Porter, 1996; Zott \& Amit, 2005).

Based on the existing literature, all of the strategic orientations have an impact on the activities they help guide. The following sections will outline the implications each orientation has for firm activities, focused on the implications for proactive activities. The activity implications are summarized in Table 2 below. 


\subsubsection{Customer-oriented activities}

The most central aspect of having a customer orientation is to be focused on the customer and how to find and satisfy their wants and needs (Narver \& Slater, 1990). A customer-oriented firm will thus put the interests of the customer before its own, even while looking to improve the long-term performance of the firm (Deshpandé et al., 1993). Customer orientation is the very core of market orientation (Narver \& Slater, 1990) and is thus closely related to the marketing concept, which urges firms to put the customer at the center, rather than the firm (Keith, 1960).

\subsubsection{Customer needs identification}

From an activity perspective, customer orientation has large implications. Kohli \& Jaworski (1990), in presenting the activity perspective on market orientation, argue that firms must generate market intelligence, disseminate that intelligence throughout the organization, and then respond to it. Thus, the imperative customer-oriented activities are engaging with customers to identify their needs and preferences, spreading this information throughout the firm so it can be considered, and creating market offerings to satisfy those needs and preferences (Kohli \& Jaworski, 1990; Narver \& Slater, 1990).

However, it is not enough for firms to focus only on the expressed needs of customers, they must also consider latent needs, i.e. the needs which a customer is unaware of having (Narver et al., 2004). This is the core of proactive market orientation: finding and satisfying the latent needs of customers (Slater \& Narver, 1998; Narver et al., 2004; Atuahene-Gima et al., 2005). Furthermore, a customer-oriented firm must also consider customers' future needs evolution, i.e. how their needs will change over time, and strive to have the right offerings ready for customers at all times (Kohli \& Jaworski, 1990).

\subsubsection{Customer needs satisfaction}

It is not enough for a firm to be aware of customer needs, it also has to satisfy those needs. In doing so, there is a division between expressed solutions and latent solutions, i.e. whether the firm satisfies customer needs through solutions the customer is aware of, or those that they are not (Narver et al., 2004). It is important to note that both latent and expressed needs may have latent solutions (Narver et al., 2004), and also that the latent solution does not necessarily have to be a new innovation, it is simply a solution that the customer is unaware of (cf. Olson, Walker \& Ruekert, 1995; Ali, Krapfel \& LaBahn, 1995).

Narver et al. (2004) describe this proactive approach to satisfying customer needs as implicitly present in the original view of market orientation as well, but argue that it had not been accounted for by most scholars. Indeed, some of the earliest descriptions of the marketing concept actually mention it, like Keith (1960, p. 37), who writes: “The company's purpose was no longer to mill flour, nor to manufacture a wide variety of products, but to satisfy the needs and desires, both actual and potential, of our customers". 
Table 2: Summary of activity categories

\begin{tabular}{|c|c|c|}
\hline & Typical activities & Typical proactive activities \\
\hline 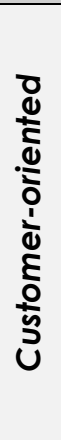 & $\begin{array}{l}\text { CUSTOMER NEEDS IDENTIFICATION } \\
\text { - Generating customer intelligence on } \\
\text { customers' expressed needs and } \\
\text { preferences } \\
\text { - Disseminating customer intelligence } \\
\text { throughout the organization } \\
\text { CUSTOMER NEEDS SATISFACTION } \\
\text { - Satisfying expressed customer needs } \\
\text { through expressed solutions } \\
\text { CUSTOMER ENGAGEMENT } \\
-\quad \text { Engaging customers focused on } \\
\text { establishing and maintaining close } \\
\text { relationships }\end{array}$ & $\begin{array}{l}\text { CUSTOMER NEEDS IDENTIFICATION } \\
\text { - Generating customer intelligence on } \\
\text { latent customer needs } \\
\text { - Generating customer intelligence on } \\
\text { customers' future needs evolution } \\
\text { CUSTOMER NEEDS SATISFACTION } \\
\text { - Satisfying customer needs, both } \\
\text { expressed and latent, through latent } \\
\text { solutions } \\
\text { CUSTOMER ENGAGEMENT } \\
-\quad \text { Engaging customers focused on } \\
\text { gaining deeper understanding of their } \\
\text { circumstances }\end{array}$ \\
\hline 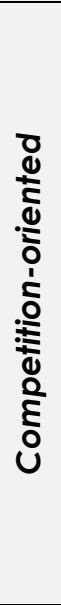 & $\begin{array}{l}\text { COMPETITOR FOCUS } \\
\text { - Generating intelligence on } \\
\text { competitors' short-term goals and } \\
\text { activities } \\
\text { - Disseminating competitor intelligence } \\
\text { throughout the organization } \\
\text { - Working to counter competitors' short- } \\
\text { term market activities } \\
\text { DOMAIN OF COMPETITION } \\
\text { - Generating intelligence on } \\
\text { competitors primarily inside current } \\
\text { product-market domain } \\
\text { MARKET SHAPING } \\
\text { - Creating entry barriers against obvious } \\
\text { new entrants }\end{array}$ & $\begin{array}{l}\text { COMPETITOR FOCUS } \\
\text { - Generating intelligence on } \\
\text { competitors' long-term strategic goals } \\
\text { and capabilities } \\
\text { - Working to erode competitors' } \\
\text { competitive advantages } \\
\text { DOMAIN OF COMPEIITION } \\
\text { - Generating intelligence on potential } \\
\text { competitors outside current product- } \\
\text { market domain } \\
\text { MARKET SHAPING } \\
\text { - Shaping the market through } \\
\text { engagement with various market } \\
\text { stakeholders and institutions, beyond } \\
\text { just customers } \\
\text { - Shifting customers' expectations of } \\
\text { suppliers' market activities and } \\
\text { offerings }\end{array}$ \\
\hline 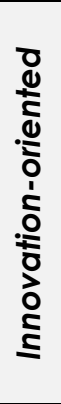 & $\begin{array}{l}\text { BUSINESS FOCUS } \\
-\quad \text { Exploiting previously found market } \\
\text { opportunities } \\
\text { INNOVATION FOCUS } \\
-\quad \text { Incrementally innovating to improve } \\
\text { current market offerings } \\
\text { CUSTOMER INVOLVEMENT } \\
-\quad \text { Involving customers to test offering } \\
\text { improvements }\end{array}$ & $\begin{array}{l}\text { BUSINESS FOCUS } \\
\text { - Exploring new market opportunities } \\
\text { - Employing ambidextrous approaches } \\
\text { INNOVATION FOCUS } \\
\text { - Using radical and architectural } \\
\text { innovation to create new market } \\
\text { offerings } \\
\text { - Establishing and maintaining } \\
\text { innovation leadership in key areas } \\
\text { CUSTOMER INVOLVEMENT } \\
\text { - Involving lead customers to } \\
\text { collaboratively develop new offerings }\end{array}$ \\
\hline
\end{tabular}

\subsubsection{Customer engagement}

As noted by Kohli \& Jaworski (1990), a key way for firms to gather market intelligence on customer needs and preferences is through engagement with the customers themselves. However, customer-oriented firms can enjoy performance benefits beyond those of simple intelligence generation from engaging closely with their customers (Kumar \& Pansari, 2016). Engagement with customers has two core components: (1) customer engagement, indicating the 
firm is cultivating an engagement from the customers towards the company, e.g. through its branding activities (e.g. Kumar et al., 2010; Kumar \& Pansari, 2016), and (2) employee engagement, indicating that the firm is cultivating a higher level of connectedness among its employees towards the customers (Kumar \& Pansari, 2016; Kumar et al., 2017). Through these two components, a firm strengthens its customer management to focus on ensuring customer satisfaction, rather than just a purely transactional or relationship-maintaining contact, enabling the firm to achieve superior performance (Pansari \& Kumar, 2017).

In the context of proactiveness, there are three aspects of customer engagement that are particularly interesting: proactive service, customer knowledge, and customer influence (Winer, 2001; Narver et al., 2004; Kumar et al., 2016). Proactive service refers to the firm proactively taking action to ensure customer satisfaction, e.g. through regularly checking if they have any issues the firm can help with rather than waiting for them to start complaining (Winer, 2001; Reinartz, Krafft \& Hoyer, 2004). Customer knowledge refers to using the close relationship with the customers to gain a superior understanding of their circumstances, but also to actively involve key customers in the product development process in order to better ensure that their needs will be satisfied by a new offering (Joshi \& Sharma, 2004; Kumar \& Bhagwat, 2010). Finally, customer influence refers to using the close engagement with the customer to encourage them to influence other market actors, such as potential customers or institutions, in a way that strengthens the firm's competitiveness (Kumar et al., 2016) This is usually viewed as the influence the customer wields on social media (e.g. Hogan, Lemon \& Libai, 2003; Trusov, Bucklin \& Pauwels, 2009; Chakravarty, Kumar \& Grewal, 2014), but viewed from the wider perspective of market shaping, customer influence can take on a larger role than just social media activity (Elg et al., 2012; Kindström et al., 2018)

\subsubsection{Competition-oriented activities}

Having a traditional competitor orientation means a firm is concerned with the activities of its competitors and puts effort into generating competitor intelligence, disseminating it within the organization, and responding to the significant activities of competitors (Kohli \& Jaworski, 1990; Narver \& Slater, 1990). However, a very strong focus on competitor-oriented objectives, such as measuring market share or other forms of competitor benchmarking, can actually be detrimental to a firm's performance, since these may be prioritized to the detriment of profitability (Armstrong \& Collopy, 1996). Furthermore, Kohli et al. (1993) criticize the customer and competitor orientation view of market orientation (Narver \& Slater, 1990) as focusing too much on these two groups to the exclusion of other important market stakeholders, such as suppliers, customers' customers or market institutions. Thus, we broaden the term into competition orientation, which refers to focusing on a wider range of issues related to a firm's competitiveness rather than just competitors themselves, indicating a shift from a potentially detrimental focus on competitors to a more holistic view of the firm's own competitiveness (cf. Narver \& Slater, 1990; Armstrong \& Collopy, 1996; Tajeddini et al., 2006). 


\subsubsection{Competitor focus}

Focus on competitors is still one of the core aspects of a competition orientation. Using the conduct framework forwarded by Kohli \& Jaworski (1990), competition-oriented firms will focus their market intelligence generation on holistically collecting intelligence on the competitive environment, in which direct and indirect competitors feature heavily. This means that competition-oriented firms will generate intelligence on competitors' activities and capabilities, disseminate this intelligence throughout the firm, and craft and deploy responses to competitors' actions (Kohli \& Jaworski, 1990). The responses will come in different forms, depending on the level of proactiveness of the competition-oriented firm. A non-proactive firm will be focused on competitiveness in the short term, while a proactive firm will take a more long-term and strategic perspective (Narver \& Slater, 1990; Narver et al., 2004; Li et al., 2008). Thus, while a non-proactive firm is focused on the short-term market activities of competitors and how to respond to them, a proactive firm is focused on the strategic goals and competitive advantages of competitors and how to best counter those (Narver \& Slater, 1990; Narver et al., 2004; Li et al., 2008).

\subsubsection{Domain of competition}

Proactive firms will employ a broader view of present and potential competitors when generating competitor intelligence (Tan \& Liu, 2014). Less proactive firms focus their intelligence collection and knowledge generating efforts on competitors inside the firm's present product-market domain, along with the most obvious potential entrants and indirect competitors (Li et al., 2008; Tan \& Liu, 2014). More proactive firms will, however, broaden their horizons when generating competitor intelligence and knowledge to include a wider range of indirect competitors and potential entrants from outside the current product-market domain (Zhang \& Duan, 2010; Tan \& Liu, 2014).

\subsubsection{Market shaping}

Finally, one of the key differences in adopting a competition orientation rather than a more focused competitor orientation is represented by the more dynamic approach to positioning found in market shaping (and the quite similar "blue ocean strategy" concept presented by Kim \& Mauborgne, 2004). The traditional view of positioning is that a firm should identify a market or niche where it can be more competitive than other firms, position itself there, and erect entry barriers to stop new competitors from appearing (Porter, 1980, 1985; Mintzberg, 1987). This is fundamentally a rather static way of looking at competitive advantage that does not accurately represent the dynamic markets of the 21* century (Day, 2011; Teece, Pisano \& Shuen, 1997).

However, there is still strength in positioning; firms should simply adopt a more dynamic way of approaching the concept. By viewing markets as dynamic and shapeable rather than static, firms can continuously work to shape the market to better fit their positioning, rather than just change their positioning to fit the market (Elg et al., 2012; Storbacka \& Nenonen, 2015; Ottosson \& Kindström, 2016; Kindström et al., 2018). Market shaping represents a fundamentally proactive way of viewing markets, since it emphasizes taking the initiative and creating positive change for the firm in the market, rather than just reactively adapting to changing market circumstances (Ottosson \& Kindström, 2016; Kindström et al., 2018; cf. Crant, 2000; Grant \& Ashford, 2008). 
From an activity perspective, proactive firms employing a market shaping strategy will make "active and conscious choices aiming at shaping the market structure and shaping market behavior" (Kindström et al., 2018, p. 37). Thus, the proactive firm will employ a broad range of activities aimed at shaping the market in its favor and strengthening its competitiveness, while at the same time eroding the advantages and positions of competitors (Storbacka \& Nenonen, 2015; Kindström et al., 2018). Blue ocean strategy (Kim \& Mauborgne, 2004) maintains a similar perspective, that firms can refine their market offerings, remove superfluous aspects of the offerings and refocus on the aspects that create the most customer value, thereby enabling them to strengthen firm competitiveness by making it hard for competitors using the old offering model to keep up.

\subsubsection{Innovation-oriented activities}

Innovation holds an important position in firms' efforts to develop solutions to customers' needs (Kohli \& Jaworski, 1990; Narver et al., 2004). An innovation-oriented firm is focused on achieving superior performance through its focus on creating innovative market offerings and improving internal processes (Hurley \& Hult, 1998). Several authors (e.g. Deshpandé et al., 1993; Hurley \& Hult, 1998; Narver et al., 2004; Atuahene-Gima et al., 2005; Li et al., 2008; Bodlaj et al., 2012) have studied the relationship between market orientation and, despite early criticisms to the contrary (Christensen \& Bower, 1996; Berthon et al., 1999), market orientation does not have a negative impact on firm innovation (e.g. Slater \& Narver, 1998; Narver et al., 2004). The innovativeness of a firm is both a consequence of (amongst other things) its configuration of market orientation and helps to strengthen the performance impact of marketoriented behavior (Deshpandé et al., 1993; Hurley \& Hult, 1998; Narver et al., 2004; Bodlaj et al., 2012).

\subsubsection{Business focus}

One of the fundamental choices in business is between exploiting previously identified opportunities and exploring new ones (March, 1991; Tushman \& O'Reilly, 1996). Proactiveness has a significant impact on this choice, as several scholars of proactive market orientation have pointed out (e.g. Li et al., 2008; Tan \& Liu, 2014; Herhausen, 2016). Through their broader perspectives on knowledge generation from outside the present product-market domain, proactive firms are more geared toward exploration, while non-proactive firms are more focused on exploitation ( $\mathrm{Li}$ et al., 2008).

Firms are, however, not limited to only choosing one of the two focuses for their businesses; they can also combine the two in what is known as an ambidextrous approach (March, 1991; Tushman \& O’Reilly, 1996; Li et al., 2008). The crux of this approach is the high resource cost of applying the often-opposing organizational processes necessary to simultaneously exploit existing opportunities and explore new ones (March, 1991). However, as Herhausen (2016) finds, firms can gain significant performance benefits by balancing the exploratory and exploitative aspects of market orientation, even if the absolute level of the two aspects is relatively low.

Proactive firms will thus primarily employ exploratory or ambidextrous approaches, with associated market activities, while non-proactive firms will default to exploiting their existing opportunities (Li et al., 2008; Tan \& Liu, 2014). 


\subsubsection{Innovation focus}

Firms' innovation efforts can be guided in different directions; often this is simplified to focusing on incremental innovation, radical innovation, or both (Ettlie, Bridges \& O'Keefe, 1984; Garcia \& Calantone, 2002; Li et al., 2008; March, 1991). Henderson \& Clark (1990) present a framework wherein firms' innovation efforts are categorized based on how the core concepts are changed and how the linkages between these concepts are changed. They define incremental innovation as when the components are improved, and the linkages remain unchanged, while radical innovation is represented by changed linkages and overturned concepts (Henderson \& Clark, 1990). Li et al. (2008) find that proactive firms are more aligned toward radical innovation, based on their more creative and change-inducing way of developing new offerings (cf. Crant, 2000) Ashford \& Grant, 2008), while less proactive firms are more geared toward incremental innovation.

However, Henderson \& Clark (1990) also identify other kinds of innovation, among which architectural innovation resonates with proactiveness. Architectural innovation refers to innovation where the core concepts remain the same, yet the linkages between them, the architecture, are changed (Henderson \& Clark, 1990). This resonates with proactive firms being creative in generating latent solutions to better satisfy customer needs; by using their existing components and tailoring new market offerings after customer needs, proactive firms can create superior customer value (Narver et al., 2004; Henderson \& Clark, 1990; Li et al., 2008).

\subsubsection{Customer involvement}

As noted by Slater \& Narver (1998), involving customers in the innovative processes of a firm, e.g. product development, does not have to mean that a firm is being led by its customers (cf. Christensen \& Bower, 1996). On the contrary, basing the firm's development of new market offerings on concrete information about customer needs has been proven to lead to strengthened innovation performance (Narver et al., 2004; Bodlaj et al., 2012; Herhausen, 2016). However, firms that are not being proactive in their approach to customer needs identification and satisfaction risk being led by their customers and failing to innovate (Slater \& Narver, 1998; Narver et al., 2004).

Involving customers in the innovation process has several benefits (Slater \& Narver, 1998), but the nature of the involvement will look different depending on the firm's level of proactiveness. Proactive firms will involve lead users-i.e. customers or potential customers whose needs are advanced compared to the market average (von Hippel, 1986)-in order to tailor their new solutions to satisfy the needs of these customers (Slater \& Narver, 1998). By using customers with advanced needs to advise and inform the offering development process, the firm gains the knowledge to both anticipate where other customers' needs will be in the future and to develop offerings that can provide superior customer value to a wide range of customers (von Hippel, 1986; Urban \& von Hippel, 1988; Slater \& Narver, 1998). 


\section{Methodology}

This chapter will focus on the methodology used in the research for this licentiate thesis. In particular, I will focus on the philosophy of science-i.e. my views on the fundamental philosophical issues at hand and encountered during the research-and the research design used. The research design will detail the thesis work and how it is intended to answer the research questions asked. Furthermore, validity and reliability-simply put, the integrity and repeatability of the research-are two key methodological considerations that will be covered. Finally, the research for this thesis, like all research, involves ethical issues, which will be discussed.

\subsection{Philosophy of science}

In order to conduct research that is likely to produce trustworthy results, a scholar must use research designs and analytical techniques that fit the objectives of the research and the nature of the research subject (Creswell \& Creswell, 2018). However, there is no one configuration of designs and techniques that is "correct" for each and every study, but these methodological concerns must rather be aligned with the scholar's perspective on science and knowledge (Creswell \& Creswell, 2018; Okasha, 2002; Chandler, 1999). There are numerous ways of approaching science, depending on the discipline and nature of the research, the time it is being conducted, and what the goal of conducting it is, just to mention a few influencing variables (Okasha, 2002). In this first section, I will outline the ontological and epistemological perspectives used in the research for this licentiate thesis. 


\subsubsection{The philosophy of scientific realism}

Firstly, I believe that there is a physical world that exists independently of any observers. Furthermore, this world is full of different tangible and intangible phenomena, through which the world can be understood. This standpoint is usually ascribed to the scientific realism school of thought (e.g. Leplin, 1984; Hunt, 1990), which has its basis in the natural sciences (Chandler, 1999; Okasha, 2002). The crux of scientific realism is that scientific inquiry is both intended to and capable of producing insights regarding both tangible and intangible phenomena in the real physical world (Chandler, 1999). Moreover, scientific realism is being used by many scholars in marketing, implicitly or explicitly (Hunt, 1990), and produces useful results (Leplin, 1984).

Moreover, I consider the great objective of science to be the furtherment of collective human knowledge, which is achieved through studies that each aim to produce correct statements about the world and its assorted phenomena. One of my colleagues pointed me to this great quote regarding scientific reality, describing what I consider to be the main strength of the approach:

\section{"Scientific realism is also critical, without being nihilistic. All knowledge claims and their methods of production are to be subjected to critical scrutiny, but the nihilistic view that knowledge and truth are impossible to achieve are emphatically rejected". (Hunt, 1990, p. 13)}

Thus, while any study can potentially be flawed, and all studies should be thoroughly scrutinized for flaws and errors, knowledge and truth are attainable (Hunt, 1990). I consider this outlook to be careful but optimistic, ensuring that worry about potential problems does not overpower the potential for producing valuable results that bring us ever closer to correctly describing reality. Since it is my strong belief that there exists a real world and my research is intended to explore the intangible phenomenon of proactive market strategy, I believe that the scientific realism school of thought is a good fit to my personal worldview and the research objectives of this thesis.

However, at this point it must be considered that market strategy is not a natural part of the world, like, for instance, magnetism or atoms, but is rather a phenomenon that emerges from the social context of individuals who organize into firms and engage in economic activity (Hunt, 1990; Bhaskar, 2009). The phenomenon of proactive market strategy thus emerges from and is embedded in the social context of firms proactively engaging with the market (on embedded phenomena, see Yin, 2018). There is no inherent conflict between the idea that a phenomenon emerges from a social context and that it exists as a real, but intangible, phenomenon in the world (Lepin, 1984; Hunt, 1990; Bhaskar, 2009). My perspective is that, while the phenomenon of market strategy is intangible and arises from a particular social context, it is not subjective, in the sense that it exists separately from the subjective perspectives of the individuals in that context (Hunt, 1990).

In this thesis, proactive market strategy is viewed as a real yet intangible phenomenon that emerges from and is embedded in the context of individuals organizing in firms and engaging in economic activities. 


\subsubsection{Doing research in scientific realism}

It is important at this point to note the difference between science being capable of producing statements that can correctly describe phenomena in the world and an individual study actually managing to do so. The lack of prior understanding regarding the phenomenon of proactive market strategy poses some problems that have to be managed in this research. The parable of the blind men investigating an elephant comes to mind, wherein the men reach vastly different conclusions about what they are investigating due to their limited information. Since each of them only uses the information they individually have at hand and fails to aggregate and synthesize their collective information into a more holistic picture of the phenomenon, they all draw incorrect conclusions about what they are researching.

I interchangeably use the terms 'perspective' and 'view' to refer to a set of information regarding a phenomenon, such as the information from an interview or from a case study. By synthesizing several perspectives into a more holistic one, which considers all the information from multiple sources, I strive to produce a statement that is more likely to be correct (see e.g. Hunt, 1990; Yin, 2018; Creswell \& Creswell, 2018). A holistic perspective is, in this sense, a perspective that considers a phenomenon from a wider angle and synthesizes multiple views of it, in order to give a more correct statement about what it is.

Moreover, science is conducted using particular designs and techniques, which are (ideally) chosen by the scholar for their particular usefulness in a particular study (Creswell \& Creswell, 2018). These designs and techniques, which can be called models of conducting research, are primarily designed to be more sensitive to certain things and less sensitive to others; thus, while a particular model might be very good for finding certain types of results, it might completely fail to find others, because of the way it is designed (Giere, 2010). What this means is that the results a study finds can to some degree be dependent on the research design and techniques used, which may possibly influence their truthfulness (Chandler, 1999; Giere, 2010).

Because of the lack of prior knowledge about proactive market strategy, this thesis aims to explore and increase our understanding of the topic, meaning that the subject of the research is currently a rather blurry elephant to study. To ensure that I get as correct a statement of the phenomenon as possible, I must consider multiple perspectives. For the purposes of this thesis, this entails dividing the research work into two parts that capture different perspectives and synthesizing a wide range of views, in order to develop a more holistic perspective on the phenomenon of proactive market strategy.

Furthermore, it is important to note that the phenomenon being studied in this thesis is nuanced, meaning that the correctness of any statement about proactive market strategy is dependent on many contextual factors besides the phenomenon itself (Creswell \& Creswell, 2018; Chandler, 1999). In the case of strategic marketing, contingency factors like industry and market characteristics, firm resources and capabilities, and many others influence the performance outcomes of firms' strategic choices (e.g. Drazin \& Van den Ven, 1985). Thus, it is important to consider that the contextual characteristics of the firms being studied, as noted above, will influence the investigation of the phenomenon of proactive market strategy itself. 


\subsection{Research process}

My work on this licentiate thesis began in early September 2015, when I was admitted to the graduate research school of the Department for Management and Engineering at Linköping University. From the start, my thesis project was aimed at studying proactive market strategy in some shape or form, which was a topic I was previously unfamiliar with. Due to my personal academic interest in topics at the boundary between marketing and strategy, my interest was piqued, and I started to consider the conceptual ramifications of proactiveness in firms' approaches to the market and to customer value creation. However, I also consider it important for management research to be useful to firms, so I wanted to ensure that my research would yield meaningful managerial implications. It swiftly became apparent, however, that the concept of proactive market strategy was relatively unknown, and so I started out with a broad exploration of the topic, which is the approach I would continue using for the rest of the thesis work.

The first period was characterized by reading a large set of relevant literature, with the ai of familiarizing myself with the topic of proactive market strategy. An issue that was encountered early during this stage was the lack of clear definitions and conceptualizations for many of the concepts that were necessary for me to progress with the research. Thus, one of the early priorities became to broaden my perspectives by widening the types of literature I was reading in an attempt to capture the entirety of the concept at a surface level. These early readings began with literature in strategic marketing and strategic management, but were expanded to include innovation literature, literature on proactiveness in organizational behavior, value creation, and organizational theory. These were picked up during the ongoing readings whenever I found a new area tangentially relating to proactive market strategy that might help me to expand my understanding of the topic.

These readings were then complemented by a diverse set of doctoral courses, e.g. research in marketing, innovation management, service and relationship management, and entrepreneurship, as well as research seminars within the graduate school and at the division of industrial economics. From this theoretical foundation there started to arise a more holistic picture of proactive market strategy. Based on the body of literature directly and tangentially relevant to the subject of proactive market strategy, as well as readings of methodology and research design literature, I outlined an initial research proposal. The details of this proposal would change over the following years of research, but the fundamental aim always remained the same: to explore proactive market strategy. The rough timeframe of my two branches of research, as well as the literature readings and doctoral course and project works, are presented in Figure 6 below. 
Initial readings

In-depth and complementary readings

Focus on conceptual work

Focus on empirical work

Doctoral courses and project work

Thesis writing

\begin{tabular}{|c|c|c|c|c|c|c|c|c|c|c|c|}
\hline Q3 & Q4 & Q1 & Q2 & Q3 & Q4 & Q1 & Q2 & Q3 & Q4 & Q1 & Q2 \\
\hline $\mathbf{2 0 1 5}$ & $\mathbf{2 0 1 6}$ & \multicolumn{6}{|c|}{$\mathbf{2 0 1 7}$} & $\mathbf{2 0 1 8}$ \\
\hline
\end{tabular}

Figure 6: Rough timeframe of the stages of the thesis work ( $Q=$ quarter)

\subsubsection{Literature readings}

One of the main directions of my readings was the extensive literature on market orientation, stretching back to the early 1990s, and especially the later literature on proactive market strategy, spawned from the seminal paper by Narver et al. (2004). I consider this to have been a good starting point which helped me to frame what was already known about proactive approaches to the market in strategic marketing and find the place where I should focus my own research. Proactive market strategy is rather interesting in that it is touched upon tangentially in many different fields and disciplines, but the issues that I considered to be at the core-how firms should be proactive and what they should do to become more proactive-were never addressed.

To build the foundation for the conceptual work, I continued reading literature. From this more in-depth reading I started finding subjects that investigated particular aspects of proactive market strategy, such as market shaping (e.g. Elg et al., 2012; Storbacka \& Nenonen, 2015; Ottosson \& Kindström, 2016). From this, I was able to verify that the topic did indeed exist and produced interesting and relevant empirical results. However, these studies only covered parts of proactive market strategy.

The readings were continuously expanded with new topics and adapted to help propel me along as the conceptual development and empirical studies unearthed new aspects of proactive market strategy to consider. In order to find relevant literature, I used a combination of the scientific databases Google Scholar, Scopus, and Web of Science, the latter two especially being used to do more nuanced searches, while Google Scholar was used more to quickly check literature and to get an overview of a topic. Furthermore, I used existing papers from top journals that touched upon proactive market strategy in order to ensure that I did not miss any key papers that were not appearing in the searches.

When reading the papers, I focused on identifying aspects of their findings that related to proactive market strategy. Since proactive market strategy is not an established term in the area and there has been a lack of clear conceptualizations of the subject, these readings were qualitative in manner, focused on ascertaining whether the results were: (1) related to proactive market strategy, and (2) how they influenced (and/or were influenced by) firm activities. Articles that were found to be relevant were then filed in a structured article storage system for easy retrieval during the conceptual work. 
These searches did not constitute a structured literature review as such, since they were meant to provide me with a solid theoretical foundation for the ongoing conceptual work rather than to provide a structured and detailed overview of the literature on the topic. Excellent previous literature reviews on market orientation (Liao et al., 2011), proactive and ambidextrous market orientation (Herhausen, 2016), and proactive behavior (Grant \& Ashford, 2008), in combination with the fact that the label proactive market strategy is not established in the discipline, convinced me that conducting another literature review would not be the most beneficial activity for my ongoing research.

\subsubsection{Developing the conceptual and empirical studies}

From the early readings and work with formulating a tentative research question, I noticed two main issues: (1) the lack of conceptual work that could enable me to link the more abstract concepts of proactive market orientation with concrete firm activities, and (2) the lack of qualitative research actually investigating what firms did.

Based on this, I decided to split my research efforts into conceptual work aimed at delineating and defining core concepts and qualitative case study research aimed at developing a greater understanding of what firms do when they employ proactive market strategies. These two branches were intended to represent two perspectives on the exploration of proactive market strategy; decreasing the risks of the research design and analytical techniques coloring the findings of the thesis by providing a more nuanced perspective. Abraham Maslow (1966, p. 15) formulated the problem like this: "I suppose it is tempting, if the only tool you have is a hammer, to treat everything as if it were a nair". Since I consider the qualitative case study to be the norm for management research in my research context at Linköping University, I wanted to avoid the issue of just applying the expected methodology by complementing it with more conceptual work, in order to secure a greater breadth of perspectives.

The literature readings and the conceptual work took precedence, since I found it most beneficial to have a solid conceptual foundation to work on as the empirical work started. I intended to follow the approach of Yin (2018) and create an expected pattern before beginning to collect empirical information on proactive market strategy, in order to use a pattern matching technique. An alternative approach is grounded theory, which instead maintains that researchers should avoid bias by not starting from a pre-defined conceptualization, but rather allow the rich qualitative data gathered give rise to new conceptualizations (Strauss \& Corbin, 1990). This approach was also interesting, but since I was unsure whether I could secure the very rich data and close access to firms necessary for such an approach, I instead decided to start out more deductively.

In approximately mid-spring 2016, I began on the conceptual work. This went through several iterations as my understanding of proactive market strategy evolved by conducting the conceptual development. However, this iterative process turned out to be quite timeconsuming, not to mention mentally taxing, for me, and as the empirical study started in earnest in early 2017, it was still ongoing. While I am pleased with the end results, in retrospect, it might have been better to use that empirical study as the foundation for the conceptual work rather than the other way around. This should not be considered a mistake in research design, 
but rather that my inexperience as a scholar in the early stages of the thesis work made this approach more time-consuming and difficult than might otherwise have been the case.

Nevertheless, as the ongoing conceptual work continued, the parallel process of working on the conceptual framework and the empirical study proved to heighten the work of both studies, as I could iterate between them and use inputs from one to further the work in the other. The two studies synergistically strengthened each other, since the conceptual study enabled me to create a better interview protocol and to better structure the empirical data, while the empirical study gave me vital real-world insights for the further development of the conceptualizations. They were thus of equal importance to the thesis research and present two perspectives on the phenomenon of proactive market strategy, which I then merged in this thesis.

In the end, the conceptual work became the frameworks presented in Chapter 2 of this thesis, as well as the typology in Paper I. The case studies, which are presented in greater depth in Chapter 4, resulted in the development of Paper II.

\subsection{Research design}

Simply put, research design refers to the strategy the scholar intends to use to fulfill the objectives of the study and answer, or at least work towards an answer to, the research question posed (Creswell \& Creswell, 2018). The design of a study can thus be likened to its "master plan” (Zikmund et al., 2009), outlining the approaches and techniques for collecting and analyzing the information needed to fulfill the study objectives. The research presented in this thesis has been grounded in two main branches with different designs: one study focused purely on conceptual development and one followed a qualitative multiple case study approach.

\subsubsection{Conceptual development}

Definitions and conceptualizations are very important in marketing research, as, indeed, they are in all research (Lewis, 1970; MacInnis, 2011). However, many studies are hampered by poor conceptualizations (MacKenzie, 2003; Jarvis et al., 2003), which introduce inaccuracies and decrease their scientific impact. MacInnis (2011) notes the lack of papers in recent years focusing on the development of novel conceptual work and calls for marketing scholars to expend more effort on producing novel and relevant conceptualizations that help drive future marketing research.

The conceptualizations of this thesis largely follow the framework presented by MacInnis (2011), as indicated in Table 3 below. In the paper, MacInnis (2011) creates a typology of eight different approaches to contributing to marketing research through conceptual developments. The developments I present in this thesis, along with the two appended papers, primarily fit with the types of Envisioning and Explicating conceptualizations, which refer to conceptual work that helps create new perspectives or shift existing ones, and to descriptions of entities and their relationships to each other. 
Table 3: Types of conceptualizations (adapted from MacInnis, 2011, p. 138)

\begin{tabular}{|c|c|c|c|c|c|c|c|c|}
\hline General & \multicolumn{2}{|c|}{ Envisioning } & \multicolumn{2}{|c|}{ Explicating } & \multicolumn{2}{|c|}{ Relating } & \multicolumn{2}{|c|}{ Debating } \\
\hline Specific & Ideptifying & Revising & Delineating & Summgrizing & $\begin{array}{l}\text { Differentia- } \\
\text { ting }\end{array}$ & Integrating & Advocating & Refuting \\
\hline $\begin{array}{l}\text { Metaphoric } \\
\text { al role of } \\
\text { researcher }\end{array}$ & Astronomer & Artist & $\begin{array}{l}\text { Carto- } \\
\text { grapher }\end{array}$ & Astronaut & Naturalist & Architect & Guide & Prosecutor \\
\hline $\begin{array}{l}\text { Metaphoric } \\
\text { al tool }\end{array}$ & Telescope & Paintbrysh & Mhap & Space ship & $\begin{array}{l}\text { Magnifying } \\
\text { glass }\end{array}$ & $\begin{array}{l}\text { Architec- } \\
\text { tural plans }\end{array}$ & Compass & Evidence \\
\hline
\end{tabular}

MacInnis' (2011) typology goes from more exploratory work to the left (as seen in Table 3 above) towards more normative work to the right. Therefore, I find it reasonable for my conceptual developments to be focused towards the left, since my goal is the exploration of proactive market strategy, which is an entity, to use the terminology of the framework, that needs more envisioning and explicating conceptualization.

\subsubsection{Qualitative multiple case study}

The research in this thesis is aimed at exploring proactive market strategy and generating new theory, and so the qualitative multiple case study was deemed appropriate (Eisenhardt, 1989; Stake, 1995; Eisenhardt \& Graebner, 2007). As previously explained, the phenomenon of proactive market strategy is sensitive to context and the proactive activities of firms are fundamentally embedded within the firms, further indicating the multiple case study is an appropriate research design (Yin, 2018).

The empirical study reported in this thesis used an exploratory approach to the case study. The cases used were purposefully selected (Patton, 2014) from a larger pool of firms that were participating in another research program. This purposeful selection was meant to ensure that they were useful for the study and that they could provide a broad perspective on the phenomenon of proactive market strategy (Seawright \& Gerring, 2008; Patton, 2014). By selecting case firms with previous success with proactive market strategy that were of different sizes and active in different industries, the case study could ensure that proactive market strategy could be studied from a broad perspective, with consideration of the context (Seawright \& Gerring, 2008; Yin, 2018). More information on the data collection process can be found in Paper II.

\subsection{Analytical techniques}

The conceptual study and the empirical study, presented in Paper I and Paper II respectively, represent two parts of the research in this thesis. They are complementary and are together intended to answer the questions and fulfill the purpose of the thesis. Thus, they should not be seen as separate, but rather as two distinct branches of the same research process.

The studies represent two different approaches to research and thus also employ different analytical techniques. Since the research design represents the strategy for fulfilling the objective(s) of the study, the techniques mirror the different aims and approaches of the studies. 
Here follows a brief overview of the analytical techniques used for the two studies that make up this thesis.

\subsubsection{Conceptual development techniques}

The several conceptual developments made in the conceptual study were somewhat different in approach and workflow, but, taken as a whole, the analytical techniques employed in the conceptual study can be summarized in the steps seen in Table 4 below. The choice of performing these steps was based on the influential work on conceptualizations in marketing by MacInnis (2011) and they were sequenced in order of more to less exploratory.

Table 4: Analytical techniques for different steps of conceptual development

\begin{tabular}{|l|l|}
\hline Step & Analytical technique \\
\hline 1. & Conceptual identifying \\
\hline 2. & Conceptual revising \\
\hline 3. & Conceptual delineating \\
\hline 4. & Conceptual summarizing \\
\hline
\end{tabular}

Step 1: The first step of the conceptual development was the identification of new concepts. MacInnis (2011, p. 138) summarizes the objective of conceptual identifying as "[making] us aware of what we have been missing and why it is important". In many ways, the entire thesis started in this stage, since the concept 'proactive market strategy' was not used and many key concepts were unknown and undefined. The conceptual study started with the identification of the key concept of proactive market strategy and continued with the identification of the need for new conceptual development in, e.g., defining proactiveness and explicating the relationship between market strategy and its related concepts.

Step 2: This second step in many cases actually coincide dwith the first step, in that the process of identifying new concepts was performed alongside the evaluation of existing ones. The real objective behind revising an existing concept is to "reveal the advantages of the revised view and what novel insights it generates" (MacInnis, 2011, p. 138). Creating the definition of proactiveness is a good example of this, where existing conceptualizations did exist, but were either rather vague, like proactive market orientation, or were intended to describe different entities, as with proactive personality and personal initiative.

Step 3: While the first two steps were centered around conceptual envisioning (MacInnis, 2011), the third step marks the first of the two steps meant to describe and (to some extent) explain the concepts. Much of the conceptual development lies in this category, such as the framework for delineating the relationships between strategic orientations, market strategy, and strategic behavior, or the typology of market-oriented strategic behaviors from Paper I. The objective in this step is simply to describe what a concept is and where it stands in relation to others. 
Step 4: Finally, the fourth step of the conceptual development refers to the organization of existing literature to describe a concept (MacInnis, 2011). While not as thorough as a formal literature review, my categorization of proactive activities in the proactive activity framework still fits this technique the best. The objective of summarizing conceptualizations is to "see the forest for the trees" (MacInnis, 2011, p. 138), meaning it is intended to synthesize the existing literature in a holistic way.

As a final note, it should be said that these analytical techniques were applied in an iterative process, rather than in a single sequence from start to finish. Thus, I alternated between the different stages as the continuing development in one step might lead to new insights or issues to be handled in another step.

\subsubsection{Case study techniques}

The analytical techniques employed in the qualitative multiple case study can be roughly summarized in the three steps seen in Table 5 below: pattern matching, cross-case synthesis, and new pattern creation. Each of these steps had different goals and followed slightly different approaches, as will now be explained.

Table 5: Analytical techniques for different steps of case study analysis

\begin{tabular}{|l|l|}
\hline Step & Analytical technique \\
\hline 1. & Pattern matching \\
\hline 2. & Cross-case synthesis \\
\hline 3. & Conceptual development \\
\hline
\end{tabular}

Step 1: The first of the analytical techniques used in the case study was a pattern matching approach. Pattern matching is used to produce an empirically derived pattern and then matching that pattern to a predicted one, made before the data collection (Yin, 2018). In this case, the predicted pattern was based on the strategic orientation framework developed in the conceptual study, which included expected proactive activities for each category of activities. The information from each case firm was collected, structured according to the framework, and then matched with the expectation for proactive activity in each category and matched with the characteristics of proactive activity from the definition of proactive behavior in a marketing context. Overall, this first step had a mostly deductive approach, in which the data collected were compared with the expectations derived from the literature. This resulted in a proactiveness profile for each case firm, depending on the number and intensity of proactive activities in each category of activities, i.e. based on the matching of the empirical pattern to the theoretically derived expectations.

Step 2: After the cases had been individually matched with the expected pattern, I conducted a cross-case synthesis of the case firms' proactiveness profiles (Yin, 2018). In doing so, their respective patterns were compared, and the nature of their differences investigated. It is not surprising that the firms were different in their approaches to proactive market strategy, but it was not expected to find new patterns present in the form of the themes of proactiveness that arose from the cross-case synthesis of the individual case results. The pattern recognition and 
findings from step 2 were highly inductive in nature, being almost entirely empirically derived from the case synthesis. The approach to this resembled grounded theory (e.g. Strauss \& Crobin, 1990) in that the richness of the case data was allowed to guide the identification and subsequent investigation of the new pattern.

Step 3: The final step of the analysis of the case data consisted of the conceptual development of the themes-of-proactiveness patterns found during the second step. In this step, the deductive approach of step 1 was iteratively combined with the inductive approach from step 2 to arrive at a mixed method whereby I alternated conceptual development of the themes between being driven by the empirical data and the existing literature. Using this approach, I developed the framework of three generic themes of proactiveness, as presented in Paper II.

The design of the empirical study followed an abductive approach (Dubois \& Gadde, 2002), in which the scholar alternates between theory-driven and theory-creating research methods, in order to iteratively work towards answering the research questions.

\subsection{Validity and reliability}

In order to ensure that a study has been properly conducted and that its results are reliable, researchers must consider validity and reliability (Creswell \& Creswell, 2018). These concepts can roughly be summarized as: "have you done things properly?", and "could someone else do that again?". In this section, I will outline the measures taken to ensure the validity and reliability of the two studies that are presented in this thesis.

\subsubsection{Validity of the studies}

The validity of a study is concerned with the integrity of the research that has been conducted (Yin, 2018). In broad terms, this refers to the researcher using the analytical methods and techniques of the study in the correct way, and that they follow the research process in the proper way, i.e. do not make unnecessary deviations from the plan (Creswell \& Creswell, 2018). However, Creswell \& Creswell (2018, p. 199) argue that "[v]alidity does not carry the same connotations in qualitative research as it does in quantitative research; nor is it a companion to reliability ... or generalizability". What this means is that, in qualitative research, it is more difficult to identify whether tools have been improperly used, potentially leading to mistaken results. Instead, scholars performing qualitative research must check for validity using a multitude of procedures, in order to ensure that the research has been properly conducted and that the analysis is sound (Creswell \& Creswell, 2018; Yin, 2018). The two studies presented in this thesis employed a multitude of qualitative validation measures, as presented in Table 6 below. 
Table 6: Validity procedures used for both studies

\begin{tabular}{|l|c|c|}
\hline Validity procedure & Conceptual study & Empirical study \\
\hline Triangulate data sources & YES & YES \\
\hline Member checking & N/A & YES \\
\hline Rich, thick description & YES & YES \\
\hline Clarify researcher bias & NO & NO \\
\hline Present negative information & NO & YES \\
\hline Prolonged field study & N/A & YES \\
\hline Peer debriefing & YES & NO \\
\hline External auditor & NO & \\
\hline
\end{tabular}

\subsubsection{Conceptual study}

The conceptual study ensures validity primarily by using multiple data sources, here meaning case articles, to underpin its core developments. A good example of this is the definition of proactiveness in a marketing context presented in Section 2.2 of this thesis, where I use multiple sources from two different perspectives on proactive behavior, the proactive personality (e.g. Bateman \& Crant, 1993; Crant, 2000) and personal initiative (e.g. Frese et al., 1996; Frese \& Fay, 2001), combined with multiple authors on proactive market orientation (e.g. Narver et al., 2004; Atuahene-Gima et al., 2005) to derive a definition of proactive behavior at the firm level. By using multiple sources, I validate that the definition fits the broader perspectives on proactiveness in each field, not just that of a single article I have found, thereby ensuring good construct validity (Yin, 2018).

Furthermore, by describing the constituent concepts of my frameworks richly, I attempt to give the reader a good overview of the concepts that underpin the definition, giving independent reviewers the ability to evaluate for themselves whether my synthesis is reasonable. Finally, the model has been thoroughly tested through collaboration with my supervisor and through rigorous discussion with my colleagues at the division, further validating the conceptualization. By using these three validity procedures, I have attempted to ensure that my conceptual development work has been sound and that the results, i.e. the frameworks and definitions, are valid.

\subsubsection{Empirical study}

The empirical study is also based on well-triangulated information, the frameworks of the conceptual study for the theoretical underpinnings of the study and the multiple cases employed for the study itself. The cases resulted in the rich descriptions presented in Chapter 4 , which are intended to give the reader a chance to evaluate whether my conclusions are reasonable. Since the interviews were conducted by multiple researchers and I was not present at all of them, research notes were taken and later compared. Through extensive discussions, any dissimilarities in views were addressed and a common view was established (Campbell et al., 2013). Furthermore, we performed member checks (Creswell \& Creswell, 2018; Lincoln \& Guba, 1985), wherein the data and analysis were verified with the case firms to ensure that we had not misunderstood them. 
Finally, to ensure the external validity, or generalizability, of the study, I identified the most appropriate theoretical concepts to work with beforehand and through the use of multiple case firms in the study that were approached in the same way (Yin, 2018). This made sure that the patterns arising from the synthesis of the cases were likely to be general trends, and not just representing the peculiarities of a single firm (Yin, 2018; Creswell \& Creswell, 2018). However, five case firms do not constitute a very large sample, so caution should be exercised in generalizing the findings of the study.

\subsubsection{Reliability of the studies}

The reliability of a study is often synonymous with its reproducibility, i.e. whether someone else could do the same thing and arrive at the same (or at least similar) results. For qualitative researchers, this entails describing the procedures used in the study and documenting information so that it can be reviewed later (Yin, 2018). For my conceptual study, I do not consider reliability to be an issue; since the literature is available for anyone to find and I try to clearly describe how I synthesize the different concepts, the results are clearly reproducible by anyone else. Whether someone else would arrive at the same conclusion is another matter, but that is a question of validity, which has been addressed above, rather than reliability.

For the empirical study, the main reliability measures were the interview protocols used during the interviews to ensure the same types of questions and areas were covered in all interviews, and the research notes produced during and after the interviews. To reduce the uncertainty caused by having multiple researchers in the same study, the researchers involved in the study made independent evaluations of the cases, followed by a comparing of notes and discussion about any items or topics where there was a difference of opinion. Through such checks, the study ensured intercoder agreement (Creswell \& Creswell, 2018; Yin, 2018).

\subsection{Ethical considerations}

Since the empirical study dealt with many types of sensitive data, both personal information about the interviewees and important business information about the case firms, there are a number of ethical concerns that have been deemed important. The most important of these are: informed consent, protection of personal information, and anonymization of the findings.

During the early stages of contact with a prospective case firm, the respondents were made aware that their contributions were voluntary, but that they were of great importance to the study. The respondents in each firm were chosen by the firm itself, based on how it deemed it could best assist with answers and explanations for the study. Thus, the respondents were not entirely anonymous with regard to the contacts at each firm, but all individual interview material was solely held by the researchers and never presented in a non-anonymized form to the firm or in any other presentation of the research. 
Moreover, the information about the firms themselves was anonymized. The firms were informed that they could choose to have their identities hidden as well, in order to hopefully provide more detailed explanations about activities and intentions. The firms chose to use this opportunity, and thus the case firms were given the pseudonyms/labels used in this thesis and in all other presentations of the case study results. This included obfuscating the exact industry, sizes and performance figures of case firms that found such information too revealing. 


\section{Empirical Cases}

This chapter will describe the five case firms that were investigated in the empirical study. The case firms are of different sizes and located in different industries, although all are B2B focused. They are presented briefly in Table 7 below.

Table 7: Brief case firm presentations

\begin{tabular}{|l|l|l|l|}
\hline Case firm & Main business & Main driver of proactivity & No. of interviews \\
\hline $\begin{array}{l}\text { Waste } \\
\text { Wollection } \\
\text { Colled }\end{array}$ & $\begin{array}{l}\text { Waste } \\
\text { collection } \\
\text { systems }\end{array}$ & $\begin{array}{l}\text { Need to stimulate recognition } \\
\text { of, and global demand form, its } \\
\text { products }\end{array}$ & $\begin{array}{l}\text { 5 (CEO, chairman of the } \\
\text { board, marketing director, } \\
\text { CTO, regional sales director) }\end{array}$ \\
\hline $\begin{array}{l}\text { 2. Industrial } \\
\text { Golutions }\end{array}$ & $\begin{array}{l}\text { Industrial } \\
\text { systems and } \\
\text { related services }\end{array}$ & $\begin{array}{l}\text { Need to increase } \\
\text { competitiveness across several } \\
\text { highly competitive product } \\
\text { segments }\end{array}$ & $\begin{array}{l}\text { 5 (Marketing \& sales director, } \\
\text { 2 product area managers, } \\
\text { sales region managers) }\end{array}$ \\
\hline 3. IOT Platform & $\begin{array}{l}\text { Software } \\
\text { (platform) and } \\
\text { consulting }\end{array}$ & $\begin{array}{l}\text { Need to achieve rapid firm } \\
\text { growth on a competitive } \\
\text { emerging market }\end{array}$ & $\begin{array}{l}\text { 5 (CEO, chairman of the } \\
\text { board, COO, CFO, CTO) }\end{array}$ \\
\hline $\begin{array}{l}\text { 4. Education \& } \\
\text { Services }\end{array}$ & $\begin{array}{l}\text { Education and } \\
\text { training services }\end{array}$ & $\begin{array}{l}\text { Need to create competitive } \\
\text { market offerings and influence } \\
\text { stakeholder perception }\end{array}$ & $\begin{array}{l}\text { 5 (CEO, chairman of the } \\
\text { board, CMO, product } \\
\text { manager, project leader) }\end{array}$ \\
\hline $\begin{array}{l}\text { 5. Custom } \\
\text { Product } \\
\text { Solutions }\end{array}$ & $\begin{array}{l}\text { Product } \\
\text { development } \\
\text { services and } \\
\text { production }\end{array}$ & $\begin{array}{l}\text { Need to maximize customer } \\
\text { value by developing } \\
\text { customized solutions }\end{array}$ & $\begin{array}{l}\text { 5 (CEO, COO, ClO, } \\
\text { production manager, project } \\
\text { leader) }\end{array}$ \\
\hline
\end{tabular}


Each case firm will now be described in greater depth, following this outline. First, there will be a general description of the case firm, its customers, and its industry. This is followed by a delineation of the firm's proactive activities into customer-oriented activities, competitionoriented activities, and innovation-oriented activities, using the proactive activity framework. Finally, the description of the firm is summarized into a table, which describes: (1) the aim behind the firm's proactive behavior, (2) the key proactive activities performed by the firm in each category of activity, and (3) the consequences of these proactive activities. Furthermore, each activity is accompanied by a quote from the interviews, as an illustration of the firm's activity.

Each key proactive activity in the tables is followed by a set of initials, which represents the proactive characteristics that it exhibits, as derived from my definition proactive behavior. The characteristics and their initials are: Future-oriented (FO), Initiative-taking (IT), Changeinducing (CI), and Creative (C). If an activity has e.g. (FO, IT) written after it in the table, this means that the activity is future-oriented and initiative-taking. Along with these characteristics, the proactiveness of each activity was also determined based on how closely it fits activities that have been linked to proactiveness in the literature, as described in the proactive activity framework.

\subsection{Case 1: Automated Waste Collection}

Case firm number 1, called Automated Waste Collection, is the industry leader in automated vacuum collection (AVAC) systems, with a global market share substantially larger than any competitor. AVAC technology functions by sucking waste through underground pipes to a central collection point, from which the waste is then transported by truck for final disposal. The sales situation for a new AVAC system tends to be quite complex. Basically, there are four types of stakeholder that have to be satisfied when delivering a system for a construction project:

(1) the property owner, the actor who will own the building in the future, who is the one that covers the operating costs of an AVAC system,

(2) the property developer, the actor who designs and constructs the building, who is the one that usually has to pay the larger up-front costs of an AVAC system as compared to traditional solutions,

(3) the municipality, which is responsible for collecting waste from the system and disposing of it, and

(4) the end users, i.e. the persons who will be living or working in the building and using the system for waste disposal.

The main concern of top management at Automated Waste Collection was not primarily with handling customers, but that the AVAC industry's share of overall waste collection has been and still continues to be very low, on the order of 1-2 percent globally. Thus, even though the firm can handle their direct AVAC competitors, it is harder to manage competitors using traditional waste collection. One large part of this problem lies with the low level of awareness of the benefits, and indeed even the existence, of AVAC technology. Therefore, top management at Automated Waste Collection made it one of the top priorities of the firm's 
sales-enhancing proactive market strategies to influence relevant stakeholders in target markets in order to stimulate global recognition and demand for AVAC technology. A summary of the main proactive activities of Automated Waste Collection can be found in Table 8 below.

\subsubsection{Customer-oriented activities}

Automated Waste Collection has to manage the non-homogeneous needs of these stakeholders, and those of a few other, less important stakeholders, and ensure that the systems they deliver can provide differentiated value for each stakeholder. To do so, the firm has put much effort into understanding what each of its stakeholders finds valuable, and to understand how the design and operation of the system will affect the value they can gain from it.

An illustrative example regarding customer value creation: for property developers, the main value of the system comes from the fact that it removes the need for dedicated areas in the building for storing waste. The property developer can then instead use the floor space freed up in this way for more lucrative purposes, such as more apartments or business premises. Automated Waste Collection markets these benefits to property developers and helps them to understand the potential for better usage of floor space in the building, which helps to mitigate the negative feelings caused by the higher costs of AVAC systems and instead build a positive opinion of AVAC technology in the construction industry. Management considers this to be an important part of the firm's marketing efforts, since many stakeholders and potential customers have to be educated about the potential benefits and value of the technology, or else they will not consider buying a system because of the higher cost of installation.

In managing these complex customer needs, Automated Waste Collection is exhibiting a proactive approach to value creation; since customers are often not aware of the potential benefits they can gain from the technology, i.e. do not know how it can fulfil their needs, the firm must educate them regarding these needs and how AVAC systems can help fulfil them. As described by Narver et al. (2004), the firm is focusing on the latent needs of its customers and fulfilling them with latent solutions, both of which are at the very core of proactive customer orientation. Furthermore, sAutomated Waste Collection is also proactive in working with all of the stakeholders, thereby adding to the probability that one of them will demand the technology for a new project, in a vein similar to the proactive customers of customer marketing described by Homburg et al. (2014).

Every system installed by Automated Waste Collection comes with an extended service contract, stretching over many years. By having its own service technicians maintain the systems, the firm can ensure that customers and end users are well taken care of. Another benefit is that potential faults in the system can be found earlier than if users have to report them; because users almost never see the actual system, only the hatches for inserting waste, they will often not notice faults until they become serious enough to cause the system to fail. By taking good care of customers and keeping in touch with key customers around the globe, Automated Waste Collection has built a number of flagship systems that can be used as references, which prospective customers and other stakeholders can visit to better understand the functioning and benefits of the firm's systems. These reference customers also tend to promote the firm and its technology to others, giving Automated Waste Collection valuable referrals. 
These close relationships with customers have culminated in recent years in a collaborative project with key customers in the Nordic countries, where the firm and the customer collaborate to ensure that the delivered systems fit extensive customer usage and evolving needs. The project has also resulted in tangible benefits for the firm, in the form of new products and system features that can be transferred to other customers' projects. Automated Waste Collection is currently working on expanding this collaborative model, but also says that it is important for the customers to reach a high level of maturity with the technology before they enter into such a relationship, so it is progressing cautiously.

This collaboration with customers serves as a way for the firm to gather market intelligence on advanced customers' needs and how those needs evolve over time. Having knowledge about such issues is key for proactively uncovering the latent needs of customers and developing latent solutions for those needs (Narver et al., 2004; Li et al., 2008).

\subsubsection{Competition-oriented activities}

Automated Waste Collection works proactively with market shaping (see e.g. Elg et al., 2012; Kindström et al., 2017) through a model quite similar to the work of providing differentiated customer value for different stakeholders described above. By actively working to influence potential customers and other stakeholders in target markets, the firm is steadily building global awareness of AVAC technology and recognition of its potential benefits. These efforts are very long-term; one interviewee in sales comments that the firm has often spent several years talking to different officials and civil servants in municipalities before being offered a contract; in a few cases, it had even taken a decade to create a project. This does not dissuade the firm, however; instead, one interviewee comments, it showcases that very determined and long-term activity is "absolutely necessary" for the market shaping to have a positive effect. Furthermore, the firm arranges technology workshops in which different technology consultancy firms and property developers are educated on how AVAC technology works and can be implemented. In order to further raise the profile of the technology and the firm, Automated Waste Collection often accompanies Swedish officials on visits of state, which enables the firm to present the technology to top-level politicians in many influential countries around the world.

One of the quite uncommon concerns of management at Automated Waste Collection is that they do not have enough "serious" competitors in the industry. One interviewee mentions that they sometimes have a hard time winning projects through public procurement, since there are too few competitors also turning in bids. This supposedly makes many politicians wary of the firm, since it is seen as somewhat suspicious. Furthermore, the firm is at times undercut by competitors on certain projects, only for those competitors to fail to provide a system that delivers on the project demands. Because many competitors are young and small, they tend to underestimate the complexity of getting a large AVAC system functioning properly, which creates a situation in which many customers are put off by the under-performance of these "unserious" firms. To mitigate this damage to the image of AVAC technology, Automated Waste Collection offers to fix the problems with competitors' systems; although the firm does not offer maintenance contracts for other firms' systems, it can help to upgrade or replace a system to ensure that it meets customer needs and expectations. 
The firm has an outspoken desire for more and larger competitors, since that would help improve the legitimacy of the entire industry. As it stands, Automated Waste Collection, through its market-shaping efforts, is putting a lot of effort into promoting AVAC technology globally and improving the standing and attractiveness of the industry. Many competitors take advantage of this, but the firm considers it the duty of the industry leader to bear the brunt of the costs for promoting the technology and stimulating demand. One interviewee remarked that, if the overall size of the AVAC market could be increased, they would earn more money than currently even if they lost some market share. Furthermore, if they could gain some larger competitors, these could help bear the costs of stimulating demand. The firm's focus on profitability before market share reflects a healthy competition orientation, as per Armstrong and Collopy (1996).

\subsubsection{Innovation-oriented activities}

The product development efforts at Automated Waste Collection have long been driven mainly by internal R\&D considerations. According to one interviewee, the culture of the product development division at the firm has traditionally been quite "engineer-oriented", rather than customer-oriented. This development setup has had two branches: developing new products and features that the engineers believe will better serve customer needs, and developing more incremental improvements in system performance, with a particular focus on decreasing system energy usage and operating costs. However, this development paradigm has recently started to shift with a major customer-collaboration project. The customer is starting to take a more central role in product development, which one interviewee comments has helped Automated Waste Collection to realize that customers have needs that had not previously been properly understood or even perceived. However, customers did take part in product development to a lesser degree even before this project; many of the smaller and incremental improvements came from decentralized innovation work at a regional level, where specific customer demands in projects could lead to the development of particular requested features. 


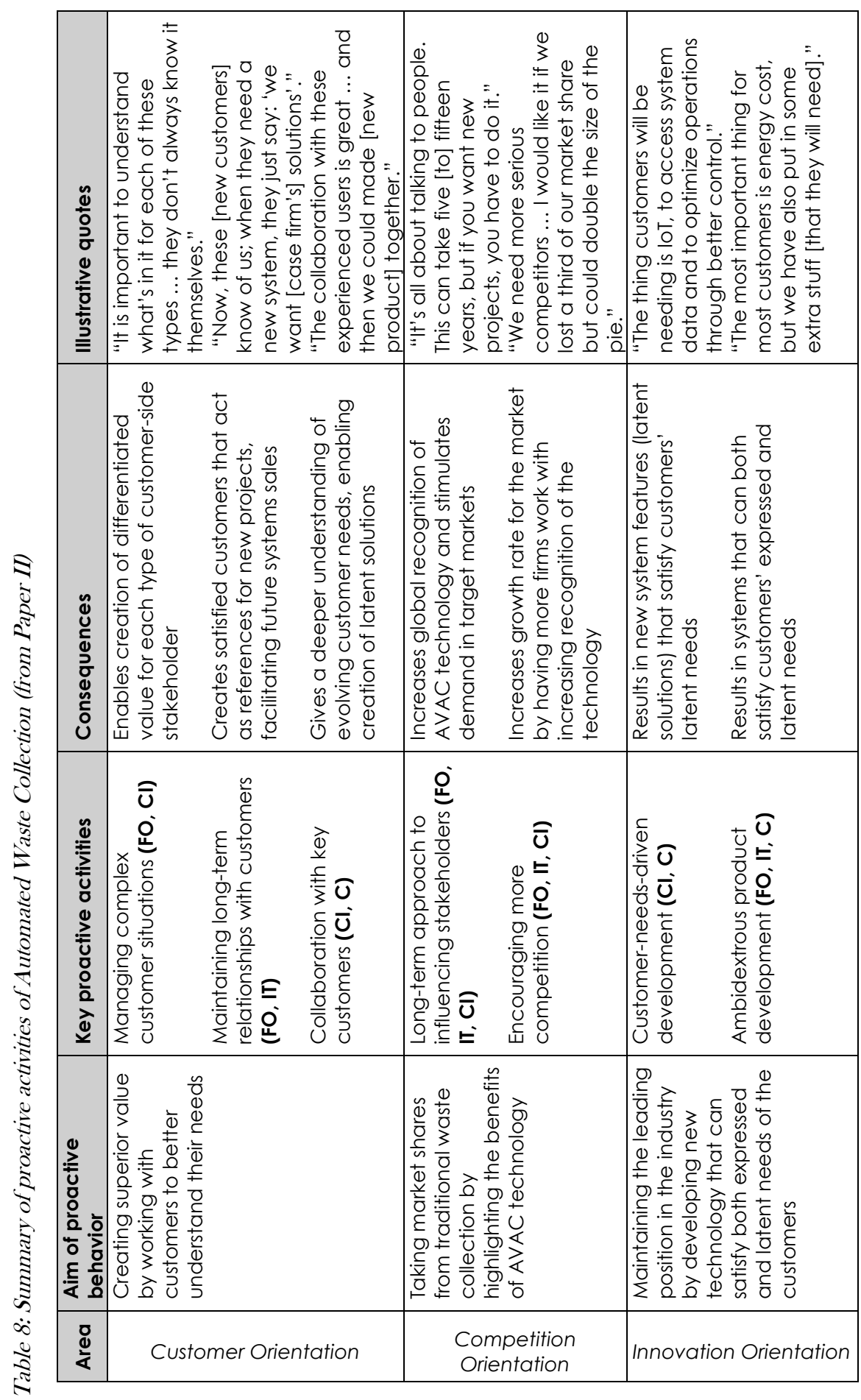




\subsection{Case 2: Industrial Solutions Group}

The second case firm, Industrial Solutions Group, is a large Swedish multinational firm providing industrial solutions across several related B2B markets. The firm's offerings range from relatively simple products to complex systems and related services, and are intended to cover the potential needs of all customers on the target markets. The products and systems contain a high proportion of new, advanced technology and the firm continuously works on developing its products to maintain a leading edge in the market. The firm employs a matrix organization, with product areas and sales regions working together to provide customer value to customers across the globe, with a focus on Europe, North America, and East Asia. Competition across global markets is fierce, coming both from other multinationals and from local firms in each target market.

The main market-strategic concern of top management is to maintain the leading position of Industrial Solutions Group in key product markets to ensure competitiveness remains high, which will lead to higher-than-average business performance. A summary of the main proactive activities of Industrial Solutions Group can be found in Table 9 below.

\subsubsection{Customer-oriented activities}

The main customer-oriented concern of Industrial Solutions Group is to provide high customer value to its customers, in order to match the premium profile and pricing that it employs. Managers at the firm suggest that, for them to be able to provide superior customer value compared to competitors, Industrial Solutions Group must achieve a superior understanding of customers' needs and circumstances. This understanding of what will create customer value is gained and maintained principally through three mechanisms: (1) collaboration with key customers, (2) collection of market intelligence on customer preferences and important developments in customers' markets, and (3) extensive on-site evaluation of solution effectiveness and customer satisfaction.

To strengthen the firm's understanding of the needs and needs evolution of customers, Industrial Solutions Group collaborates with key customers in each product market. These key customers are market leaders in their respective industries and working with them informs Industrial Solutions Group about the needs and circumstances of advanced customers. Thus, the collaboration enables the firm to understand both how to better serve these key customers and where currently less advanced customers are likely to be in a few years' time. The main point of collaboration is the joint development of systems and solutions to manage the complex circumstances of customers whose needs cannot be sufficiently satisfied with standardized solutions. While many of these collaborative projects contain a large degree of customization, they help Industrial Solutions Group to maintain its important relationships with large customers and also to inform the firm about what types of needs their standardized solutions will have to cover in the future.

To complement the information on customer needs and preferences gained from the key customers, Industrial Solutions Group also has processes in place to gather information from 
other sources. Auxiliary collection of market intelligence on customer needs and preferences in the firm mostly stems from the salesforces of the regional sales divisions, who are the front-line employees most in contact with current and potential customers. The product area divisions are responsible for keeping abreast of relevant developments regarding such issues as new technology and regulations in their respective markets. This information is complemented by intelligence from the headquarters marketing division, which regularly conducts and purchases market analyses to pinpoint relevant trends and other large-scale developments that the firm needs to consider. The headquarters marketing division then summarizes this market intelligence and sends it out to all parts of the firm in the form of a series of regular newsletters on the company intranet. The director of marketing notes that, while a lot of work goes into collecting all this information from the various divisions of the firm and drafting the newsletters, they seem to be effective in disseminating market intelligence within the firm. The firm had previously had issues with compartmentalization of information, meaning that potentially valuable information got stuck in the division where it originated. Such problems have decreased since the new process for managing market intelligence was implemented, although the director of marketing notes that there is still work to be done in that respect. Of particular interest is an ongoing project to improve the sales regions' surveying of customers, which will hopefully streamline the compiling of intelligence across product areas and sales regions and yield more information.

The last mechanism for ensuring that the firm's solutions provide customers with great customer value is the extensive on-site evaluation of the effectiveness of larger systems. After installing a major system for a customer, the firm has two evaluation periods. The first of these starts immediately after installation and is focused on ensuring the proper functioning of the system and that the customer's staff operates the system properly. Thus, during this period, the focus is on making sure the system can perform to specification, and helping the customer realize the value of the system. The second period comes some time after deployment and is focused on ensuring the continued performance of the system and that the customer is satisfied with it. The firm then advises the customer on how to develop their operation of the system to improve efficiency or performance. If the customer is dissatisfied, the firm investigates the possibility of tweaking the system to take care of the problems. Thus, the goal of the second period of evaluation is to continue aiding the customer in realizing the full value of the system. This type of on-site evaluation of the firm's systems also provides valuable insights for the continuing product development process, which greatly benefits from these real-world examples of problems that customers have with the systems and any needs that the systems currently cannot properly satisfy.

\subsubsection{Competition-oriented activities}

To ensure that their solutions are competitive, Industrial Solutions Group focuses its competition-oriented activities on evaluating the capabilities of competitors and establishing in which product segments competition is fiercest. The goal of the competition-oriented market strategies of Industrial Solutions Group is to deliver superior customer value to its customers, which means the firm must understand where its competitiveness is strongest. 
To better understand the relative strengths of competitors, the firm strives to acquire new products from key competitors in each product market whenever reasonable. The competitors' products are then reverse-engineered by product development engineers in the different product areas of Industrial Solutions Group. The information gained from dissecting competitors' products provides the firm with valuable insight into how product development and research and development activities are going for the competition. One issue with this approach is that it is unfeasible to acquire competitors' larger systems, so only certain products can be evaluated in this way. Furthermore, as a product area manager concedes, a lot of the value of complex systems comes from their deployment, the training of customer staff, and complementary services, so investigating competitors' products cannot give a full picture of the relative competitiveness of the firm. However, the insights that can be gained by reverseengineering competitors' products and reviewing competitors' patent filings are valuable to inform continued product development efforts, and to assess in which product segments Industrial Solutions Group has the potential to be best.

This assessment forms the basis for the firm's large-scale marketing-strategic targeting of certain product-market segments. The goal is to focus development in the product segments where Industrial Solutions Group has the potential to be the world leader in product technology and functionality. Other areas are less strongly prioritized; if a competitor has a large advantage in a product segment, Industrial Solutions Group's strategy is to maintain a second-mover position and wait for an opportunity to outstrip competitors, such as a discontinuous technology change. However, one product area manager says that this strategy is not always properly implemented, since there is prestige attached to developing new products and solutions. This results in certain product areas investing more into $\mathrm{R} \& \mathrm{D}$ and product development than the strategy suggests they should, because they want to overtake dominant competitors, even when there is no external shock to help such efforts.

In principle though, the goal of Industrial Solutions Group is to maintain competitiveness without over-spending on innovation by finding the product segments where they can build a leading edge and focusing on those. These products are then complemented by fast-follower tactics in less prioritized segments, ensuring that solutions contain an industry-leading technological core and keep up to standard market expectations in other, less important, areas.

\subsubsection{Innovation-oriented activities}

Innovation is one of the key areas at Industrial Solutions Group for ensuring that customer gain Innovation is one of the key areas at Industrial Solutions Group for ensuring that customers gain superior value from the firm's different solutions. As well as the prioritization mentioned in the previous section, the firm complements traditional $R \& D$ and product development activities with close collaboration with key customers and suppliers, to ensure that the firm's innovation processes result in relevant and valuable new products, systems, and services.

As mentioned in customer-oriented activities, Industrial Solutions Group seeks deeper relationships and collaborations with key customers, which can help the firm to better understand customer needs and preferences and how to improve the effectiveness of solutions. These collaborations often result in projects to develop custom solutions for customers' 
complex or even unique problems, which helps the firm to understand how value is created for leading customers. This insight helps inform ongoing efforts to standardize solutions to complex problems and develop a comprehensive set of products and systems to satisfy all customers' needs. In practice, these collaborations require Industrial Solutions Group product development engineers to work closely with the customer in order to understand how to develop a solution that could serve those needs better than present approaches. Via a recombination of the diverse products the firm already has, coupled with the development of new features, the engineers, in concert with relevant customer staff, develop a customized solution through an iterative project process. The recombination of existing components, products, and services, coupled with the limited development of new innovations, to create new offerings enables the firm to flexibly serve complex customer needs and preferences without investing too heavily in innovation for a single customer project. Thus, the firm can develop latent solutions for both latent and articulated customer needs while maintaining high profit margins.

Industrial Solutions Group is able to use this approach to customized solution development thanks to the relatively extensive basic R\&D work that all product areas are expected to perform. R\&D in prioritized product areas is focused on the development of next-generation product and process technology, while product development focuses on putting this technology into products and developing organizational routines for improved production efficiency and performance. Less prioritized areas focus product development efforts on investigating competitors' products and ways of implementing the standards for the next product generation, with only limited basic R\&D to keep abreast of mainstream competitors. In general, product development in prioritized areas is geared mostly towards really new and radical innovation, while less prioritized areas focus more on incremental innovation and copying competitors. 


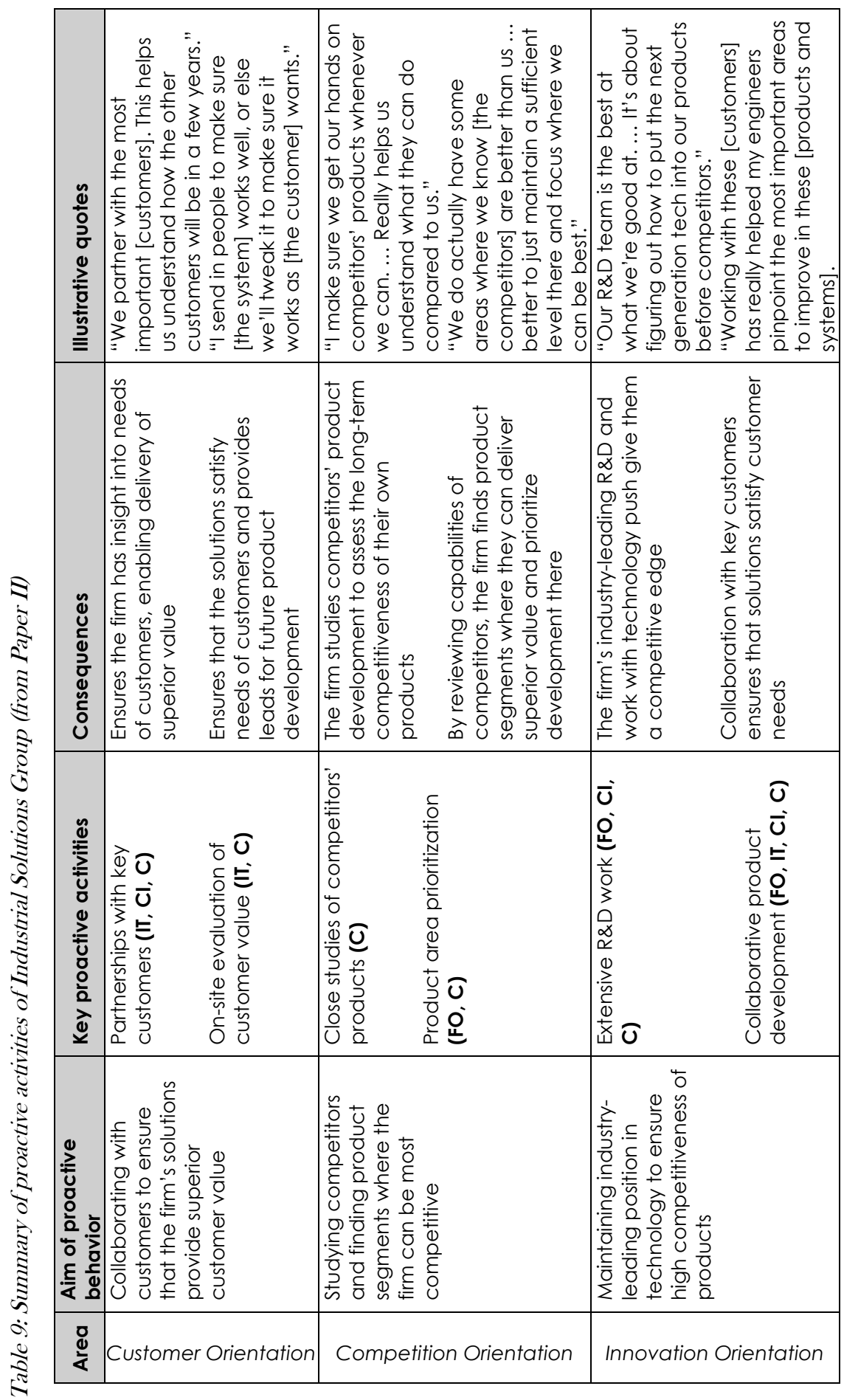




\subsection{Case 3: IoT Platform}

IoT Platform is a Swedish SME focusing on the development of a manufacturer-agnostic, cloud-based platform for connecting and controlling various Internet-of-Things (IoT) products, i.e. a platform where all products, irrespective of manufacturer, can be connected. They develop, market, and sell the platform under their own brand, focusing on B2B and B2G markets. Several large customers have been signed up in the last year and the firm is starting to internationalize, with top management expecting continued rapid growth. The main part of the firm's offering to customers consists of the platform itself, which offers high ease-of-use and performance for connecting and controlling various IoT products, such as remote sensors and control systems, but it is also complemented by tech consultancy services such as management advice and application development. The focus of the value-creating activities at IoT Platform is based around enabling customers to avoid lock-in to a particular manufacturer and being flexible while satisfying various customer preferences at a relatively low cost.

The main goal of IoT Platform's market strategies is to enable rapid growth by using its relatively small size and closeness to the customer to out-maneuver its large, multinational competitors. The idea is that large competitors cannot offer the same flexibility at such low cost while maintaining reasonable profit margins. A summary of the main proactive activities of $I o T$ Platform can be found in Table 10 below.

\subsubsection{Customer-oriented activities}

The idea behind the firm's platform came from discussions with a future customer, who had started investing in IoT devices but had run into problems with managing a wide set of products from different manufacturers. IoT Platform has developed the platform internally with the aim of making a control system that is compatible with IoT products from any manufacturer, which should also enable easier management of devices. The main value of the platform thus primarily stems from three aspects: ease of use, greater flexibility, and assisting IoT value realization. One issue that many firms and governmental actors investing in IoT devices fail to fully consider beforehand is the increasing complexity of managing, connecting and controlling a large number of devices from different manufacturers. Thus, many IoT projects fail to fully realize the value of their IoT technology because of administrative or organizational problems that hamper deployment or operations. By offering a platform solution that can handle connections from any manufacturer's devices, IoT Platform hopes to give customers a way to centralize their management of IoT devices. This platform thus removes the administrative problems that arise from controlling and collecting data from different devices through different applications and networks and enables customers to better realize the value inherent in IoT technology.

To ensure that their platform satisfies the needs of customers, IoT Platform builds close relationships with all customers and makes efforts to take good care of them. This is exemplified by the explicit policy that it is better for employees to spend a few hours extra to make sure that the customer is really satisfied. These close relationships enable the firm to 
continue assisting the customers in IoT-related issues and to sell more projects when additional devices are to be connected to the platform. Moreover, the firm maintains cooperation with other actors relevant to the relationship, such as providers of municipal broadband services, which further enables IoT Platform to provide superior customer value.

\subsubsection{Competition-oriented activities}

The focus of the competition-oriented activities at IoT Platform is to improve competitiveness against the firm's often much larger competitors, mainly multinational technology and consultancy firms. Key to the firm's strategy is to maintain a high degree of organizational flexibility, which enables IoT Platform to better serve more complex or specific customer needs or preferences without scaling up costs and pricing to the same degree that a larger competitor would require. To ensure that development is flexible, the firm uses modern, agile development methods and puts much effort into providing developers with great freedom to self-organize within a clear support structure, which keeps projects on track and on time. One manager is dedicated to working with building up the development processes at the firm and work is ongoing to implement and improve processes for different types of activities.

While a lot of these advantages over larger competitors can be offset by the firm's lesser capabilities in managing really large projects, there is a relatively large niche of mid-sized to smaller large firms and municipalities in Sweden that cannot readily afford the services of large tech firms and consultancies, and lack the capabilities to tackle development of a similar solution in-house. IoT Platform employs a differentiated focus strategy targeting these customers with an offering based around flexibility and avoiding lock-in, complemented by the development of custom applications and add-ons to the main product.

\subsubsection{Innovation-oriented activities}

Since IoT Platform is an ICT firm specializing in the relatively new market of IoT devices, innovation is an important focus. Since the platform itself is the core of most of the firm's market offerings, it receives the lion's share of development resources, including performance improvements, new features, and improved ability to connect devices. Other development efforts concern the firm's secondary offering of development services, where they develop applications on behalf of customers.

To ensure that the rather limited development resources available to the firm are used well, IoT Platform uses its relationships with customers and key partners to guide efforts towards the most relevant areas for improvement. Thus, the development focuses on two areas, one of which is a technology push side, where the firm develops new features and improves the platform based on its own experience with IoT and its understanding of what brings value to customers. The other, the development undertaken in collaboration with key customers and partners, has more of a technology pull nature, where the customer can help the firm to understand how best to improve the platform. 


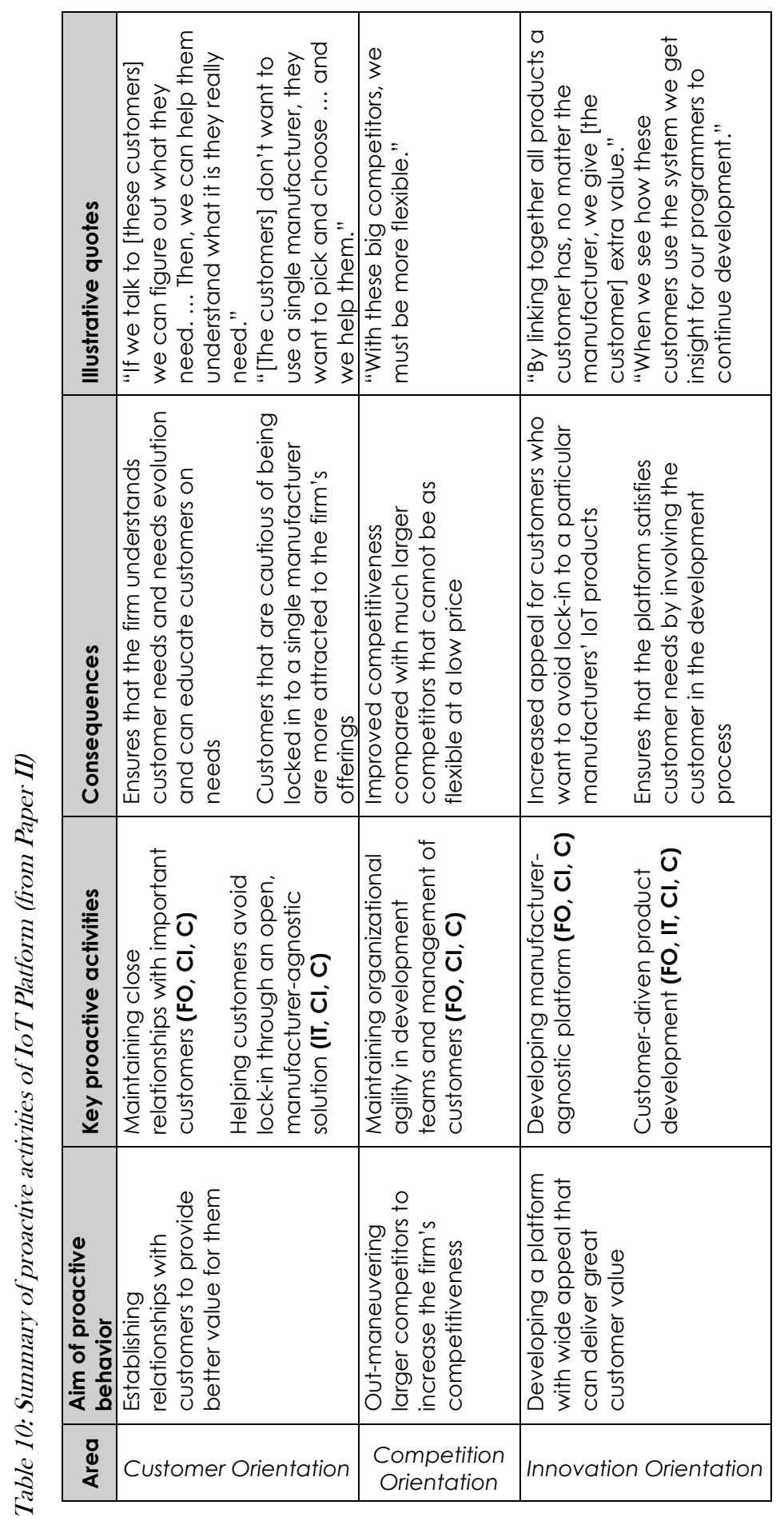




\subsection{Case 4: Education \& Services}

Education \& Services is a large actor in the Swedish private school market (competing with public schools, which are run by the municipalities), with a large number of private schools across the country, teaching pupils ranging from ages 6 to 18 . The focus of the firm is to provide education that is highly relevant to the demands of industry/academia and will be useful for pupils in their future careers/continued education. In addition to education for children, the firm offers education services for various industrial customers, such as educating customer staff for certifications and other types of on-demand education.

The main market-strategic focus of the firm is to create the best education in Sweden and to shape expectations thereafter. This allows Education \& Services to strengthen its competitiveness in the Swedish market and to improve public opinion of private schools, which is not always the greatest. The goal is to continue growing and being a good example of what education should look like; the firm reinvests most profits to improve operations and drive further growth. A summary of the main proactive activities of Education \& Services can be found in Table 11 below.

\subsubsection{Customer-oriented activities}

The customer situation for Education \& Services is quite complex. There are three principal groups of stakeholders for whom the firm must create customer value: (1) pupils and parents, (2) municipalities, and (3) industrial and academic partners. The firm's efforts to understand the needs of each will now be explained.

(1) Pupils and parents are those who are most obviously interested in obtaining a highquality, valuable education from the schools the firm runs. The firm bases its development of educational content for the various programs it offers on the principle that the knowledge should be useful and connected to reality, meaning that it focuses on knowledge that will be relevant to the pupils as adults and in their future careers.

(2) Municipalities are interested in making sure the money they spend on education results in properly educated schoolchildren, so Education \& Services must prove to the municipalities that its schools give better results than the public schools.

(3) The industrial and academic partners of Education \& Services are interested in gaining new employees and students who have been well prepared for their future careers and continued studies.

There is potentially a large amount of overlap between these needs; for example, pupils and parents will want the education they receive to prepare the children well for the future, meaning that they should be prepared to enter industry or continued studies, which is exactly what the industrial and academic partners want. Furthermore, if this process of educating pupils in relevant knowledge and skills works well and the majority of pupils successfully enter college or the workforce, then municipalities will find that their money has been well spent. Thus, while there are several groups of stakeholders to whom Education \& Services pays close attention, their needs largely coincide. Municipalities are in a sense the most important "customer", since 
they are the ones that pay for the education of schoolchildren, but if the schools cannot provide good customer value to their pupils, there will be little demand for their services. Furthermore, the quality of large parts of the education hinges on the support and cooperation of industry, meaning that it is also important to fulfill their needs in order to achieve a superior overall educational offering.

In order to ensure that the firm provides relevant curricula and educational programs, Education \& Services continuously works with industrial and academic partners in the ongoing development of their schools. This cooperation consists of activities such as shaping the design of vocational programs to match the key demands of industrial firms and working with a local university to ensure that students on preparatory programs manage the transition to studying engineering, business administration, etc. at university level.

\subsubsection{Competition-oriented activities}

With regard to the direct competition faced by Education \& Services, there are two categories of competitors: public schools and other private schools. In recent years, Sweden has seen a large expansion of private firms on the traditionally public-dominated school market, especially for schools for grades 10-12. Education \& Services, being one of the earlier entrants to the market and focused on long-term growth and profitability, has been well-equipped to handle the increased competition stemming from the many new entrants thanks to its reliable brand and good reputation.

A major concern for the private school industry is the ongoing public debate regarding private firms making profits from public welfare, primarily in healthcare and education. This was further highlighted by the high-profile bankruptcy of the John Bauer group in 2013, which at the time was one of the largest actors on the Swedish private school market. The firm had previously received strongly negative remarks from the $S$ wedish Schools Inspectorate (Swedish: Skolinspektionen), the governmental agency tasked with evaluating the quality of education in Swedish schools, and was being warned that its permits would be withdrawn if the issues were not resolved (Lagerström \& Zachrisson Winberg, 2012). The issues with educational quality began when the founders sold the group in 2008. The new owners, Danish venture capital firm Axcel, were perceived to underprioritize investment in the firm, development of the educational offerings and taking care of the students in favor of improving profits (SvD, 2013). After the problems and warnings from the inspectorate in 2012, Axcel decided against making the necessary investments to improve quality and looked to sell the group instead. However, they were unable to find a buyer, and so instead put the John Bauer group (at this time called $J B$ Education) into bankruptcy and shut down operations on the $12^{\text {th }}$ of June 2013, leaving the autumn semester uncertain for the 7,000 pupils still enrolled in the firm's schools (Lagerström \& Zachrisson Winberg, 2013; SvD, 2013). While this dramatic event was the worst of its kind, $J B$ Education was not the only private school firm to go bankrupt. In fact, according to TT, a Swedish news distributor, a quarter of Swedish private school firms did not make any profit in 2012 and several went bankrupt (TT, 2013).

While Education \& Services was not badly affected by the underlying decrease in the number of children reaching school age during 2010-2015 or the stiffening competition, thanks to greater 
capabilities in strategic planning and responsible owners with a long-term vision for the development of the firm, the resulting bad publicity for the industry affected all private school firms. Education \& Services redoubled its efforts to improve the reputation of the industry by actively seeking to be a good example of how well private schools can work. Through their collaboration with industry and academic partners and a desire to set the standards for firm conduct and educational quality, Education \& Services employs a market-shaping strategy, aimed at improving the public image of private schools and driving away dishonest actors that do not provide quality education. The firm has set a high standard for itself not to make an offer if it cannot deliver a very high level of customer value for all the actors involved, since failing to deliver a high-quality education will damage their enrollment of new students, decreasing revenue and profits, and will also damage its reputation. Through its policy of leading by example, Education \& Services strives to influence the public debate on profits in private welfare firms so that potential customers do not reject the potential benefits of private schools out of hand.

\subsubsection{Innovation-oriented activities}

Education \& Services is one of the leading adopters of education technology in Sweden, working to implement many new applications and technologies to improve the quality of its educational content. This adoption is part of a digitalization strategy aimed at providing students with more effective digital tools to aid their educational activities and relieving teachers of routine teaching tasks, enabling them to instead spend their time with more value-creating tasks. One aspect of this value-creating digitalization is learning analytics, which refers to using information about students to tailor tests and feedback to their needs, making educational tasks more relevant and improving student engagement and study results. Another example is the firm's use of virtual reality headsets to aid in design and the visualization of new concepts and ideas.

However, Education \& Services makes it clear that the firm's digitalization is not about adopting just any new technology or app, but rather about continuously surveying the environment for new possibilities, the most promising of which are then tested in-house using focus-group research. Through these tests, the firm evaluates the potential of the technology and determines whether it can take a meaningful part in value-creation at a reasonable cost. Thus, the firm develops a roadmap of which new technologies to implement, which to wait for, and which to avoid. This adoption process is strengthened through a strong team focus in the firm, facilitating knowledge transfer between the different schools operated by the firm.

Furthermore, the firm exhibits strong innovativeness in developing new offerings, being one of the first private school firms to build such strong relationships with industry and academic partners. By remaining focused on providing students with an education that will be highly relevant for their future careers or continued education, and working together with partners, Education \& Services creates market-leading offerings. Through its introduction of new offerings by establishing new educational programs at its current schools or opening new schools in areas where it is already present, the firm maintains a rapid pace of growth. While many private schools are accused of inflating students' grades to attract new students instead of delivering quality education (Svensen, 2018), Education \& Services instead focuses on 
continuously improving its educational programs to maintain its reputation for relevant and engaging education. The firm often draws inspiration for this ongoing development from outside the education industry, through both its industry partnerships and its technology surveying. 


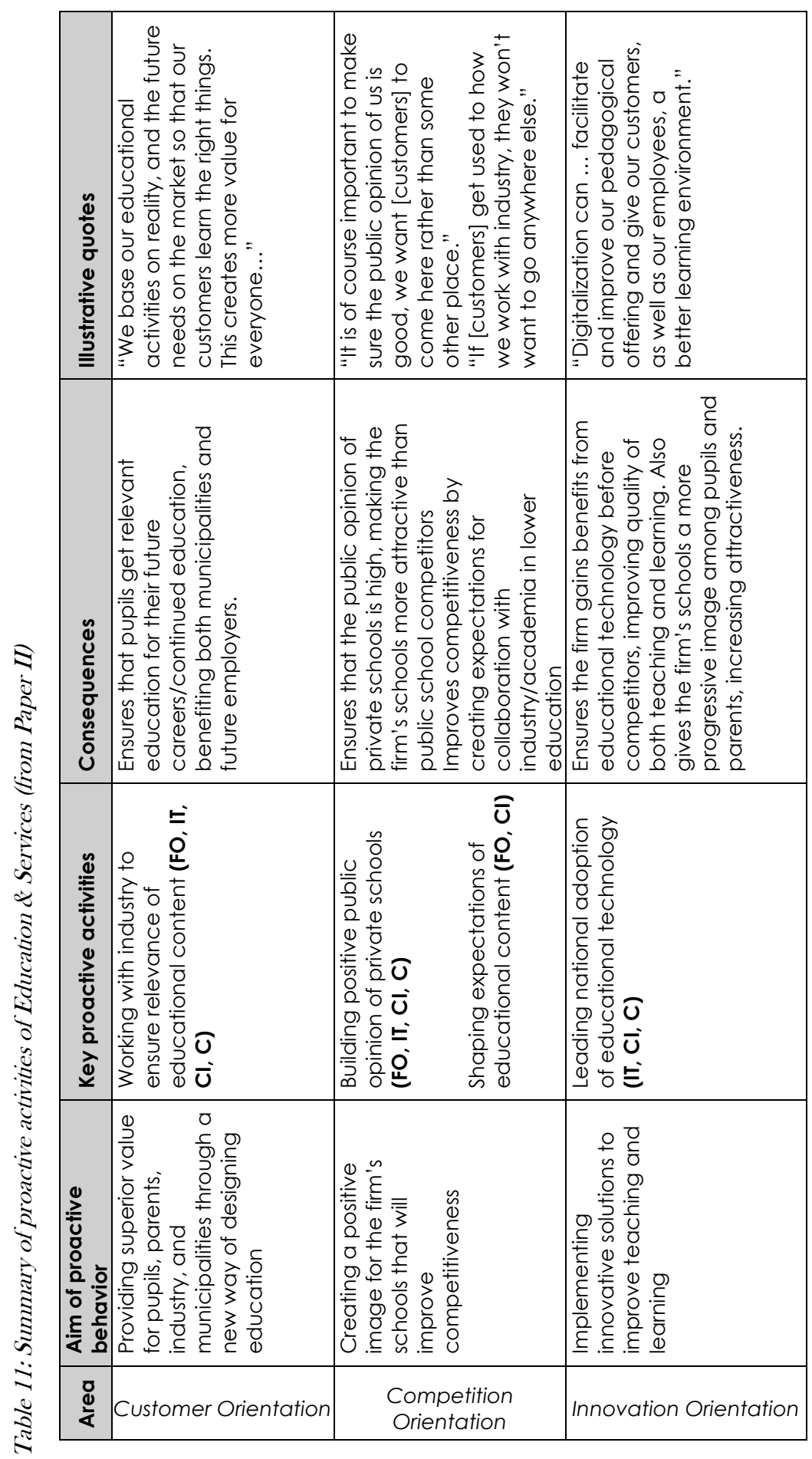




\subsection{Case 5: Custom Product Solutions}

The last case firm, Custom Product Solutions, is a Swedish SME focused on developing custom industrial products for solving the unique problems of its customers. This rather unique business concept arose from the firm's special expertise in wet-room and plumbing applications and experience with prototyping and manufacturing.

The concept was created when the firm was tasked by a customer in the plumbing business to produce a solution to issues with leakages in central water and sewage pipes in apartment buildings creating significant water damage before being detected. Faced with this challenge, Custom Product Solutions investigated the issue by interviewing plumbers, surveying the shafts where such pipes are led through buildings, and researching water damages in common areas of apartment buildings. Based on this investigation, the firm rapidly prototyped a series of highly innovative products for ensuring that leakages were contained to the floor on which they appeared, enabling faster detection and decreasing water damage. This development process was entirely funded by Custom Product Solutions itself, and the firm retained ownership of the finished product, packaging it into a new product offering which it then sold to other plumbing services.

Thus, the firm ensured that the product resulted in not only return purchases from the original customer, who regularly needs to stock up on the product, but also additional revenue streams from other customers. Because of the highly innovative product concept, most plumbing services targeting new construction or renovations of older apartment buildings in Custom Product Solution's region purchases the product; thus, the firm has made a great return on investment on the original product development costs.

The main market-strategic focus of Custom Product Solutions is to create latent solutions to satisfy customers' problems, with special focus on finding problems that are shared by many other potential customers. This allows Custom Product Solutions to innovatively create superior customer value by leveraging its special capabilities in product development to deliver customized solutions that are superior to the standardized offerings already on the market. By retaining all product rights, Custom Product Solutions ensures that it secures a new revenue stream rather than just selling a single project, also enabling the firm to put a competitive price on its products since multiple customers can share the costs of development. A summary of the main proactive activities of Custom Product Solutions can be found in Table 12 below.

\subsubsection{Customer-oriented activities}

The customers of Custom Product Solutions are mostly SMEs that lack their own capabilities or resources to develop special solutions to problems that arise, but the firm also has larger customers that want to use the firm's technical expertise to create special product solutions at a lower cost than in-house development.

Although the new product development projects are initiated in response to customer demand, the needs that Custom Product Solutions satisfies are not only the expressed ones. In many 
cases, such as the first major product development described previously, the problem expressed by the customer turned out to only cover part of the needs satisfied by the final product. In that case, the customer sought an unknown solution to limit water damage during leaks, but the final product also helped improve the ability to swiftly detect leaks. Thus, the latent solution provided by Custom Product Solutions satisfied latent as well as expressed customer needs, based on the thorough needs identification work performed by the firm.

Since the goal is to create a superior solution to the existing offerings on the market, Custom Product Solutions places great emphasis on its needs identification process, which is aimed at gaining a deep understanding of the customer, the actual expressed problem, and the context of the problem. These investigations enable the firm to identify latent needs as well as providing a solid foundation for its continued product development work. Moreover, the experience that Custom Product Solutions builds from learning so much about its customers also helps the firm to create custom products that can often be generalized to cover other customers' needs as well, maximizing the revenue and profits from each development project.

Throughout the development process, Custom Product Solutions maintains a deep relationship with the customer, working closely with the customer's own development team and other staff who have some insight into the problem to be solved. Having these relationships has proven very important for the firm's ability to swiftly understand the problem at hand and then develop a product solution through a customer-centric rapid prototyping process, in which the customer tries various prototypes and adjustments are continuously made to improve needs satisfaction. Custom Product Solution's goal is then to retain these close relationships after the completion of the initial project, both to ensure that the customer is satisfied with the product solution and to open up the possibility of establishing new development projects.

\subsubsection{Competition-oriented activities}

Because of the unique business concept of Custom Product Solutions and the relatively small scale of the firm, it has very limited awareness of any direct competitors. The obvious competitors are large technology consultancies, which control several times the resources of Custom Product Solutions and can offer expertise in a much broader range of topics, but the offerings of these large firms are quite different from those of Custom Product Solutions. While such competitors, thanks to their superior resources and capabilities, can do many things that Custom Product Solutions cannot, they usually offer these services as costly development projects. The mainly SME customers of Custom Product Solutions are either unable to afford such projects, or not interested in solving the problem at that kind of cost, making them a much better fit for Custom Product Solutions' relatively low-cost offerings. Since the firm bears the costs of initial development and then reaps returns on it over a long-term revenue stream, often spread over many customers, Custom Product Solutions can offer development projects within its areas of expertise at a very competitive price, without sacrificing profitability.

The main substitute competitors of Custom Product Solutions are instead the firms that produce the standard market offerings that Custom Product Solutions aims to surpass with its customized products. These firms range from other SMEs to much larger firms and are usually unaware of the competition from Custom Product Solutions, which competes against these 
firms based on the superior customer value provided by its product solutions that are tailored to specific customer needs. Although the custom products are more costly than the standard offerings on the market, the extra value the firm can provide to the right customer is relatively even higher. It should also be noted that the firm has several large customers as well, which are attracted by the low cost of gaining a custom solution to a problem in a situation where using inhouse development resources or technology consultants would be prohibitively expensive. Thus, Custom Product Solutions bases its competitiveness on a positioning from which it can offer its target customers a superior price-performance point.

This type of situation resembles that of a blue ocean (Kim \& Mauborgne, 2004), but with the important difference that Custom Product Solutions has not proactively created such a protected niche, but has rather arrived at it by following and exploiting a string of opportunities that appeared on the market.

\subsubsection{Innovation-oriented activities}

The innovation efforts at Custom Product Solutions are squarely focused on the firm's customer-centric custom-product development process. These products are usually latent solutions to satisfy both expressed and latent customer needs. By working closely with the customer throughout the product development process and employing rapid prototyping techniques, Custom Product Solutions has an unusually good opportunity for evaluating the effectiveness and value of latent solutions to customer problems. Since the firm mainly initiates product development projects in collaboration with a customer who requested a solution to a problem-meaning that customers are often more advanced than the average firm, since they are seeking special solutions to their problems-the firm can work together with a lead user during most development projects. Such practices, coupled with the ease of making adjustments to a product that stems from rapid prototyping, helps to ensure that the firm can develop highly innovative custom solutions to the customer's problems relatively swiftly and at a reasonable cost.

The firm also performs some in-house R\&D work aimed at developing components that can subsequently be used in multiple customer projects, such as generalizable sensors and materials. By developing such components and reusing components and solutions from previously developed products and combining them in new ways, Custom Product Solutions demonstrates a case of architectural innovation (Henderson \& Clark, 1990). This refers to innovation based on novel reconfigurations of (mostly) previously developed components-as opposed to development of novel components that are then either combined in new architectures or used to improve the performance of old ones-and represents a very innovative way of creating new products without incurring the significant R\&D costs that often stem from developing new technology (Henderson \& Clark, 1990).

The approach to innovation taken by Custom Product Solutions thus achieves its high performance by basing development on actual customer problems, ensuring that the solution is valuable through collaboration and testing with the customer, and by keeping costs relatively low through an architectural innovation approach to developing latent solutions. 


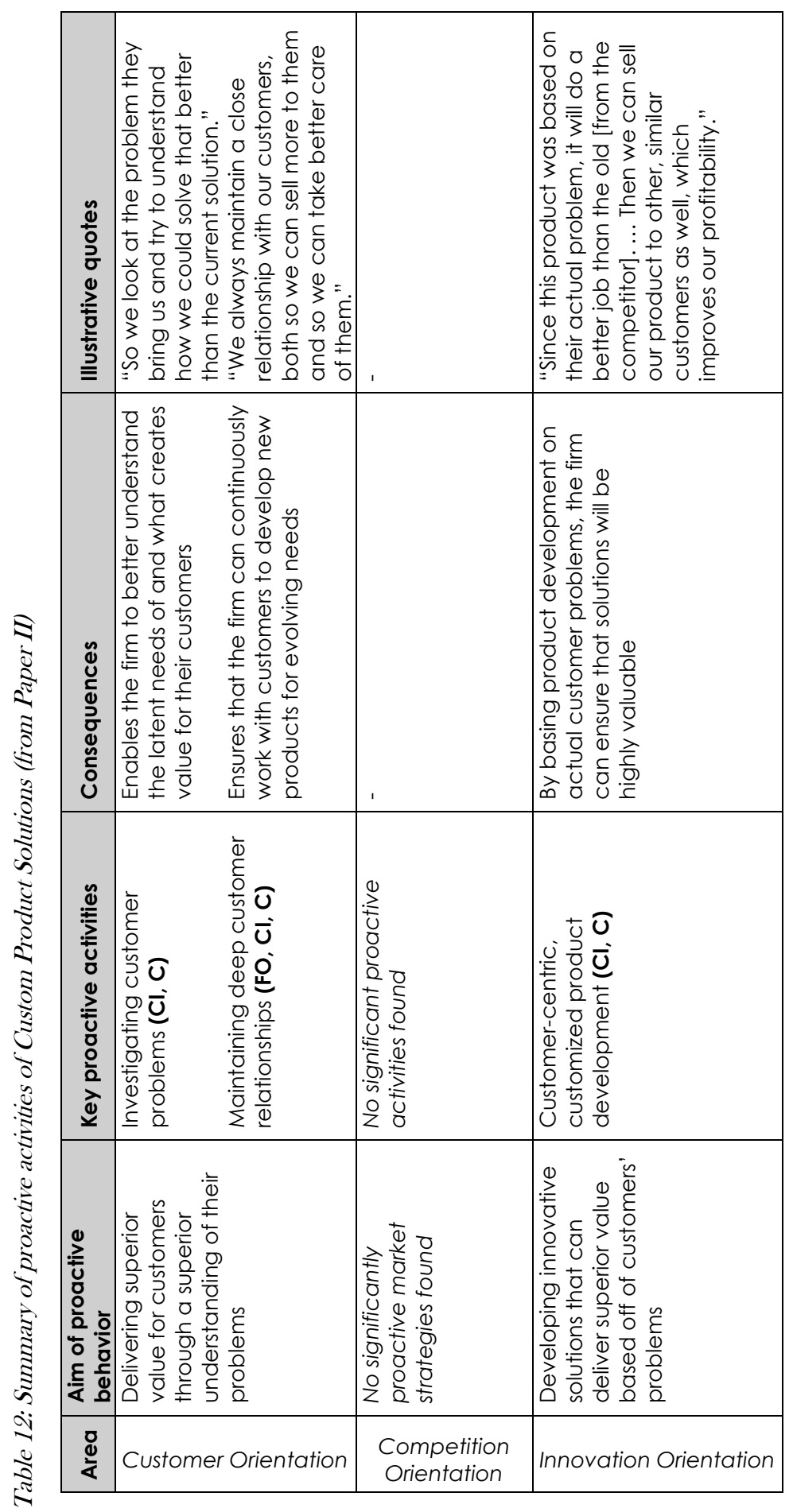




\section{Summaries of the Appended Papers}

In this chapter, the two appended papers will be briefly summarized. The papers present the main thrusts from the two studies that jointly make up the research work in this thesis. The focus of the summaries is to highlight the most important aspects of each paper for the thesis. The full papers can be found in their respective appendices at the end of the thesis.

\subsection{Paper I: Conceptual study}

The first paper represents the main thrust of the conceptual development that is performed in the conceptual study. The paper argues that market orientation has been a great source of competitive advantage for firms over the past few decades, but that recent research shows this relationship is starting to become more complex (e.g. Kumar et al., 2011; Frösén et al., 2016). Market orientation is turning from a source of competitive advantage into a cost of competing, to use the terminology of Venkatraman (1989), it is turning from a success-producer into a failure-preventer. The time of easy performance gains from market orientation is thus over. Based on the findings of Frösén et al. (2016) - who find that while market-oriented firms are not necessarily high-performing, most high-performing firms are market-oriented-the paper argues that firms must place more emphasis on their market orientation in order to gain the potential benefits. 
By highlighting different configurations of proactive and responsive market orientation as sources a firm can use to establish a market orientation that allows it to distinguish itself (Kumar et al., 2011), a starting point for the investigation is established. From this starting point, the paper conceptually delineates strategic behavior in market-oriented firms using a modified version of the strategic orientation framework developed by Gatignon \& Xuereb (1997). This results in three categories of activity-customer-oriented, competition-oriented, and innovationoriented-in each of which the impact of responsive and proactive behavior on likely firm activities is described, using the existing literature.

The paper continues by using the different potential levels of proactive market orientation and responsive market orientation exhibited by a market-oriented firm to create a $2 x 2$ matrix, describing four combinations of high or low proactiveness and responsiveness in the firm's strategic behavior. This $2 \mathrm{x} 2$ matrix is the foundation for a conceptual typology of marketoriented strategic behaviors, describing four types of behavior: Visionary, Adaptive, Ambidextrous, and Habitual. Each of these is then conceptually investigated in greater depth, including the activities performed by a firm to exhibit such behavior.

The main emphasis of this framework is the importance of firms achieving a behavioral fit among their customer-oriented, competition-oriented, and innovation-oriented activities, meaning that they should exhibit the same configuration of proactiveness and responsiveness in all three categories. Thus, for a firm to achieve the full benefits of its market orientation, it should create a behavioral fit among its different activities, aimed at producing a marketoriented strategic behavior that has a good fit to its circumstances.

\subsection{Paper II: Empirical study}

In this paper, the focus is on the empirical study that is part of the thesis. The paper starts by explaining the importance of being proactive in managing the market in order to achieve high performance, but also that there is a lack of knowledge regarding proactivity in market strategy. From this starting point, the paper sets out to explore firms' use of proactive market strategies and the proactive activities they perform in using them. The paper uses many of the conceptual developments that were made in the conceptual study, but tailors them to focus more on categorizing proactive activities. By using the proactive activity framework as a foundation, the paper establishes an expected pattern of activities to act as the basis for the analysis.

The empirical study is based around a qualitative multiple case study using five case firms that are proactive in their market strategy and perform above the average for their industries. The firms were of different sizes and from different industries to ensure they represented a broad perspective on proactive market strategy. The five case firms are then presented, along with selection criteria and an explanation of the empirical context of the study. These firms' activities are then described in greater depth using tables that match important proactive activities and their consequences to the firms' goals. From this analysis, each firm gets a proactive profile, which describes its configuration of proactive activities. These profiles do not fully match the 
expected pattern, since no firms were equally proactive across all categories of activity, and, furthermore, the firms' profiles differed from each other.

From the analysis of these differences in configurations of activities, a new set of patterns started to emerge; rather than having an equal focus on proactiveness in each category, firms' proactive efforts followed certain themes, which represent particular configurations of proactive activities aimed at achieving the firm's market-strategic goals through particular means. Three such themes of proactiveness were identified in the study: proactiveness through market shaping, proactiveness through customer engagement, and proactiveness through innovation leadership. Each theme results in a different proactive profile for the firm and they represent different cross-functional proactive efforts at achieving the firm's market-strategic goals. Furthermore, many firms appeared to use multiple themes at once, but no firm used all three and most did put more emphasis on one than the other.

The main contribution from the second paper is thus its identification of the three themes of proactiveness and their implications for creating configurations of cross-functional proactive activities for firms to achieve their market-strategic goals and enjoy superior performance. 


\section{Discussion}

This chapter will detail the findings of this licentiate thesis. Its focus is on answering the thesis' research questions through discussing and synthesizing the frameworks presented in the two appended papers. Furthermore, the papers' individual contributions will be discussed in the wider context of the objective of this licentiate thesis.

\subsection{What is a proactive market strategy?}

The main aim of this thesis is to explore proactive market strategies, which first invites the question: what, more precisely, is a proactive market strategy? The quick answer is that a proactive market strategy is a firm's strategy for how to create superior customer value by having a more proactive approach to managing the needs of many market-side stakeholders. I will now present the perspectives on proactive market strategy from the two studies that make up this thesis, followed by a synthesis that considers and combines the conceptual and empirical studies to create a more holistic perspective.

\subsubsection{In the conceptual study}

The conceptual study presented in the first paper approaches proactive market strategies from a perspective driven by the literature on strategic orientation. The conceptualization from the strategic orientation-market strategy-strategic behavior framework puts forward the notion that market strategies-and thus also proactive market strategies-are the strategies that a firm formulates in order to create customer value and achieve high business performance. These strategies are guided by the strategic orientations of the firm (Noble et al., 2002), which refers to 
the firm's principles for successfully doing business. The market strategy itself is implemented through the activities of the firm (Okumus, 2001a, 2001b), meaning that these activities can be viewed as constitutive parts of the strategy itself, each responsible for implementing a particular aspect of the strategy. Thus, the activities that make up the market strategy can be viewed as being guided by the firm's strategic orientation as well, which I present in the proactive activity framework. Thus, for a firm's market strategy to be proactive, it must be guided through proactive strategic orientation, meaning that strategic orientation drives the firm to perform proactive activities in striving to create superior customer value. In this sense, a firm successfully employing proactive market strategy could be said to be driven by some type of 'proactive orientation' that guides it toward more proactive ways of approaching the management of markets as well as managing customer value creation.

However, as Mintzberg \& Waters (1985) argue, not all planned strategies are implemented, and neither are all activities that are performed necessarily part of the planned strategy. They introduce the concept of emergent strategy, which blends with the planned strategy to become the realized strategy (Mintzberg \& Waters, 1985). This same concept is also true for proactive market strategies; in order for a market strategy to be proactive, it is not enough that it is formulated under the guidance of a 'proactive orientation', it must also be implemented. Thus, it is not enough that the firm's management is 'proactive-oriented' in its approach to market strategy formulation, the employees of the firm must also be proactive-oriented in their implementation of the strategy, otherwise it is likely to fail to be fully realized.

The final aspect of the strategic orientation-market strategy-strategic behavior framework that needs to be considered is the strategic behavior of the firm. Since the strategic behavior reflects an aggregation of the activities the firm performs in the implementation of its market strategy, this behavior can be viewed as the realization of that strategy. Thus, in the strategic behavior, planned proactive activities that are components of the market strategy are combined with the emergent activities to give rise to the firm's realized market strategy. These emergent activities can be proactive as well as non-proactive, but if they are proactive, they are so because they are guided by a type of proactive orientation within the firm. Since proactive activities and proactive market strategies must be conscious (Crant, 2000; Kindström et al., 2018), emergent activities do not make a firm's market strategy proactive unless they fit into its pattern (cf. Mintzberg \& Waters, 1985). The degree to which the realized market strategy resembles the intended strategy is dependent on how well it is implemented, as well as the firm's tendency to perform emergent activities that were not part of the plan. In any case, the strategic behavior reflects the actual market strategy of the firm as it is experienced by those customers and other market actors that interact with the firm.

Viewing the realized market strategy of the firm through the lens of its strategic behavior enables the identification of proactive market strategies through the proactiveness exhibited in the activities it performs. In 


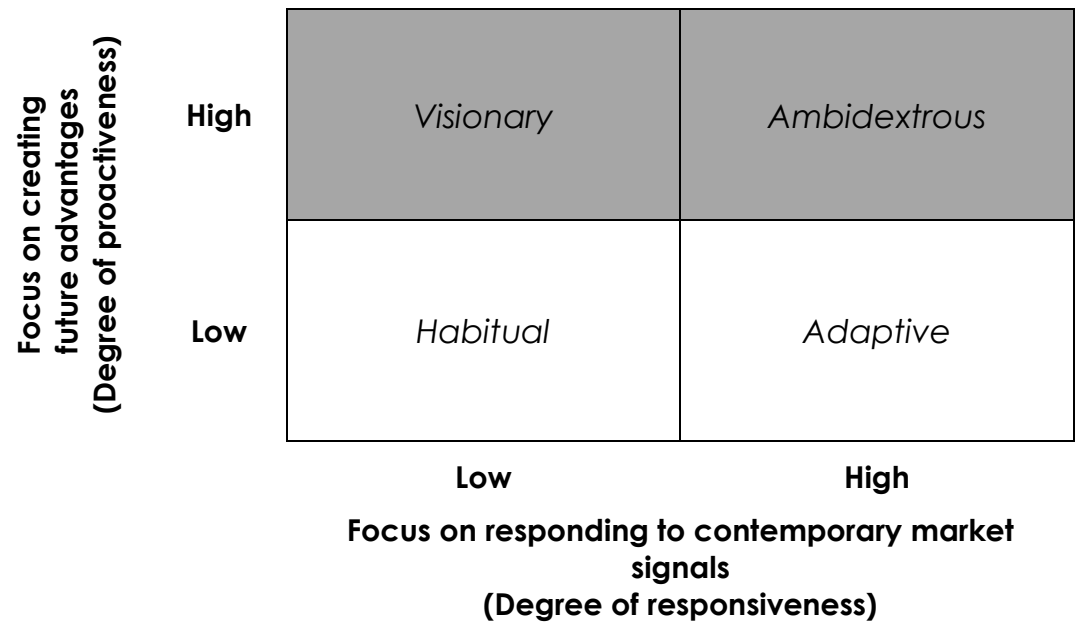

Figure 7A below, the typology of market-oriented strategic behaviors from Paper I is presented. The framework structures strategic behaviors based on the configuration of proactiveness and responsiveness they exhibit, creating a typology from the four extremes that emerge from different combinations of high or low exhibition of each behavioral component. In this framework, firms that are characterized by Visionary or Ambidextrous behavior (as seen in

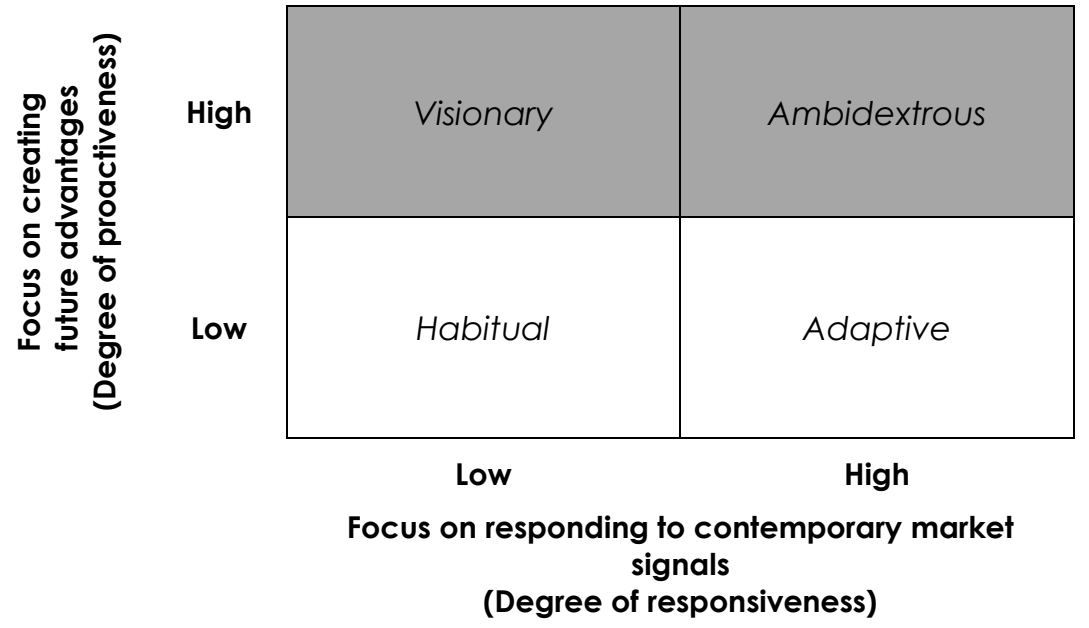

Figure 7B) are firms that exhibit a high degree of proactiveness in their behavior, and are thus also employing proactive market strategies. 
A.

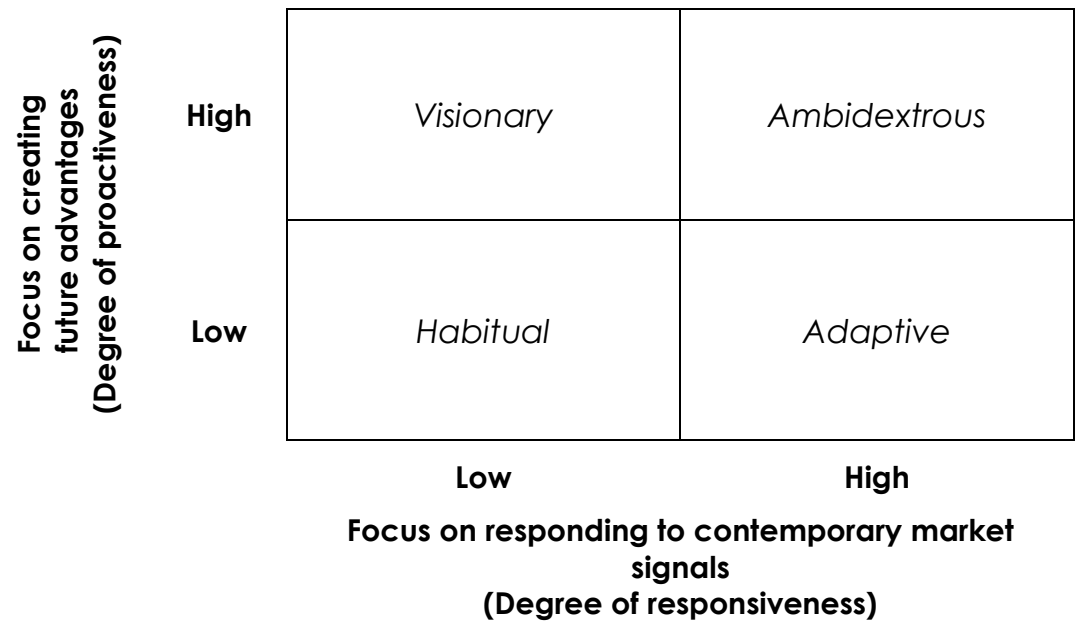

B.

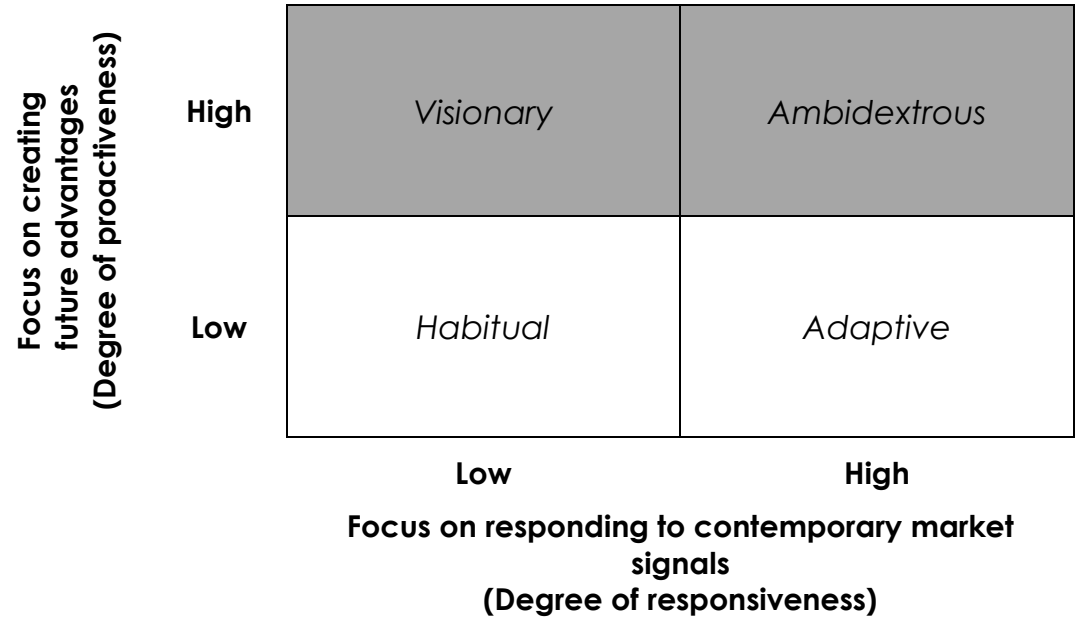

Figure 7: The typology of market-oriented strategic behaviors (from Paper I) 
The level of responsiveness in a firm's behavior does not directly impact upon the firm's proactive market strategy, although a firm with a highly responsive behavior will find it difficult to combine that with a highly proactive behavior, as seen in the literature on ambidexterity (March, 1991; Tushman \& O’Reilly, 1996).

The conceptual study thus concludes that a proactive market strategy is a market strategy-i.e. a firm's strategy for creating superior customer value-that is being guided by a set of proactive strategic orientations, implemented through proactive activities, and resulting in the firm exhibiting a proactive strategic behavior.

\subsubsection{In the empirical study}

The empirical study starts off from the same point as the conceptual study, the strategic orientation-market strategy-strategic behavior framework, but produces a more nuanced concept of what a proactive market strategy is.

The study investigates the proactive activities of a set of five case firms with a history of employing proactive market strategies and achieving above-average performance. By investigating these activities and matching them against the expected pattern of proactive activities from the proactive activity framework, as well as using the characteristics of proactive behavior derived from my definition of proactiveness in a marketing context, the study aims to understand the proactive market strategies of these firms. These pattern-matching efforts resulted in a proactive profile for each case firm, seen in Fel! Ogiltig självreferens i bokmärke. below, which describes the different firms' somewhat different focuses on proactive activities in each category of activity.

Table 13: Proactive profiles for the case firms (from Paper II)

\begin{tabular}{|l|c|c|c|}
\hline \multicolumn{1}{|c|}{ Case } & $\begin{array}{c}\text { Customer } \\
\text { Orientation }\end{array}$ & $\begin{array}{c}\text { Competition } \\
\text { Orientation }\end{array}$ & $\begin{array}{c}\text { Innovation } \\
\text { Orientation }\end{array}$ \\
\hline $\begin{array}{l}\text { Case 1: } \\
\text { Automated Waste Collection }\end{array}$ & & & \\
\hline $\begin{array}{l}\text { Case 2: } \\
\text { Industrial Solutions Group }\end{array}$ & & & \\
\hline $\begin{array}{l}\text { Case 3: } \\
\text { loT Platform }\end{array}$ & & & \\
\hline $\begin{array}{l}\text { Case 4: } \\
\text { Education \& Services }\end{array}$ & & & \\
\hline $\begin{array}{l}\text { Case 5: } \\
\text { Custom Product Solutions }\end{array}$ & & & \\
\hline
\end{tabular}

$\mathbf{x}$ - Not proactive Proactive Highly proactive

From these profiles it becomes obvious that, although all firms are performing proactive activities

-and thus also implementing some form of proactive market strategies-they are quite different in their ways of being proactive. That all five firms are performing proactive activities furthermore implies that they have some form of proactive strategic behaviors, but from looking 
at the different configurations of proactive activities for each firm seen in Table 13 above, it seems unlikely that they are implementing the same proactive market strategy. Since the market strategy is implemented by, and in many ways consists of, the activities performed in association with it, the same proactive market strategy should not produce the different configurations of proactive activities seen among the case firms.

From an investigation of the proactive activities performed by the firms and a search for explanations for the differences in configurations, a new set of patterns started to emerge. These patterns represent configurations of proactive activities that are aimed at achieving a firm's market strategic objectives. These patterns are called themes of proactiveness to indicate that they represent a common direction in a firm's proactive activities. The activity profiles for the three themes identified in the empirical study are presented in Fel! Ogiltig självreferens i bokmärke. below.

Table 14: Profiles for the themes of proactiveness (from Paper II)

\begin{tabular}{|l|c|c|c|}
\hline \multicolumn{1}{|c|}{ Theme } & $\begin{array}{c}\text { Customer } \\
\text { Orientation }\end{array}$ & $\begin{array}{c}\text { Competition } \\
\text { Orientation }\end{array}$ & $\begin{array}{c}\text { Innovation } \\
\text { Orientation }\end{array}$ \\
\hline $\begin{array}{l}\text { Proactivity through } \\
\text { market shaping }\end{array}$ & & & \\
\hline $\begin{array}{l}\text { Proactivity through } \\
\text { customer engagement }\end{array}$ & & & \\
\hline $\begin{array}{l}\text { Proactivity through } \\
\text { innovation leadership }\end{array}$ & & & \\
\hline
\end{tabular}

Primary activity focus

Secondary activity

As argued above, the themes of proactiveness do represent different configurations of proactive activities and are thus also representations of a firm's proactive market strategy. However, since the themes only cover certain configurations of activities, they are not necessarily representative of the entirety of a firm's market strategy, but rather represent a particular aspect of it. As can be seen from comparing Tables 13 and 14, the firms do not just use one theme, but also perform other proactive activities as part of their market strategies.

As an example, the market shaping theme refers to firms that are focused on shaping the market to strengthen their competitiveness and performance. By using such a theme, the proactive profile, or configuration of proactive activities, of the firm will take on a particular characteristic by which the firm prioritizes competition-oriented and, to a lesser degree, customer-oriented proactive activities. Thus, using the market shaping theme will have an impact on the firm's actual market strategy, as realized through its activities. Moreover, a firm is not limited to only using one theme; in fact, most case firms use more than one, although they are not as focused on all of them, which can be seen in Table 15 below. 
Proactivity through...

\begin{tabular}{|l|c|c|c|}
\hline \multicolumn{1}{|c|}{ Case } & $\begin{array}{c}\text {..market } \\
\text { shaping }\end{array}$ & $\begin{array}{c}\text {...customer } \\
\text { engagement }\end{array}$ & $\begin{array}{c}\text {...innovation } \\
\text { leadership }\end{array}$ \\
\hline $\begin{array}{l}\text { Case 1: } \\
\text { Automated Waste Collection }\end{array}$ & & & \\
\hline $\begin{array}{l}\text { Case 2: } \\
\text { Industrial Solutions Group }\end{array}$ & & & \\
\hline $\begin{array}{l}\text { Case 3: } \\
\text { loT Platform }\end{array}$ & & & \\
\hline $\begin{array}{l}\text { Case 4: } \\
\text { Education \& Services }\end{array}$ & & & \\
\hline $\begin{array}{l}\text { Case 5: } \\
\text { Custom Product Solutions }\end{array}$ & & & \\
\hline
\end{tabular}

Thus, a firm's proactive market strategy can make use of one or more of the themes of proactiveness, which has implications for the proactive profile the firm will exhibit, i.e. the configuration of proactive activities the firm performs. In this sense, the themes can be viewed as varieties of generic proactive market strategies, since they refer to specific ways of proactively creating superior value and performance. From the viewpoint of the empirical study, then, a proactive market strategy refers to a particular configuration of different categories of proactive activities, aimed at enabling the firm to create superior customer value and achieve superior business performance.

\subsubsection{A holistic perspective}

Combining these two similar yet slightly different ways of viewing proactive market strategies into a holistic perspective allows this thesis to address its main purpose: to explore proactive market strategies. The two papers are complementary parts of the thesis work and are intended to be combined together to provide a more holistic exploration of the phenomenon.

The two approaches of the studies use the same starting point, but have different focuses in their exploration of proactive market strategy. The conceptual study delves more into the theoretical linkages between proactive market strategies and other, related terms. It concludes with a viewpoint that relates proactive market strategy to strategic orientations and strategic behavior and describes how a proactive market strategy is derived from the proactive activities of a firm. This provides a conceptualization of the antecedents and consequences of proactive market strategies which is useful in going forward, but does not offer many details about what, more exactly, a proactive market strategy will look like in the real world. The proactive activity framework provides guidance as to what types of proactive activities we can expect to find in each category of activity, but is not focused on how activities are combined into coherent market strategies. 
The typology of market-oriented strategic behaviors presented in Paper I describes four types of more archetypal strategic behaviors in terms of fit between the behavioral characteristics of activities in the categories of activity, which gives some indication of the market strategies associated with such behaviors, but does not explain how different proactive activities are combined into a proactive market strategy.

At this point, it should be noted that the typology in Paper I was never actually meant to categorize proactive market strategies as such, but rather to capture the strategic behaviors that emerge from firms performing different configurations of proactive activities. Furthermore, the types of behavior given in the typology reflect extremes, meaning that firms resemble one type more than they do the others, rather than that they are perfect matches to one type. Since the strategic behavior represents the realization of a firm's actual market strategy, this strategy is obviously reflected in the behavior. While this is the case, the types of strategic behavior given in the framework should be viewed as representations of how firms achieve a behavioral fit among their activities rather than representations of particular market strategies.

Looking at the empirical study gives a different viewpoint; instead of a perspective that describes the antecedents and consequences of proactive market strategies well, leading to a generic understanding of the core concept, the perspective of the empirical study provides a more detailed understanding of what a proactive market strategy is and its consequences. The three themes of proactiveness that I have put forward act as generic market strategies, and their consequences are explored both through the case firms and conceptually.

Moreover, the firms in the case study performed some proactive activities that were not identified as singularly belonging to a particular configuration. This poses the interesting question: does a firm necessarily have a proactive market strategy because it performs some proactive activities? Since a proactive action has to be intentional (Crant, 2000; Kindström et al., 2018), a firm that consciously performs some proactive activities but lacks a coherent strategy that specifies how they collectively help to fulfill the firm's market-strategic goals does not have a proactive market strategy. Thus, a firm that has a proactive orientation but lacks a focused market strategy is likely to perform individual proactive activities, but will fail to perform the intentional configuration of activities that represents a proactive market strategy.

Thus, a proactive market strategy can be defined in the following way:

1. A proactive market strategy is guided by and arises from a firm's proactive strategic orientations, which indicates that the firm has a proactive orientation influencing its activities.

2. It is implemented through particular configurations of proactive activities that, when performed, will result in the strategy being realized, which is represented in the firm's proactive strategic behavior.

3. These proactive activities must be part of an intentional strategy, aimed at fulfilling the firm's market-strategic objectives, in order to be part of a proactive market strategy. Otherwise they are merely indicative of a proactive orientation driving the firm, not a proactive market strategy. 


\subsection{Answering the research questions}

To ensure that the purpose of the thesis is fully met, I will now address the research questions posed in the introduction.

\section{RQ1 What does proactiveness in a market-strategic context entail?}

From the definition of proactive behavior in a marketing context presented in the conceptual development, it is found that proactiveness at the firm level entails future-oriented, initiativetaking, change-inducing, and creative behavior. In the previous discussion about proactive market strategy as a concept, it is argued that the proactiveness of proactive market strategy stems from it being implemented through proactive activities. These are identified using the characteristics of proactive behavior just mentioned, but also using the activities linked to particular behaviors in the proactive activity framework. Furthermore, in order for proactive behavior to be proactive, it must be intentional (Crant, 2000; Kindström et al., 2018), meaning that a market strategy is only proactive if the proactive activities performed to implement it represent an intentional configuration that will help the firm achieve its market-strategic objectives.

In summary, proactiveness in a market-strategic context entails that a firm crafts a proactive strategy that is aimed at achieving the firm's market-strategic objectives, and is implemented through an intentional configuration of proactive activities.

\section{RQ2 What activities do firms perform in the implementation of their proactive market strategies?}

In the proactive activity framework, a wide variety of the types of activities that proactive firms perform is presented, following the previous literature. These are categorized using an amended version of the strategic orientation framework proposed by Gatignon \& Xuereb (1997), wherein they are structured according to the strategic orientation that most guides the behavior. The three categories making up the proactive activity framework are: customer-oriented, competition-oriented, and innovation-oriented activities. Each of these is described, and expected proactive activities from the literature are presented.

However, these are mostly generic types of activity derived from the conduct perspective of market orientation (Kohli \& Jaworski, 1990) and other literature that does not directly concern proactive market strategy. Thus, they do not necessarily give a full picture of the proactive activities performed by real proactive firms. The empirical study provides more insight into the real activities that the case firms have actually performed, which fits relatively well with the perspective offered by the proactive activity framework. In particular, the study finds that firms do not just perform a number of individual proactive activities, but that they are gathered in configurations of activity that are aimed at fulfilling a certain aspect of the firm's market-strategic goals. 
In summary, firms perform particular configurations of proactive activities when implementing their proactive market strategies. These are categorized as customer-oriented, competitionoriented, and innovation-oriented activities and are collectively aimed at fulfilling a firm's market-strategic objectives. 


\section{Conclusions}

The purpose of this licentiate thesis is to explore proactive market strategies, and how firms use them to achieve superior business performance. The area of proactive market strategy shows great potential for better understanding how firms can be successful (e.g. Narver et al., 2004; Homburg et al., 2014; Kumar \& Pansari, 2016; Kindström et al., 2018), and, even though many aspects of it and related areas had been previously studied, it is to a great extent unexplored. The two papers appended to this thesis took two different approaches to exploring these proactive market strategies: the first did so through the conceptual development of previous work in related areas, and the second did so through an empirical investigation of five successful proactive firms and the activities that had brought their success. Furthermore, this kappa synthesizes the conceptual contributions of these two papers and provides a more in-depth study of the five case firms, further enriching the exploration of proactive market strategies.

\subsection{Summary of key findings}

The findings and contributions presented below are distilled from the papers and the previous discussion and constitute a summary of the most important results of this thesis:

- Firstly, firms do indeed actually use proactive approaches to managing the market and creating customer value, as seen from the proactive activities they perform, and also these proactive market strategies do lead the firms to superior business performance (at least in these case firms). 
- Secondly, successfully proactive firms do not just exhibit proactiveness in a single way, but are proactive across multiple categories of activity-herein categorized as customeroriented activities, competition-oriented activities, and innovation-oriented activities. Furthermore, this conceptual framework implies that firms should strive to match their level of proactiveness across all three categories and find a fit between their marketoriented strategic behavior, their market environment, and their resource/capability base.

- Thirdly, there are patterns to firms' use of proactive value-creating activities. These patterns consist of a cross-functional integration of proactive efforts, meaning that proactive activities are coordinated across multiple functions in a firm to ensure superior competitiveness and the creation of customer value. Firms should thus not just increase their proactiveness across the categories of activity, but should also integrate their activities to maximize value creation. Through a configuration of proactive activities across multiple categories of activity-a theme of proactiveness, aimed at achieving the firm's market-strategic goals-a firm can be more focused in its value-creation than if it just engaged in an unstructured collection of proactive activities.

- Fourthly, increasing proactiveness is a resource-intensive effort, meaning that there are cost and capability reasons for expecting that firms will not always maintain the same level of proactiveness across all three categories of activity. Furthermore, while successful firms employ multiples of the integrated patterns of proactiveness in what is called themes, for the same cost and capability reasons as previously, many firms are limited in their ability to simultaneously use multiple themes. However, this does not mean that they will be unable to gain benefits from their proactiveness, just that they will be unlikely to gain the full potential benefits.

\subsection{Theoretical implications}

Since proactive market strategies was such an unexplored area, this thesis focused to a large extent on the development of conceptual frameworks for assisting in ongoing and future research. These important conceptual developments are presented below.

Defining proactive firm behavior: One of the first things that was needed in order to forge ahead with the research into proactive market strategies was a clear and concise definition of what proactive behavior at the firm level really is. Based on the work on proactive personality (e.g. Bateman \& Crant, 1993; Crant, 2000) and personal initiative (e.g. Frese et al., 1996; Frese \& Fay, 2001) from organizational behavior, and the work on proactive market orientation (e.g. Narver et al., 2004; Atuahene-Gima et al., 2005), the following definition was created:

In a marketing context, proactive firm behavior is defined as

future-oriented, initiative-taking, change-inducing, and creative. 
This definition presents four key characteristics of proactive behavior and provides a clear method for gauging whether an activity is proactive or not, based on its adherence to these behavioral characteristics.

The strategic orientation-market strategy-strategic behavior framework: To better understand what the activities were that firms actually performed to achieve success with their proactive market strategies, a framework was needed to help conceptualize the connections between: (1) strategic orientations, (2) market strategies and the activities that implement them, and (3) strategic behavior. This conceptual framework conceptualizes strategic orientations as the business principles that guide a firm's strategy formulation (Noble et al., 2002), while strategic behavior represents the consistent behavioral pattern in the firm's activities (Burgelman, 1983; cf. Mintzberg, 1987). The strategies, and the constituent firm activities that implement them, act as the link between orientation and behavior, being influenced by the firm's strategic orientation and aggregated into the firm's strategic behavior. This conceptualization clearly divides the antecedents (strategic orientations) and consequences (strategic behaviors) of the activities a firm performs in the execution of its strategies, paving the way for investigations into how different proactive firm activities jointly create a proactive strategic behavior.

The proactive activity framework: With the strategic orientation-market strategy-strategic behavior framework in place, the last missing piece of the conceptual development was a framework for conceptualizing proactive firm activities that are part of a proactive market strategy. This conceptualization took its starting point in a modified version of the strategic orientation framework proposed by Gatignon \& Xuereb (1997; cf. Olson et al., 2005), which was then further developed to incorporate more dynamic perspectives on the market (Day, 2011) and a broader range of market actors (adhering to criticism by Kohli et al., 1993). The resulting model conceptualizes activities into three categories: customer-oriented, competitionoriented, and innovation-oriented, also making it clear what types of activity within each category can be considered proactive. This framework enables the delineation of a complex strategic behavior into its component strategies and activities, thereby making it possible to investigate how each component helps give rise to the whole.

The typology of market-oriented strategic behaviors: In the first appended paper, the conceptual typology of market-oriented strategic behaviors is presented. The four behaviors of the typology-Visionary, Adaptive, Ambidextrous, and Habitual-represent the archetypal behaviors that arise from the different configurations of responsive and proactive market orientation in a firm. These types of behavior have different implications for the types of activity that a firm is likely to perform and are expected to have a better fit with different firm circumstances and capabilities. Moreover, the typology implies that a firm will benefit from achieving a fit between its behavior across the three categories of activity. However, increasing the levels of proactiveness and responsiveness is costly and makes demands on a firm's capabilities, meaning that not all firms can achieve a high level in both dimensions simultaneously. Lastly, the model concludes that, because of these cost issues, there is an equifinality situation, in which all behaviors (except perhaps Habitual) can perform equally well under the right circumstances. 
The three themes of proactiveness: The final conceptual contribution of this thesis is the themes of proactiveness framework. In the empirical study, these themes were found as consistent patterns in the value-creating proactive activities of the case firms. These themes represent the cross-functional integration of proactive efforts within a firm, resulting in categories of activity being coordinated across several functions within the firm to enhance its value-creating and competitiveness-enhancing goal fulfillment. The three themes identified in the study are: proactiveness through market shaping, proactiveness through customer engagement, and proactiveness through innovation leadership.

\subsection{Managerial implications}

The research presented in this thesis is exploratory, so it is important to be careful when making generalizations from it and prescribing normative statements. Nevertheless, the research does present some interesting and important managerial implications.

The typology of market-oriented strategic behaviors given in Paper I presents the concept of behavioral fit between different categories of activity. This implies that firms which present a more consistent behavior through a homogeneous set of activities will have a more focused configuration of market orientation, aiding them in achieving the potential performance benefits that can still be gained from market orientation. Getting such a behavioral fit implies crossfunctionally integrating proactiveness efforts within the firm, so activities headed by employees in different divisions or functions can have the same behavioral characteristics. Moreover, firms should strive to match their strategic behavior with their capabilities and resources in order to achieve a fit with the market characteristics of the markets within which they are active.

The main implications for management practice from the themes of proactiveness is that firms striving to adopt proactive market strategies must integrate proactive activities across multiple functions into a common drive, aimed at achieving the firm's market-strategic objectives. Furthermore, the study shows that even proactive firms that have achieved above-average success through their proactive efforts are not fully proactive across all categories of activity. This implies that achieving configurations that serve to fulfil a firm's objectives might be more important than an overall higher level of proactiveness that is not part of a configuration, although this is not entirely clear.

Thus, managers should carefully consider how to cross-functionally integrate their proactive efforts and create configurations of activities that enable multiple parts of the firm to proactively strive towards fulfilling the same goal. Furthermore, while considering their configurations of activities, they should also strive to create a coherent strategic behavior for the firm, in which activities across multiple functions have similar behavioral characteristics. 


\subsection{Future research}

The purpose of this licentiate thesis is to explore proactive market strategy and its findings present multiple interesting avenues for future research. Now that the exploratory phase of research into proactive market strategy is covered, future research should in general focus more on descriptive research and on research aimed at a better understanding of the concepts presented in this thesis, although there might still be room for further exploration as well.

I believe that there are four major branches of future research arising from this thesis: (1) performing more in-depth case studies, to better understand the internal antecedents and influencing factors of proactive market strategies and proactive activities, (2) creating measurable constructs that can enable quantitative studies, (3) investigating configurations of market strategies and different contingency factors, such as firm capabilities and market characteristics, and (4) further conceptual development of the concepts.

For the next part of my PhD studies, after the licentiate thesis has been defended, I intend to continue my research into proactive market strategy by following the four branches presented below.

\section{MORE IN-DEPTH CASE STUDIES}

The case study presented in this thesis' empirical study only represents an exploration of proactive market strategy in firms that were pre-selected for being proactive. By broadening the perspective and including a wider range of firms, including some that are not necessarily proactive, a more in-depth qualitative case study can aim at better understanding and explaining the antecedents of proactive market strategies. Moreover, I can investigate the differences between proactive and non-proactive firms in order to better understand the proactive orientation that seems to influence some firms' activities.

\section{CONSTRUCT CREATION \& QUANTITATIVE RESEARCH}

Proactive market strategy also opens up space for interesting quantitative research. An important first step in quantitatively investigating proactive market strategy is a continuation of the conceptualization in order to create a measurable construct. Having such a measure enables future research in such areas as investigating the relationship between different types of proactive market strategy and performance.

\section{CONFIGURATIONS \& CONTINGENCY FACTORS}

An interesting approach to investigating proactive market strategy is through contingency theory, in which research studies how different configurations of proactive market strategies and contingency factors influence firm performance. So-called fuzzy set qualitative comparative analysis opens up an avenue for understanding such configurations and seems to be a promising direction for future research. 


\section{FURTHER DEVELOPMENT OF CONCEPTUAL FRAMEWORKS}

Finally, the conceptual developments presented in this thesis all need further development work. All of them currently resemble tentative frameworks rather than well-established models and require more work on multiple fronts. Firstly, the typology of market-oriented strategic behaviors presented in Paper I should be empirically tested and validated. Furthermore, the proactive activity framework needs a stronger empirical investigation as well, establishing the proactive activities that proactive firms actually perform through continued case study and survey research and linking activities more closely to actual proactive market strategies. Lastly, the themes of proactiveness must be developed further; these themes should be investigated through e.g. empirical validations and studied in greater depth to understand how they are employed by firms. 


\section{References}

Adams, S. (1997, March 20th). Dilbert. Retrieved from dilbert.com: http://dilbert.com/strip/1997-03-20.

Ali, A., Krapfel, R., \& LaBahn, D. (1995). Product Innovativeness and Entry Strategy: Impact on Cycle Time and Break-even Time. Journal of Product Innovation Management, Vol. 12, No. 1, pp. 54-69.

Aragón-Correa, J. A. (1998). Strategic Proactivity and Firm Approach to the Natural Environment. Academy of Management Journal, Vol. 41, No. 5, pp. 556-567.

Aragón-Correa, J. A., \& Sharma, S. (2003). A Contingent Resource-Based View of Proactive Corporate Environmental Strategy. The Academy of Management Review, Vol. 28, No. 1, pp. 71-88.

Armstrong, J. S., \& Collopy, F. (1996). Competitor Orientation: Effects of Objectives and Information on Managerial Decisions and Profitability. Journal of Marketing Research, Vol. 33, No. 2, pp. 188-199.

Aspara, J., \& Tikkanen, H. (2013). Creating Novel Consumer Value vs. Capturing Value: Strategic Emphases and Financial Performance Implications. Journal of Business Research, Vol. 66, No. 5, pp. 593-602.

Atuahene-Gima, K., Slater, S. F., \& Olson, E. M. (2005). The Contingent Value of Responsive and Proactive Market Orientations for New Product Program Performance. The Journal of Product Innovation Management, Vol. 22, No. 6, pp. 464-482.

Bateman, T. S., \& Crant, J. M. (1993). The Proactive Component of Organizational Behaviour: A Measure and Correlates. The Journal of Organizational Behavior, Vol. 14, No. 2, pp. 103-118.

Bateman, T. S., \& Crant, J. M. (1999). Proactive Behavior: Meaning, Impact, Recommendations. Business Horizons, Vol. 42, No. 3, pp. 63-70.

Berthon, P., Hulbert, J. M., \& Pitt, L. F. (1999). To Serve or Create? Strategic Orientations Toward Customers and Innovation. California Management Review, Vol. 42, No. 1, pp. 37-58.

Beverland, M. B., \& Lindgreen, A. (2007). Implementing Market Orientation in Industrial Firms: A Multiple Case Study. Industrial Marketing Management, Vol. 36, pp. 430-442.

Bhaskar, R. (2009). Scientific Realism and Human Emancipation. London, UK \& New York, NY: Routledge. 
Blocker, C. P., Flint, D. J., Myers, M. B., \& Slater, S. F. (2011). Proactive Customer Orientation and Its Role for Creating Customer Value in Global Markets. Journal of the Academy of Marketing Science, Vol. 39, No. 2, pp. 216-233.

Bodlaj, M., Coenders, G., \& Zabkar, V. (2012). Responsive and Proactive Market Orientation and Innovation Success under Market and Technological Turbulence. Journal of Business Economics and Management, Vol. 13, No. 4, pp.666-687.

Bowman, C., \& Ambrosini, V. (2002). Value Creation Versus Value Capture: Towards a Coherent Definition of Value in Strategy. British Journal of Management, Vol. 11, No. 1, pp. 1-15.

Burgelman, R. A. (1983). A Model of the Interaction of Strategic Behavior, Corporate Context, and the Concept of Strategy. The Academy of Management Review, Vol. 8, No. 1, pp. $61-70$.

Buysse, K., \& Verbeke, A. (2003). Proactive Environmental Strategies: A Stakeholder Management Perspective. Strategic Management Journal, Vol. 24, No. 5, pp. 453-470.

Campbell, J. L., Quincy, C., Osserman, J., \& Pedersen, O. K. (2013). Coding In-Depth Semistructured Interviews: Problems of Unitization and Intercoder Reliability and Agreement. Sociological Methods \& Research, Vol. 42, No. 3, pp. 294-320.

Chakravarty, A., Kumar, A., \& Grewal, R. (2014). Customer Orientation Structure for InternetBased Business-to-Business Platform Firms. Journal of Marketing, Vol. 78 (Spetember), pp. 1-23.

Chan, D. (2006). Interactive Effects of Situational Judgement Effectiveness and Proactive Personality on Work Perceptions and Work Outcomes. Journal of Applied Psychology, Vol. 91, No. 2, pp. 475-481.

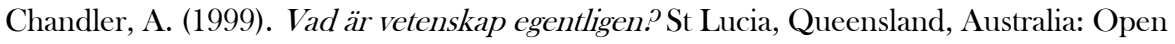
University Press.

Chom, N. H. (1991). The "Alignment" Theory: Creating Strategic Fit. Management Decision, Vol. 29, No. 1, pp. 20-24.

Christensen, C. M., \& Bower, J. L. (1996). Customer Power, Strategic Investment, and the Failure of Leading Firms. Strategic Management Journal, Vol. 17, No. 3, pp. 197-218.

Crant, J. M. (2000). Proactive Behaviour in Organizations. Journal of Management, Vol. 26, No. 3, pp. 435-462.

Creswell, J. W., \& Creswell, J. D. (2018). Research Design: Qualitative, Quantitative, and Mixed Methods Approaches: 5th ed. Thousand Oaks, CA: Sage.

Day, G. S. (1992). Marketing's Contribution to the Strategy Dialogue. Journal of the Academy of Marketing Science, Vol. 20, No. 4, pp. 323-329.

Day, G. S. (1994). The Capabilities of Market-Driven Organizations. Journal of Marketing, Vol. 58 , pp. $37-52$. 
Day, G. S. (2011). Closing the Marketing Capabilities Gap. Journal of Marketing, Vol. 75, No. 4, pp. 183-195.

Day, G. S., \& Moorman, C. (2010). Strategy from the Inside Out. New York, NY: McGrawHill.

Drazin, R., \& Van den Ven, A. H. (1985). Alternative Forms of Fit in Contingency Theory. Administrative Science Quarterly, Vol. 30, No. 4, pp. 514-539.

Du, S., Bhattacharya, C. B., \& Sen, S. (2007). Reaping Relational Rewards from Corporate Social Responsibility: The Role of Competitive Positioning. International Journal of Research in Marketing, Vol. 24, No. 3, pp. 224-241.

Dubois, A., \& Gadde, L.-E. (2002). Systematic Combining: An Abductive Approach to Case Research. Journal of Business Research, Vol. 55, No. 7, pp. 553-560.

Eisenhardt, K. M. (1989). Building Theories from Case Study Research. The Academy of Management Review, Vol. 14, No. 4, pp. 532-550.

Eisenhardt, K. M., \& Graebner, M. E. (2007). Theory Building from Cases: Opportunities and Challenges. The Academy of Management Journal, Vol. 50, No. 1, pp. 25-32.

Elg, U., Delignul, S. Z., Ghauri, P. N., Danis, W., \& Tarnovskaya, V. (2012). Market-Driving Strategy Implementation through Global Supplier Relationships. Industrial Marketing Managment, Vol. 41, No. 6, pp. 919-928.

Ettlie, J., Bridges, W., \& O'Keefe, R. (1984). Organization Strategy and Structural Differences for Radical Versus Incremental Innovation. Management Science, Vol. 30, No. 6, pp. 682-695.

Farrell, M. A., \& Oczkowski, E. (1997). An Analysis of the MKTOR and MARKOR Measures of Market Orientation: An Australian Perspective. Marketing Bulletin, Vol. 8, pp. 3040 .

Frambach, R. T., Fiss, P. C., \& Ingenbleek, P. T. (2016). How Important is Customer Orientation for Firm Performance? A Fuzzy Set Analysis of Orientations, Strategies, and Environments. Journal of Business Research, Vol. 69, pp. 1428-1436.

Frese, M., \& Fay, D. (2001). Personal Initiative: An Active Performance Concept for Work in the 21st Century. Research in Organizational Behavior, Vol. 39, pp. 133-187.

Frese, M., Kring, W., Soose, A., \& Zemple, J. (1996). Personal Initiative at Work: Differences between East and West Germany. The Academy of Management Journal, Vol. 39, No. 1, pp. 37-63.

Frösén, J., Luoma, J., Jaakkola, M., Tikkanen, H., \& Aspara, J. (2016). What Counts Versus What Can Be Counted: The Complex Interplay of Market Orientation and Marketing Performance Measurement. Journal of Marketing, Vol. 80, No. 3, pp. 60-78. 
Garcia, R., \& Calantone, R. (2002). A Critical Look at Technological Innovation Typology and Innovativeness Terminology: A Literature Review. The Journal of Product Innovation Management, Vol. 19, No. 2, pp. 110-132.

Gatignon, H., \& Xuereb, J.-M. (1997). Strategic Orientation of the Firm and New Product Performance. Journal of Marketing Research, Vol. 34, No. 1, pp. 77-90.

Grant, A. M., \& Ashford, S. J. (2008). The Dynamics of Proactivity at Work. Research in Organizational Behavior, Vol. 28, pp. 3-34.

Gröönros, C., \& Gummerus, J. (2014). The Service Revolution and Its Marketing Implications: Service Logic vs Service-Dominant Logic. Managing Service Quality, Vol. 24, No. 3, pp. 206-229.

Groza, M. D., Pronschinske, M. R., \& Walker, M. (2011). Perceived Organizational Motives and Consumer Responses to Proactive and Reactive CSR. Journal of Business Ethics, Vol. 102, No. 4, pp. 639-652.

Han, J. K., Kim, N., \& Srivastava, R. (1998). Market Orientation and Organizational Performance: Is Innovation a Missing Link? Journal of Marketing, Vol. 62, No. 4, pp. $30-45$.

Harris, L. C. (2000). The Organizational Barriers to Developing Market Orientation. European Journal of Marketing, Vol. 34, No. 5/6, pp. 598-624.

Henderson, R. M., \& Clark, K. B. (1990). Architectural Innovation: The Reconfiguration of Existing Product Technologies and the Failure of Established Firms. Administrative Science Quarterly, Vol. 35, No. 1, pp. 9-30.

Herhausen, D. (2016). Unfolding the Ambidextrous Effects of Proactive and Responsive Market Orientation. Journal of Business Research, Vol. 69, pp. 2585-2593.

Hogan, J. E., Lemon, K. N., \& Libai, B. (2003). What Is the True Value of a Lost Customer? Journal of Service Research, Vol. 5, No. 3, pp. 196-208.

Hoppe, H. C. (2000). Second-Mover Advantages in the Strategic Adoption of New Technology Under Uncertainty. International Journal of Industrial Organization, Vol. 18, pp. 315338.

Houston, F. S. (1986). The Marketing Concept: What Is It and What Is It Not. Journal of Marketing, Vol. 50, No. 2, pp. 81-87.

Hunt, S. (1990). Truth in Marketing Theory and Research. Journal of Marketing, Vol. 54, No. 3, pp. 1-15.

Hurley, R. F., \& Hult, G. M. (1998). Innovation, Market Orientation, and Organizational Learning: An Integration and Empirical Examination. Journal of Marketing, Vol. 62, No. 3, pp. 42-54. 
Jarvis, C., MacKenzie, S., Podsakoff, P., Mick, D., \& Bearden, W. O. (2003). A Critical Review of Construct Indicators and Measurement Model Misspecification in Marketing and Consumer Research. Journal of Consumer Research, Vol. 30, No. 2, pp. 199-218.

Jaworski, B. J., \& Kohli, A. K. (1996). Market Orientation: Review, Refinement, and Roadmap. Journal of Market-Focused Management, Vol. 1, No. 2, pp. 119-135.

Joshi, A., \& Sharma, S. (2004). Customer Knowledge Development: Antecedents and Impact on New Product Performance. Journal of Marketing, Vol. 68 (October), pp. 47-59.

Keith, R. J. (1960). The Marketing Revolution. Journal of Marketing, Vol. 24, No. 4, pp. 35-38.

Kennedy, K. N., Goolsby, J. R., \& Arnould, E. J. (2003). Implementing a Customer Orientation: Extension of Theory and Application. Journal of Marketing; Vol. 67, No. 4, pp. 67-81.

Kerin, R. A., Varadarajan, P. R., \& Peterson, R. A. (1992). First-Mover Advantage: A Synthesis, Conceptual Framework, and Research Propositions. Journal of Marketing, Vol. 56, No. 4, pp. 33-52.

Ketchen, D., Hult, G., \& Slater, S. F. (2007). Toward Greater Understanding of Market Orientation and the Resource-Based View. Strategic Management Journal, Vol. 28, No. 9, pp. 961-964.

Kim, W. C., \& Mauborgne, R. (2004). Blue Ocean Strategy. Harvard Business Review, Vol. 82, No. 10, pp. 76-84.

Kindström, D., Kowalkowski, C., \& Parment, A. (2012). Marknadsföring mellan företag lin Swedish]. Malmö, Sweden: Liber.

Kindström, D., Ottosson, M., \& Carlborg, P. (2018). Unraveling Firm-Level Activities for Shaping Markets. Industrial Marketing Management, Vol. 68 (January), pp. 36-45.

Kirca, A. H., Jayachandran, S., \& Bearden, W. O. (2005). Market Orientation: A MetaAnalytical Review and Assessment of Its Antecedents and Impact on Performance. Journal of Marketing, Vol. 69, No. 2, pp. 24-41.

Kohli, A. K., \& Jaworski, B. J. (1990). Market Orientation: The Construct, Research Propositions and Managerial Implications. Journal of Marketing, Vol. 54, No. 2, pp. 118.

Kohli, A. K., Jaworski, B. J., \& Kumar, A. (1993). MARKOR: A Measure of Market Orientation. Journal of Marketing Research, Vol. 30, No. 4, pp. 467-477.

Kotler, P. (1972). A Generic Concept of Marketing. Journal of Marketing; Vol. 36, No. 2, pp. 46-54.

Kumar, K., Subramanian, R., \& Yauger, C. (1998). Examining the Market OrientationPerformance Relationship: A Context-Specific Study. Journal of Management, Vol. 24, No. 2, pp. 201-233. 
Kumar, V., \& Bhagwat, Y. (2010). Listen to the Customer. Marketing Research, Vol. 22, No. 2, pp. 14-19.

Kumar, V., \& Pansari, A. (2016). Competitive Advantage through Engagement. Journal of Marketing Research, Vol. 53, No. 4, pp. 497-514.

Kumar, V., Aksoy, L., Donkers, B., Venkatesan, R., Wiesel, T., \& Tillmanns, S. (2010). Undervalued or Overvalued Customers: Capturing Total Customer Engagement Value. Journal of Service Research, Vol. 13, No. 3, pp. 297-310.

Kumar, V., Jones, E., Venkatesan, R., \& Leone, R. P. (2011). Is Market Orientation a Source of Sustainable Competitive Advantage or Simply the Cost of Competing? Journal of Marketing, Vol. 75, No. 1, pp. 16-30.

Kumar, V., Rajan, B., Gupta, S., \& Dalla Pozza, I. (2017). Customer Engagement in Service. Journal of the Academy of Marketing Science, DOI 10.1007/s11747-017-0565-2.

Lagerström, K., \& Zachrisson Winberg, J. (2012, June 14th). John Bauer-gymnasier får hård kritik. Retrieved from Sveriges Television: https://www.svt.se/nyheter/inrikes/johnbauer-gymnasier-far-hard-kritik

Lagerström, K., \& Zachrisson Winberg, J. (2013, October 24th). En miljard fattades i konkursen. Retrieved from Sveriges Television: https:/www.svt.se/nyheter/inrikes/enmiljard-fattades-i-konkursen

Lamore, P. R., Berkowitz, D., \& Farrington, P. A. (2013). Antecedents of Proactive and Responsive Market Orientation. International Journal of Sustainable Strategic Management, Vol. 4, No. 1, pp. 2-23.

Lepak, D. P., Smith, K., \& Taylor, M. S. (2007). Introduction to Special Topic Forum: Value Creation and Value Capture: A Multilevel Perspective. The Academy of Management Review, Vol. 32, No. 1, pp. 180-194.

Leplin, J. (1984). Scientific Realism. Berkeley \& Los Angeles, CA: University of California Press.

Lewis, D. (1970). How to Define Theoretical Terms. Journal of Philosophy, Vol. 67, No. 13, pp. $427-446$.

Li, C.-R., Lin, C.-J., \& Chu, C.-P. (2008). The Nature of Market Orientation and the Ambidexterity of Innovations. Management Decision, Vol. 46, No. 7, pp. 1002-1026.

Liao, S.-H., Chang, W.-J., Wu, C.-C., \& Katrichis, J. M. (2011). A Survey of Market Orientation Research (1995-2008). Industrial Marketing Management, Vol. 40, pp. 301310 .

Lieberman, M. B., \& Montgomery, D. B. (1988). First-Mover Advantages. Strategic Management Journal, Vol. 9, Summer special issue, pp. 41-58.

Lincoln, Y. S., \& Guba, E. G. (1985). Naturalistic Inquiry. Newbury Park: CA: Sage. 
Lukas, B. A. (1999). Strategic Type, Market Orientation, and the Balance Between Adaptability and Adaption. Journal of Business Research, Vol. 45, pp. 147-156.

MacInnis, D. (2011). A Framework for Conceptual Contributions in Marketing. Journal of Marketing, Vol. 75, No. 4, pp. 136-154.

MacKenzie, S. (2003). The Dangers of Poor Construct Conceptualization. Journal of the Academy of Marketing Science, Vol. 31, No. 3, pp. 323-326.

March, J. G. (1991). Exploration and Exploitation in Organizational Learning. Organization Science, Vol. 2, No. 1, pp. 71-87.

Maslow, A. H. (1966). The Psychology of Science: A Reconnaissance. New York, New York: Harper \& Row.

Matsuno, K., \& Mentzer, J. T. (2000). The Effects of Strategy Type on the Market OrientationPerformance Relationship. Journal of Marketing, Vol. 64, No. 4, pp. 1-16.

Matsuno, K., Mentzer, J. T., \& Rentz, J. O. (2000). A Refinement and Validation of the MARKOR Scale. Journal of the Academy of Marketing Science, Vol. 28, No. 4, pp. 527-539.

Matsuno, K., Mentzer, J. T., \& Rentz, J. O. (2005). A Conceptual and Empirical Comparison of Three Market Orientation Scales. Journal of Business Research, Vol. 58, No. 1, pp. $1-8$.

McCarthy, E. J., \& Perreault, W. (1991). Essentials of Marketing, 5th ed. Toronto, Canada: Irwin.

McNamara, C. P. (1972). The Present Status of the Marketing Concept. Journal of Marketing, Vol. 36, No. 1, pp. 50-57.

Miles, R. E., \& Snow, C. C. (1978). Organizational Strategy, Structure, and Process. New York, NY: MacGraw-Hill.

Miller, D. (1986). Configurations of Strategy and Structure: Towards a Synthesis. Strategic Management Journal, Vol. 7, No. 3, pp. 233-249.

Mintzberg, H. (1987). The Strategy Concept I: Five Ps for Strategy. California Management Review, Vol. 30, No. 1, pp. 11-24.

Morgan, N. A., Vorhies, D. W., \& Mason, C. H. (2009). Market Orientation, Marketing Capabilities, and Firm Performance. Strategic Management Journal, Vol. 30, No. 8, pp. 909-920.

Narver, J. C., \& Slater, S. F. (1990). The Effect of Market Orientation on Business Profitability. Journal of Marketing, Vol. 54, No. 2, pp. 20-35.

Narver, J. C., Slater, S. F., \& MacLachlan, D. L. (2004). Responsive and Proactive Market Orientation and New-Product Success. The Journal of Product Innovation Management, Vol. 21, pp. 334-347. 
Noble, C. A., Sinha, R. K., \& Kumar, A. (2002). Market Orientation and Alternative Strategic Orientations: A Longitudinal Assessment of Performance Implications. Journal of Marketing, Vol. 66, No. 4, pp. 25-39.

Noble, C. H. (1999). The Eclectic Roots of Strategy Implementation Research. Journal of Business Research, Vol. 45, No. 2, pp. 119-134.

Okasha, S. (2002). Philosophy of Science: A Very Short Introduction. Oxford: Oxford University Press.

Okumus, F. (2001a). Towards a Strategy Implementation Framework. International Journal of Contemporary Hospitality Management, Vol. 13, No. 7, pp. 327-338.

Okumus, F. (2001b). A Framework to Implement Strategies in Organizations. Management Decision, Vol. 41, No. 9, pp. 871-882.

Olson, E. M., Slater, S. F., \& Hult, G. T. (2005). The Performance Implications of Fit among Business Strategy, Marketing Organization Structure, and Strategic Behavior. Journal of Marketing, Vol. 69, No. 3, pp. 49-65.

Olson, E. M., Walker, O., \& Ruekert, R. (1995). Organizing for Effective New Product Development: The Moderating Role of Product Innovativeness. Journal of Marketing, Vol. 59, No. 1, pp. 48-62.

Ottosson, M., \& Kindström, D. (2016). Exploring Proactive Niche Market Strategies in the Steel Industry: Activities and Implications. Industrial Marketing Managment, Vol. 55, pp. 119-130.

Pansari, A., \& Kumar, V. (2017). Customer Engagement: The Construct, Antecedents, and Consequences. Journal of the Academy of Marketing Science, Vol. 45, No. 3, pp. 294311.

Parker, S. K., Bindl, U. K., \& Strauss, K. (2010). Making Things Happen: A Model of Proactive Motivation. Journal of Management, Vol. 36, No. 4, pp. 827-856.

Parker, S. K., Williams, H. M., \& Turner, N. (2006). Modeling the Antecedents of Proactive Behavior at Work. Journal of Applied Psychology, Vol. 91, No. 3, pp. 636-652.

Patton, M. Q. (2014). Qualitative Research \& Evaluation Models: Integrating Theory and Practise, 4th ed. Thousand Oaks, CA: Sage.

Pelham, A. M. (1997). Mediating Influences on the Relationship Between Market Orientation and Profitability in Small Industrial Firms. Journal of Marketing Theory \& Practice, Vol. 5, No. 3, pp. 55-76.

Porter, M. E. (1980). Competitive Strategy: Techniques for Analyzing Industries and Competitors. New York, NY: The Free Press.

Porter, M. E. (1985). Competitive Advantage: Creating and Sustaining Superior Performance. New York, NY: The Free Press. 
Porter, M. E. (1996). What Is Strategy? Harvard Business Review, Vol. 74, No. 6, pp. 61-78.

Reibstein, D. J., Day, G. S., \& Wind, J. (2009). Guest Editorial: Is Marketing Losing Its Way? Journal of Marketing, Vol. 73, No. 4, pp. 1-3.

Reinartz, W., Krafft, M., \& Hoyer, W. (2004). The Customer Relationship Management Process: Its Measurement and Impact on Performance. Journal of Marketing Research, Vol. 41, No. 3, pp. 293-305.

Ruekert, R. W. (1992). Developing a Market Orientation: An Organizational Strategy Perspective. International Journal of Research in Marketing, Vol. 9, No. 3, pp. 225-245.

Seawright, J., \& Gerring, J. (2008). Case Selection Techniques in Case Study Research: A Menu of Qualitative and Quantitative Options. Political Research Quarterly, Vol. 61, No. 2, pp. 294-308.

Seibert, S. E., Crant, J. M., \& Kraimer, M. L. (1999). Proactive Personality and Career Success. Journal of Applied Psychology, Vol. 84, No. 3, pp. 416-427.

Seibert, S. E., Kraimer, M. L., \& Crant, J. M. (2001). What Do Proactive People Do? A Longitudinal Model Linking Proactive Personality and Career Success. Personnel Psychology, Vol. 54, No. 4, pp. 845-874.

Shapiro, B. P. (1988). What the Hell is "Market-Oriented"? Harvard Business Review, Vol. 66, No. 6, pp. 119-125.

Slater, S. F., \& Narver, J. C. (1994). Does Competitive Environment Moderate the Market Orientation-Performance Relationship? Journal of Marketing, Vol. 58, No. 1, pp. 46-55.

Slater, S. F., \& Narver, J. C. (1998). Customer Led and Market Oriented: Let's Not Confuse the Two. Strategic Management Journal, Vol. 19, No. 10, pp. 1001-1006.

Slater, S. F., Hult, G. T., \& Olson, E. M. (2007). On the Importance of Matching Strategic Behavior and Target Market Selection to Business Strategy in High-Tech Markets. Journal of the Academy of Marketing Science, Vol. 35, No. 1, pp. 5-17.

Stake, R. E. (1995). The Art of Case Study Research. Thousand Oaks, CA: Sage.

Steenkamp, J.-B. E. (2018). The Future of the Marketing Department at Business Schools. Journal of the Academy of Marketing Science, Vol. 46, No. 2, pp. 169-172.

Stock, R. M., \& Zacharias, N. A. (2011). Patterns and Performance Outcomes of Innovation Orientation. Journal of the Academy of Marketing Science, Vol. 39, No. 6, pp. 870-888.

Storbacka, K., \& Nenonen, S. (2015). Learning with the Market: Facilitating Market Innovation. Industrial Marketing Management, Vol. 44 (January), pp. 73-82.

Strauss, A., \& Corbin, J. M. (1990). Basics of Qualitative Research: Grounded Theory Procedures and Techniques. Thousand Oaks, CA: Sage.

SvD. (2013, June 26th). 7000JB-elever svävar i ovisshet. Retrieved from Svenska Dagbladet: https://www.svd.se/7000-jb-elever-svavar-i-ovisshet 
Svensen, L. (2018, February 23rd). Friskolor: Högre betyg, sämre prestation. Retrieved from Dagens Arena: http://www.dagensarena.se/innehall/friskolor-hogre-betyg-samreprestation/

Taghian, M. (2010). Marketing Planning: Operationalising the Market Orientation Strategy. Journal of Marketing Management, Vol. 26, No. 9/10, pp. 825-841.

Tajeddini, K., Trueman, M., \& Larsen, G. (2006). Examining the Effect of Market Orientation on Innovativeness. Journal of Marketing Management, Vol. 22, No. 5-6, pp. 529-551.

Tan, M., \& Liu, Z. (2014). Paths to Success: An Ambidexterity Perspective on how Responsive and Proactive Market Orientations Affect SMEs' Business Performance. Journal of Strategic Marketing, Vol. 22, No. 5, pp. 420-441.

Teece, D., Pisano, G., \& Shuen, A. (1997). Dynamic Capabilities and Strategic Management. Strategic Mangement Journal, Vol. 18, No. 7, pp. 509-533.

Trusov, M., Bucklin, R., \& Pauwels, K. (2009). Effects of Word-of-Mouth Versus Traditional Marketing: Findings from an Internet Social Networking Site. Journal of Marketing; Vol. 73 (September), pp. 90-102.

Tsai, K.-H., Chou, C., \& Kuo, J.-H. (2008). The Curvilinear Relationships between Responsive and Proactive Market Orientations and New Product Performance: A Contigent Link. Industrial Marketing Management, Vol. 37, No. 8, pp. 884-894.

TT. (2013, August 21st). Konkurs ökat hot för fria gymnasier. Retrieved from SvD Näringsliv: https://www.svd.se/konkurs-okat-hot-for-fria-gymnasier

Tushman, M., \& O'Reilly, C. (1996). Ambidextrous Organizations: Managing Evolutionary and Revolutionary Change. California Management Review, Vol. 38, No. 4, pp. 8-29.

Urban, G. L., \& von Hippel, E. (1988). Lead User Analyses for the Development of New Industrial Products. Management Science, Vol. 34, No. 5, pp. 569-582.

van Raaij, E. M., \& Stoelhorst, J. W. (2008). The Implementation of a Market Orientation: A Review and Integration of the Contributions to Date. European Journal of Marketing, Vol. 42, No. 11/12, pp. 1265-1293.

Varadarajan, P. R. (1992). Marketing's Contribution to Strategy: The View from a Different Looking Glass. Journal of the Academy of Marketing Science, Vol. 20, No. 4, pp. 335343.

Varadarajan, P. R., \& Clark, T. (1994). Delineating the Scope of Corporate, Business, and Marketing Strategy. Journal of Business Research, Vol. 31, No. 2/3, pp. 93-105.

Varadarajan, P. R., \& Jayachandran, S. (1999). Marketing Strategy: An Assessment of the State of the Field and Oulook. Journal of the Academy of Marketing Science, Vol. 27, No. 2, pp. 120-143. 
Varadarajan, R. (2010). Strategic Marketing and Marketing Strategy: Domain, Definition, Fundamental Issues and Foundational Premises. Journal of the Academy of Marketing Science, Vol. 38, No. 2, pp. 119-140.

Venkatraman, N. (1989). Strategic Orientation of Business Enterprises: The Construct, Dimensionality, and Measurement. Management Science, Vol. 35, No. 8, pp. 942-962.

von Hippel, E. (1986). Lead Users: A Source of Novel Product Concepts. Mangement Science, Vol. 32, No. 7, pp. 791-805.

Weick, K. E., \& Roberts, K. (1993). Collective Mind in Organizations: Heedful Interrelating on Flight Decks. Administrative Science Quarterly, Vol. 38, pp. 357-381.

Wind, Y., \& Robertson, T. S. (1983). Marketing Strategy: New Directions for Theory and Research. Journal of Marketing, Vol. 47, No. 2, pp. 12-25.

Winer, R. S. (2001). A Framework for Customer Relationship Management. California Managment Review, Vol. 43, No. 4, pp. 89-105.

Workman, J. P. (1993). Marketing's Limited Role in New Product Development in One Computer Systems Firm. Journal of Marketing Research, Vol. 30, No. 4, pp. 405-421.

Yin, R. K. (2018). Case Study Research and Applications: Design and Methods, 6th ed. Thousand Oaks, CA: Sage.

Zajac, E. J., Kraatz, M. S., \& Bresser, R. K. (2000). Modeling the Dynamics of Strategic Fit: A Normative Approach to Strategic Change. Strategic Management Journal, Vol. 21, No. 4, pp. 429-453.

Zhang, J., \& Duan, Y. (2010). The Impact of Different Types of Market Orientation on Product Innovation Performance: Evidence from Chinese Manufacturers. Management Decision, Vol. 48, No. 6, pp. 849-867.

Zhou, K. Z., (Bennett) Yim, C. K., \& Tse, D. K. (2005). The Effects of Strategic Orientations on Technology- and Market-Based Breakthrough Innovations. Journal of Marketing, Vol. 69, No. 2, pp. 42-60.

Zikmund, W., Babin, B., Carr, J., \& Griffin, M. (2009). Business Research Methods, 8th ed. Mason, $\mathrm{OH}$ : South-Western Cengage Learning.

Zott, C., \& Amit, R. (2008). The Fit between Product Market Strategy and Business Model: Implications for Firm Performance. Strategic Management Journal, Vol. 29, No. 1, pp. $1-26$. 


\section{Papers}

The papers associated with this thesis have been removed for copyright reasons. For more details about these see:

http://urn.kb.se/resolve?urn=urn:nbn:se:liu:diva-147771 